\title{
Modulation of fat oxidation: nutritional and pharmacological approach
}

Citation for published version (APA):

van Can, J. G. P. (2012). Modulation of fat oxidation: nutritional and pharmacological approach. [Doctoral Thesis, Maastricht University]. Maastricht University. https://doi.org/10.26481/dis.20121031jc

Document status and date:

Published: 01/01/2012

DOI:

10.26481/dis.20121031jc

Document Version:

Publisher's PDF, also known as Version of record

\section{Please check the document version of this publication:}

- A submitted manuscript is the version of the article upon submission and before peer-review. There can be important differences between the submitted version and the official published version of record.

People interested in the research are advised to contact the author for the final version of the publication, or visit the DOI to the publisher's website.

- The final author version and the galley proof are versions of the publication after peer review.

- The final published version features the final layout of the paper including the volume, issue and page numbers.

Link to publication

\footnotetext{
General rights rights.

- You may freely distribute the URL identifying the publication in the public portal. please follow below link for the End User Agreement:

www.umlib.nl/taverne-license

Take down policy

If you believe that this document breaches copyright please contact us at:

repository@maastrichtuniversity.nl

providing details and we will investigate your claim.
}

Copyright and moral rights for the publications made accessible in the public portal are retained by the authors and/or other copyright owners and it is a condition of accessing publications that users recognise and abide by the legal requirements associated with these

- Users may download and print one copy of any publication from the public portal for the purpose of private study or research.

- You may not further distribute the material or use it for any profit-making activity or commercial gain

If the publication is distributed under the terms of Article $25 \mathrm{fa}$ of the Dutch Copyright Act, indicated by the "Taverne" license above, 


\title{
M odulation of fat oxidation:
}

\author{
nutritional and
}

pharmacological approach 


\section{niutrim}

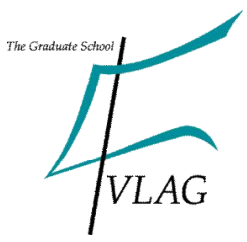

The research was presented in this thesis was performed within NUTRIM School for Nutrition, Toxicology and Metabolism which participates in the Graduate School VLAG (Food Technologym Agrobiotechnology, Nutrition and Health Sciences). Accredited by the Royal Netherlands Academy of Arts and Sciences.

Layout: Judith van Can

Cover design: Jorni Rinia

Printed by: Uitgeverij BoxPress//Proefschriftmaken.nl

@ Judith G.P van Can, M aastricht 2012 


\section{Modulation of fat oxidation:}

\section{nutritional and pharmacological approach}

\section{PROEFSCHRIFT}

Ter verkrijging van de graad van doctor aan de universiteit M aastricht, op gezag van Rector M agnificus, Prof. Dr. L.L.G. Soete,

volgens het besluit van het College van Decanen,

in het openbaar te verdedigen

op woensdag 31 oktober 2012 om 14:00

door

Judith Gerarda Paulina van Can

Geboren te Nuth op 14 november 1980 


\section{Promotor}

Prof. Dr. EE Blaak

\section{Co-promotores}

Prof. Dr. WHM Saris

Prof. Dr. LJC van Loon

\section{Beoordelingscommissie}

Prof. Dr. M A van Baak (voorzitter)

Dr. T Adam

Prof. Dr. A M asclee

Prof. Dr. A Raben (University of Copenhagen)

Prof. Dr. JA Romeijn (AM C Amsterdam)

Financial support by the Netherlands Association for the Study of Obesity (NASO) for the publication of this thesis is gratefully acknowledged. Additional support granted by DSM Nutritional Products, Basel, Switserland and Novo Nordisk, Denmark are gratefully appreciated. 


\section{Table of contents}

Chapter 1:

General introduction

\section{Chapter 2A:}

Reduced glycemic and insulinemic response following trehalose

ingestion: implications for postprandial substrate use

Chapter 2B:

51

Reduced glycemic and insulinemic responses following isomaltulose ingestion:

implications for postprandial substrate use

\section{Chapter 3:}

65

Reduced glycemic and insulinemic responses followingtrehalose and isomaltulose ingestion: implications for postprandiasubstrate use in impaired glucose tolerant subjects

\section{Chapter 4:}

A 3 day EGCG supplementation reduces interstitial lactatconcentration in skeletal muscle in overweight subjects

\section{Chapter 5:}

Effects of liraglutide on gastric emptying, appetite, 24-hour energy expenditure and glucose metabolism in obese, non-diabetic adults: A randomized placebo-controlled incomplete cross-over trial

\section{Supplement to chapter 5:}

Transcriptional regulation of adipose tissue metabolism after 5 week treatment with liraglutide in obese subjects

\section{Chapter 6:}

General discussion 



\section{Chapter 1}

\section{General introduction}

Judith GP van Can 


\section{Chapter 1}

The World Health Organization (WHO) has identified obesity as one of the emerging chronic diseases. Although genetics is a contributing factor, the rapid increase in the prevalence of obesity suggest that environmental conditions, such as high fat foods and relatively low physical activity, has allowed obesity to reach epidemic proportions in both industrialized countries and in urbanized populations around the world $(1,2)$. Obesity increases the risk of developing a number of diseases, such as type 2 diabetes mellitus, hypertension, dyslipidemia and cardiovascular disease (3). Obesity is the most important modifiable risk factor for progression from insulin resistance to type 2 diabetes mellitus (4). Under physiological conditions, the amount of insulin secreted by the $\beta$-cells of the pancreas matches the insulin demand in order to keep glucose concentrations within the normal range (5). However, when insulin demand exceeds that capacity to secrete insulin, glucose concentrations will rise and the pre-diabetic states will occur. Individuals can be grouped into those who suffer from impaired fasting glucose (IFG) or impaired glucose tolerance (IGT). Consequently, the rise in glucose concentrations in these pre-diabetic conditions are the result of defects in $\beta$-cell function and a reduced insulin action (6). IGT is a condition characterized by relatively normal fasting glucose concentrations combined with postprandial hyperglycemia (7). Individuals with isolated IGT show a moderate to severe muscle insulin resistance and suffer from defects in both the early-and late-phase insulin secretory response to an oral glucose load $(8,9)$. Subjects with IFG show increased fasting glucose levels and normal $2 \mathrm{~h}$ glucose levels and are characterized by a more pronounced hepatic insulin resistance and an impaired insulin-induced suppression of endogenous glucose production (10). Patients with IGT have a 2- to 5-fold greater risk of developing cardiovascular disease, compared with age-matched normoglycemic controls (11).

Obesity and type 2 diabetes mellitus develop as a consequence of a complex interaction between genetic and environmental risk factors. High-fat, energy dense diets, which promote obesity and reduced physical activity are the main non-genetic determinants (12). The high fat content of Western diets has been related to increased energy intake and an increasing body mass index $(13,14)$. The high palatability of high fat foods makes overeating more likely and the high energy density of fat-rich diets has been shown to increase energy intake in animals and humans (15-17). Stubbs et al. showed that when subjects were allowed to eat ad libitum, they consumed more energy as the proportion of fat in the diet increased. This is described as 'passive overconsumption' (18). Furthermore, several meta-analyses show that a reduction in dietary fat without restriction of total energy intake causes weight loss in a dose-dependent fashion (19-22). There are also indications that the more energy efficient handling of fat as compared to other macronutrients as well as between subjects differences in the capacity to handle fatty 
acids may contribute to body weight gain and in particular to the development of insulin resistance and type 2 diabetes mellitus. The ability to increase fat oxidation upon increased fatty acid availability and to switch between fat and glucose as the primary fuel source in the postprandial state, defined as metabolic flexibility, may be one of the putative physiological concepts of importance for body weight control and the development of insulin resistance $(23,24)$. The capacity to regulate fat oxidation is determined by a complex of factors including fatty acid availability, for a large extent determined by adipose tissue lipid buffering capacity, prevailing insulin and glucose concentrations and mitochondrial function (25-27).

In this introduction, at first the role of fat oxidation in body weight regulation and insulin resistance is addressed. Secondly, several dietary components, supplements and pharmacological agents that may increase fat oxidation and thereby improve body weight control and insulin sensitivity will be reviewed briefly.

\section{$\underline{1 \text { Body weight requlation }}$}

The traditional concept of energy balance implies that weight gain develops as result of a chronic positive energy balance. However, long term weight maintenance (energy balance) requires sustained macronutrient balance i.e. when the fuel mix oxidized is equal to the fuel mix consumed. Protein and carbohydrate balance are regulated more closely than fat balance (28). Consumption of dietary carbohydrate leads to increased carbohydrate oxidation mainly through the action of insulin, whereas fat oxidation only slowly adapts to an increase in dietary fat intake $(29,30)$. The rate at which this adjustment in substrate oxidation is achieved is faster in the transition from a low carbohydrate to high carbohydrate diet ( 2 days) compared to low fat to high fat diets. In response to an increase in dietary fat content $(60 \%)$, fat oxidation can take more than 1 week to adjust to the increased fat intake (31). Fat is more readily absorbed and assimilated into body fat stores and less rapidly oxidized than other macronutrients. In addition, satiety signals arising from fat ingestion are weaker than that for carbohydrate and protein (28). There is considerable evidence that macronutrients differ in their capacity to influence appetite and satiety, with fat being the least satiating and proteins the most (32).

The limited ability to increase fat oxidation to fat intake as compared to other macronutrients may translate into a positive energy balance and weight gain over time when individuals are exposed to high fat feeding (33). Horton et al. demonstrated, by overfeeding men for 14 days each with isoenergetic amounts of fat and carbohydrate, that fat storage is higher with fat (90-95\%) than with carbohydrate (70-75\%) overfeeding. This 


\section{Chapter 1}

was because the excess dietary fat produced minimal increases in fat oxidation and energy expenditure whereas excess carbohydrate significantly increased carbohydrate oxidation and total energy expenditure (34). Thomas et al. (1992) fed lean and obese subjects ad libitum with low-fat and high-fat diets for 1 week. On day 7 on each diet, $24 \mathrm{~h}$ substrate oxidation was measured using a respiration chamber. Voluntary energy intake was higher on the high-fat diet compared with the low-fat diet. On day 7 of the low-fat diet, carbohydrate intake was positively related to carbohydrate oxidation, indicating that carbohydrate intake stimulated its own oxidation, and carbohydrate balance was reached. After $7 \mathrm{~d}$ on the high-fat diet, fat intake was related to fat oxidation, but only in the lean subjects. Furthermore, even the lean subjects were not able to stimulate fat oxidation to an extent sufficient to match fat intake, and a positive fat balance was reached. The results of these studies clearly show that, both in the short as well as in the long term, fat intake does not stimulate its own oxidation, when dietary fat is given in excess of energy requirements (35).

Important work on the concept of body weight regulation was done by Flatt, who described the features of body-weight maintenance with a two-compartment model based on a fat compartment and a glycogen compartment (36-38). This model predicts that one of the driving forces for food intake is the physiological requirement to maintain glycogen stores at a certain level. Thus, an increased dietary fat intake may cause more depletion of the carbohydrate stores in those individuals with impaired capacity to upregulate fat oxidation, which may result in a stronger signal that promotes food intake. Furthermore, Flatt and colleagues argued that one of the mechanisms to adapt to a high fat diet is an increase in fat mass until a new equilibrium is reached in which fat oxidation equals intake $(29,38)$. Support for this hypothesis comes from previous studies, reporting a positive correlation between fat mass and fasting $24 \mathrm{~h}$ fat oxidation, although this relationship was not confirmed in all studies $(30,39-41)$.

As already indicated above, there are indications that obese subjects may have a diminished capacity to use fat as a fuel and adapt more slowly to a high dietary fat intake, compared with lean subjects $(25,35)$. A limited ability to adjust fat oxidation to fat intake may translate into a positive fat balance and weight gain over time when subjects are exposed to a high-fat diet. Decreased adaptation to a high fat diet has been observed in formerly obese, obese individuals and individuals with a family history of obesity (35, 40, 42-44). In the NUGENOB study, it was demonstrated that insulin resistance in obese subjects was independently associated with an impaired capacity to increase fasting fat oxidation and an impaired ability to suppress postprandial fat oxidation $(40,45)$. In addition, several studies in formerly obese women show a failure to increase fat oxidation 
after a isocaloric high fat diet ( $50 \%$ fat) compared with a low fat diet ( $20 \%$ fat) for $3-5$ days $(42,46)$. Furthermore, Raben et al. demonstrated that postprandial fat oxidation was more suppressed acutely after a single high fat meal (50\% fat) in formerly obese women when compared with matched controls (47). It was suggested that the attenuated rise in postprandial fat oxidation rates were caused by an impaired uptake and/or capacity to oxidize FFA in skeletal muscle $(48,49)$. The impairments in fat oxidation seem to be suppressed when subjects are fed a low-fat high-carbohydrate diet. Post-obese subjects adjusted their carbohydrate oxidation to its intake and achieved a new nutrient-balance (50). Prospective studies show that Pima Indians with a habitual high $24 \mathrm{~h}$ RQ are more prone to gain weight over time (51). Seidell et al. found a significant positive association between resting RQ and subsequent weight gain (52). Thus, there is accumulating evidence that there may be a primary, possibly genetically mediated component of fat oxidation, which may result in a reduced fat oxidation rate, predisposing subjects toward the development of obesity.

\section{$\underline{3 \text { Fatty acid metabolism in insulin resistant state }}$}

As indicated above, the obese insulin resistant state is often characterized by metabolic inflexibility, ie. an impaired capacity to increase fat oxidation upon increased FFA availability and to switch between fat and glucose during insulin-stimulated conditions (23). The skeletal muscle is believed to be the main site responsible for the impaired fatty acid utilization and oxidation because of its large mass and since lipids are the principal substrate of skeletal muscle after an overnight fast and during moderate-intensity exercise (53). It has become apparent that there are multiple regulatory sites controlling fatty acid metabolism $(54,55)$. Skeletal muscle FA oxidation involves: FFA delivery to skeletal muscle, transport across the cell membrane, synthesis and lipolysis of intramuscular triacylglycerol (IMTG), activation of FFA and transport through the cytosol to the mitochondria and transport across the mitochondrial membrane (56).

The adipose tissue is an important organ in lipid metabolism by buffering (in particular) the postprandial dietary FA from the circulation and preventing excessive supply of lipids to non-adipose tissues like skeletal muscle, liver, heart and pancreas. Insulin resistance may be characterized by a loss of buffering capacity of the adipose tissue resulting in increased FFA and/or TAG concentrations in the circulation, a process referred to as lipid overflow (Figure 1). The oversupply of lipids causes a redistribution of fat from adipose tissue to non-adipose tissues like skeletal muscle, liver and pancreas (ectopic fat accumulation). Not only an increased supply of lipids to the skeletal muscle, but also impairments in the regulation of FA uptake, storage and/or oxidation may results in muscle lipid accumulation (57). Increased IMTG are hypothesized to play a role in the 


\section{Chapter 1}

onset of insulin resistance. Nevertheless, endurance athletes also have elevated IMTG levels and are very insulin sensitive $(58,59)$. This apparent paradox has led to the insight that not IM TG content per se but rather skeletal muscle lipid turnover, and content or FFA composition or localization of lipid metabolites like diacylglycerol (DAG), ceramides and long-chain fatty acids (LCFA-COA) may be associated with skeletal muscle insulin resistance by interfering with the insulin signalling pathway $(60,61)$.

For a better understanding of these complex inter-organ relationships in insulin resistance, the next paragraph will describe in more detail which factors may contribute to increased lipid overflow in the obese insulin resistant state. After that, disturbances in skeletal muscle substrate oxidation will be discussed in more detail.

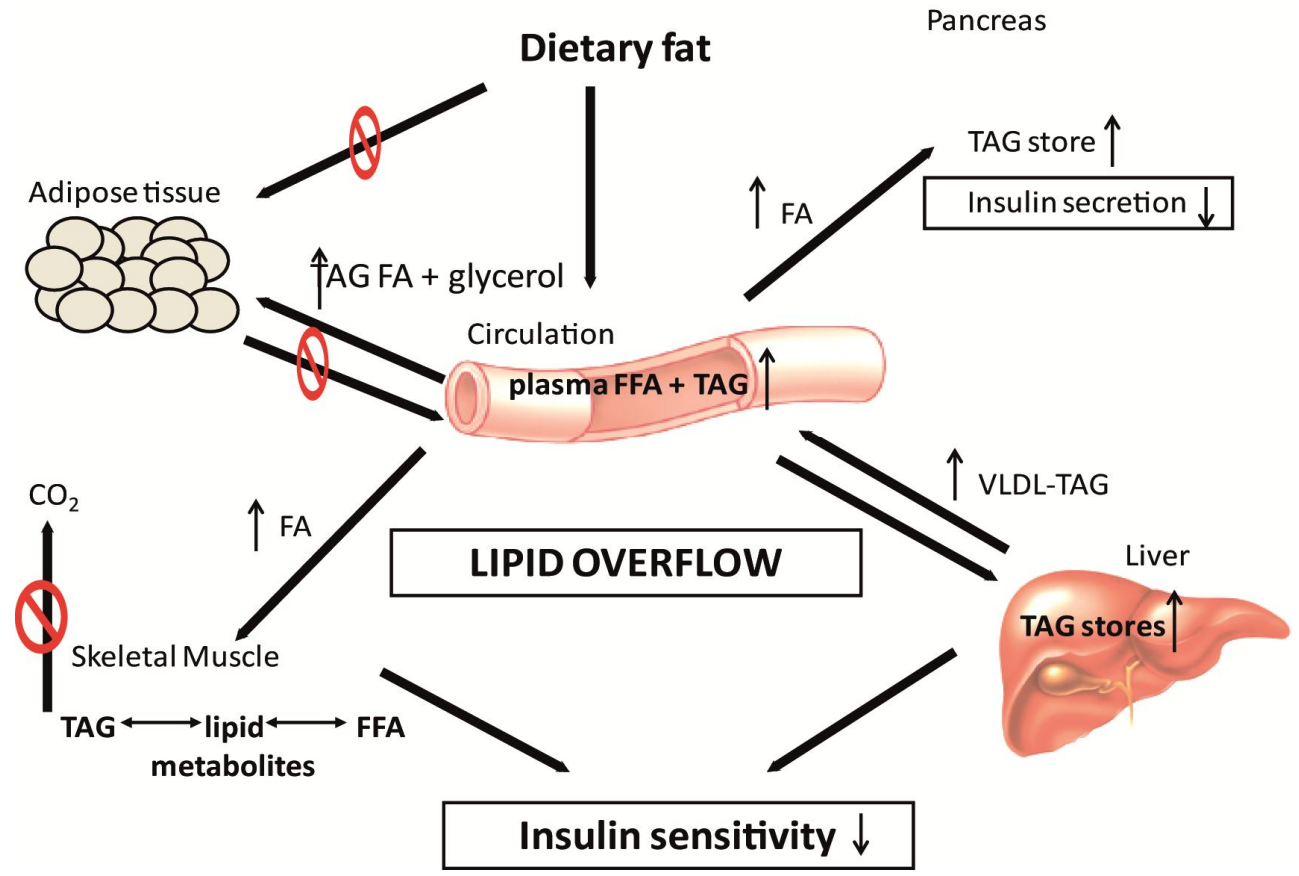

Figure 1. Lipid overflow: impaired buffering capacity of adipose tissue against the daily influx of dietary fat into the circulation leads to an excessive flux of FA and TAG into the circulation. The excess FA are deposited as TAG and lipid intermediates in non-adipose tissues where lipotoxic lipid metabolites interfere with insulin signalling or with glucose-stimulated insulin secretion. 


\section{2-1 Adipose tissue function and dysfunction}

FFA are stored as triglycerides (TAG) in adipocytes and serve as a source of energy during fasting conditions. The balance between lipogenesis and lipolysis is primarily under the control of insulin and catecholamines (62). Upon stimulation, adipose tissue triglyceride lipase (ATGL) is the main enzyme responsible for the hydrolysis of TAG into DAG, whereas hormone-sensitive lipase (HSL) is mainly responsible for the subsequent hydrolysis of DAG into monoacylglycerol. Monoacylglycerol lipase then completes the last step of TAG hydrolysis by converting monoacylglycerol into glycerol (63).

As already indicated above, the lipid overflow hypothesis describes the relationship between dysfunctional adipose tissue (ie. reduced buffering capacity), increased ectopic lipid accumulation and the development of insulin resistance in the tissues. During periods of chronic excessive energy intake, adipocytes become overloaded with TAG and adipose tissue has to expand to store the extra fatty acids. Failure of the adipose tissue to differentiate new adipocytes upon increased demand for fatty acid storage result in enlargement of existing adipocytes, which are less sensitive to insulin and are associated with impairments in buffering capacity (64). Insulin-mediated suppression of fatty acid release has been shown to be blunted in obesity, IGT and type 2 diabetes mellitus, which may contribute to in lipid overflow (65-67). Nevertheless, the role of FFA in lipid overflow and insulin resistance has recently been revisited based on studies which report that FFA concentrations are only slightly increased or not increased at all in the obese insulin resistant state (68-70). Indeed, hyperinsulinemia in obese subjects has been shown to be inversely related to adipose tissue HSL and ATGL expression and whole-body FFA rate of appearance when values are expressed per unit fat mass, indicating decreased lipolysis per unit fat mass in the obese insulin resistant state (71-73). These findings implicate that the slightly increased FFA concentrations may be largely explained by a mass effect of expanding adipose tissue and that hyperinsulinemia in obesity may occurs as a compensation to prevent further increase in plasma FFA concentrations $(71,72,74)$. Furthermore, several studies indicate that TAG rather than FFA concentrations are elevated in the obese insulin resistant state $(68,72)$. Indeed, following ingestion of a single mixed meal, impaired postprandial plasma TAG clearance by adipose tissue was reported in obese subjects (75). This is partly explained by a lower functional LPL per unit fat mass in combination with the absence of postprandial upregulation of adipose tissue LPL in obesity (76). McQuaid et al. showed the adipose tissue fat storage after meals was substantially depressed in subjects with abdominal obesity. This was especially so for chylomicron-derived FA, representing the direct storage pathway for dietary fat. They propose that this will result in a diversion of FA to be stored in tissues other than adipose 


\section{Chapter 1}

tissue and ectopic fat accumulation (77). The contribution of endogenous fat (FFA and VLDL-TAG) to the lipid overflow is relatively unknown.

Besides a lipid buffering depot, adipose tissue is seen as an endocrine organ which produces adipokines like leptin and adiponectin. Leptin is a hormone mainly secreted by adipose tissue and acts on the nervous system $(78,79)$. Leptin has been shown to direct fatty acids towards oxidation and away from storage in skeletal muscle of rats or in isolated mouse muscle $(80,81)$. Leptin also seems to promote triacylglycerol (TAG) depletion and to stimulate lipolysis in skeletal muscle and adipose tissue (82-84). This suggest that leptin may promote lipid oxidation and reduces ectopic accumulation, which may be one of the putative mechanisms for improving insulin sensitivity (85). However, leptin treatment has been shown to be efficient in leptin-deficient subjects, but has very limited effect in inducing weight loss in common obese patients (86). Plasma adiponectin levels are decreased in human obesity, insulin resistance and type 2 diabetes mellitus and are inversely associated with visceral fat mass and adipocyte size $(26,87,88)$. Administration of adiponectin stimulates fat oxidation and glucose uptake in $\mathrm{C} 2 \mathrm{C} 12$ myotubes and rat muscle strips and increases mitochondrial biogenesis in human myotubes (89-91). However, underlying mechanisms are far from clear and need further investigation. A further characteristic of adipose tissue dysfunction, is the development of 'inflamed' adipose tissue $(92,93)$. This is based on findings that immune cells infiltrate in adipose tissue during high-fat feeding, where they become activated and initiate a proinflammatory cross-talk with adipocytes. This results in low grade inflammation in adipose tissue and secretion of macrophage inflammatory cytokines, such as TNF $\alpha$ and II-6, along with FFA $(92,94)$. Recent studies show that macrophages also directly infiltrate in skeletal muscle, potentially contributing to local inflammation of this tissue (95). Plasma levels of TNF $\alpha$ are increased in the obese insulin resistant state, most likely due to increased expression levels of TNF $\alpha$ in human adipose tissue and skeletal muscle $(96,97)$. TNF $\alpha$ impaires GLUT-4 expression and glucose uptake in skeletal muscle, although findings are inconsistent $(83,98)$. The possible effects of TNFa on skeletal muscle FFA metabolism are largely unknown. IL- 6 is produced by human adipose tissue and skeletal muscle and its plasma concentrations are elevated in the obese insulin resistant state but the relationship of IL-6 with insulin resistance is controversial $(96,99,100)$. IL-6 may inhibit adipocyte differentiation and increase plasma FFA levels via an increased lipolysis in humans and has been shown to blunt the insulin-mediated suppression of fat oxidation in isolated rat soleus muscle (101-103). The mechanisms via which disturbances in adipokine production and secretion may contribute to insulin resistance, possibly party via modulation of skeletal muscle substrate metabolism, are complex and poorly understood. 


\section{$\underline{\text { 2-2 Skeletal muscle }}$}

Disturbed fat metabolism and insulin resistance

Randle and colleagues were the first to introduce the glucose-FFA cycle, which was based on the substrate competition of glucose and FFA (104). The Randle cycle suggested that an increase in FA availability would lead to an increased FFA oxidation, which in turn results in accumulation of acetyl-COA and citrate that inhibit pyruvate dehydrogenase and phosphofructokinase. As a result, glucose-6-phosphate concentrations increase and inhibit hexokinase, eventually resulting in a decrease in glucose uptake and oxidation. Several studies confirm that elevated plasma FFA concentrations rapidly inhibit glucose oxidation, but without a concomitant acute reduction in insulin-mediated glucose uptake $(105,106)$. Other studies proposed a different hypothesis, suggesting an inhibition of the insulin signalling pathway by FFA or lipid intermediates (107-109). Studies using lipid infusion demonstrated a delay in the effect of FFA on muscle insulin resistance. This delayed inhibition of glucose-stimulated glucose uptake may be caused by an accumulation of IMTG and lipid intermediates which could interfere with the insulin signalling pathway (107). In addition, it was found that FFA decreased glucose-6-phosphate concentrations in human skeletal muscle, suggesting that FFA primarily inhibit glucose transport and/or phosphorylation (109). Finally, skeletal muscle fat oxidation is rather reduced than increased in obese and/or subjects with type 2 diabetes mellitus (44, 105, 110). Complementary to the Randle cycle, it has previously been reported that increased glucose concentrations may inhibit fatty acid oxidation via increased malonyl-CoA concentrations and subsequent inhibition of carnitine palmitoyl transferase 1 (CPT-1), thereby also indicating that the regulation of glucose and fatty acid oxidation is a coordinated process (111).

Obese individuals have increased levels of IM TG storage and this has been associated with insulin resistance $(108,112,113)$. By now, it has now become evident that not IMTG per se but rather DAG, LCFA-COA and ceramides concentrations, and/or fatty acid composition and/or localization may be important for the development of insulin resistance $(114,115)$. Pinnamaneni et al. suggests that the accumulation of IM TG provides a protective effect within the cell by limiting the accumulation of other lipid metabolites (116). These data support earlier work conducted in vitro, demonstrating that the incorporation of FFA into IM TG reduced lipotoxicity in the cell (117). Animal studies showed an association between increased LCFA-COA concentrations and insulin resistance $(118,119)$. Additionally, impaired insulin-mediated glucose disposal and elevated LCFA-COA have been reported in obese subjects $(120,121)$. Elevated ceramide concentrations have been shown in skeletal 


\section{Chapter 1}

muscle of animals, obese subjects and lean offspring of subjects with type 2 diabetes mellitus (122-124). Lipid infusion resulted in a threefold increase in intracellular DAG mass in animals (125). Increased DAG content in skeletal muscle has also been reported with fasting and lipid infusions $(122,126)$. A recent study in our laboratory showed that not DAG content per se but rather DAG saturation may be associated with insulin resistance, and that saturation may determine the effect of intramyocellular DAG on insulin sensitivity (69). This should be considered in future studies.

Fatty acid uptake

The fatty acids that are liberated after lipoprotein lipase (LPL) mediated lipolysis and those from the plasma FFA pool can be taken up by skeletal muscle via passive diffusion and via protein-mediated transport $(127,128)$. A number of proteins have been identified that facilitate the uptake of FFA into skeletal muscle, like membrane-bound FA translocase (FAT/CD36), plasma membrane bound fatty acid binding protein (FABPm) and a family of fatty acid transport proteins (FAT1-6) (129-131). Of these transporter proteins, CD36 has been the best characterized (132). Studies in mice have shown that CD36 deficiency impairs fatty acid uptake, whereas CD36 over-expression in muscle was associated with reduced plasma FFA and TAG concentrations $(133,134)$. In humans, it has been shown that muscle CD36 protein expression may be acutely unregulated by insulin and that this upregulation may be more pronounced in insulin resistant conditions $(135,136)$. Studies by Bonen et al. showed that the transport of LCFA into skeletal muscle was increased in muscle strips of obese and type 2 diabetic subjects (137). Recent studies suggest that impairments in the expression of FAT/CD36 may also be directly associated with impairments in fat oxidation, but this requires further investigation (138). On the other hand, reduced capacity in FFA uptake across forearm and leg muscle during fasting have been observed in subjects with type 2 diabetes mellitus and visceral obese women compared to lean controls under in vivo conditions $(48,139)$. However, in vivo, fatty acid uptake is determined by the fatty acid supply, intracellular FFA concentrations as well as FA uptake capacity.

The contribution of TAG-derived FA to skeletal muscle FA uptake may be as important as plasma FFA, but is less understood and characterized. Activity and expression of lipoprotein lipase (LPL) is an important determinant of muscle TAG extraction. Animal studies showed that overexpression of LPL in skeletal muscle induces insulin resistance (140). M oreover, insulin has been shown to inhibit skeletal muscle LPL activity, contrary to its stimulating effects on adipose tissue (141). Recent studies from our laboratory show an increased muscle VLDL-TAG and chylomicron extraction in the postprandial state in insulin 
resistant subjects or subjects with an impaired glucose metabolism $(49,69)$. Therefore, it can be hypothesized that insulin-mediated inhibition of skeletal muscle LPL is impaired, resulting in decreased suppression of TAG extraction and possibly enhanced muscle lipid accumulation.

FFA acid partitioning and mitochondrial function

The fatty acids that enter the cell bound to FABPc for transport through the cytoplasm can either be partitioned towards oxidation in the mitochondria or towards storage in intracellular lipid fractions (142). The first step in the oxidative pathway is the activation of fatty acids to fatty acyl-CoA by the enzyme acyl-CoA synthetase and the uptake of fatty acyl-COA in the mitochondrion. This uptake is regulated by the carnitine palmitoyl transferase (CPT) system, in which CPT-1 is responsible for the transport over the outer mitochondrial membrane and CPT-2 for the transport over the inner mitochondrial membrane. CPT-1 is de rate-limiting step in the uptake of LCFA in the mitochondria and therefore an important site for regulating fat oxidation (143). CPT-1 is under control of malonyl-COA, which is formed out of acetyl-CoA by the action of acetyl-CoA carboxylase (ACC) (143). In rodent models of obesity and insulin resistance an increased content of malonyl-CoA has been shown in skeletal muscle in combination with hyperglycemia, hyperinsulinemia and a reduced lipid oxidation (130). In human skeletal muscle, it has been shown that a combination of hyperglycemia and hyperinsulinemia increases malonyl-CoA, inhibits CPT-1 activity and directs LCFA away from oxidation and towards storage (144). There are indications that a lowered mitochondrial transport through CPT-1 may contribute to the reduced fat oxidation in the muscle of obese or subjects with type 2 diabetes mellitus (145).

It is known that mitochondrial content and activity determine fatty acid oxidation in response to lipid infusion (146). Several studies indicated mitochondrial abnormalities in type 2 diabetes mellitus subjects and insulin resistant individuals (147-149). This led to the hypothesis that a lower mitochondrial capacity is associated with reduced lipid oxidation and therefore increased lipid accumulation. It should be mentioned that not all studies have reported decreased mitochondrial function in obesity or insulin resistance. Holloway et al. showed that mitochondria isolated from obese individuals were not dysfunctional, but only the amount of mitochondria were reduced (150). This may indicate that the reduction in fat oxidation that has been associated with the obese insulin resistant state results from reductions in mitochondrial content, and not from intrinsic mitochondrial alterations (56). Boushel et al. directly measured the oxygen consumption of mitochondria isolated from lean and obese diabetic individuals and concluded that there was no mitochondrial dysfunction in skeletal muscle from obese subjects. Whole-muscle fat 


\section{Chapter 1}

oxidation was impaired with obesity, but when data were normalized to mitochondrial DNA this finding was lost; indicating that obese diabetic subjects have less mitochondria in their skeletal muscle (151).

It has also been reported that the skeletal muscle of morbidly obese individuals, both from diabetic and non-diabetic subjects, contains a lower relative percentage of type 1 muscle fibers compared to lean controls $(152,153)$. Type 1 , are characterized as being insulinsensitive and geared towards more oxidative metabolism compared to type 2 muscle fibers (152). This predominance of type 2 fibers with severe obesity is again suggestive of a general phenotype in the muscle of these patients which favors a low capacity for lipid oxidation and insulin resistance. However, other studies indicate that fibre type is not altered in morbid obese subjects in response to an intervention which improves insulin action $(154,155)$. These data indicate that contractile and metabolic characteristics may not always be congruent.

\section{Fat oxidation}

Metabolic flexibility is an important characteristic of skeletal muscle. The dynamic process of adjusting fat oxidation to fatty acid uptake and IM TG turnover may prevent the muscle from excess lipid storage, whereas an impaired flexibility may lead to lipid accumulation. During fasting conditions, FFA normally are the predominant substrate for oxidation, whereas uptake and oxidation are suppressed in the postprandial phase at the expense of glucose. Several studies suggest that fasting RQ is elevated in skeletal muscle from obese insulin-resistant, IGT and type 2 diabetes mellitus subjects $(105,156,157)$. Similar findings have been reported at a whole-body level in obese adolescents and subjects with a family history of type 2 diabetes mellitus (158-160). Abnormalities in postprandial FFA metabolism have already been documented in individuals with IGT and insulin resistant obese individuals, indicating that these defects may be a primary factor in the development of type 2 diabetes mellitus $(161,162)$. In addition, impairments in the ability of skeletal muscle to utilize FFA have been reported during $\beta$-adrenergic stimulation, insulin stimulation, after a high fat meal and exercise $(44,105,156,157,161,163)$.

As described in the previous part, the insulin resistant state is characterized by an impaired metabolic flexibility. Improvements in insulin-mediated suppression of fat oxidation was found in obese subjects after weight loss by energy reduction and after weight loss induced by a combination of energy reduction and an exercise programme $(156,164)$. Corpeleijn et al. showed that weight loss in IGT men improved metabolic flexibility, which indicates that the impairments in the regulation of fat oxidation in skeletal muscle are reversible (157). Data are not consistent on fasting fat oxidation with weight loss studies showing both in increase and no change in fat oxidation or in skeletal 18 
muscle markers of fat oxidation $(44,157,165)$. Furthermore, weight loss in subjects with type 2 diabetes mellitus had no effect on plasma-derived FFA oxidation and whole-body fat oxidation during fasting (166). This lack of improvement in skeletal muscle fat oxidation after weight loss was also observed during $\beta$-adrenergic stimulation and exercise $(44,166)$. Altogether, there are clear indications that weight loss is able to partly reverse postprandial impairments in metabolic flexibility, whereas with respect to the fasting condition, improved regulation of fat oxidation could not be confirmed in all studies.

\section{$\underline{4 \text { Nutrition }}$}

Postprandial glycemia and insulinemia have been implicated in the etiology of metabolic chronic diseases like obesity, type 2 diabetes mellitus and cardiovascular disease. Indeed, fasting and postprandial glucose concentrations represent a strong risk factor for the development of type 2 diabetes mellitus $(167,168)$. It has been hypothesized that low glycemic index (GI) foods may affect body weight control and insulin sensitivity by promoting satiety and stimulating fat oxidation at the expense of carbohydrate oxidation (169). Indeed, animal studies show that a reduced GI can shift substrate use in favour of fat oxidation, independent of diet-induced changes in body composition or energy intake (170-172). The level of postprandial glycemia has been implicated in body weight control via either an effect on appetite of via an effect on nutrient partitioning (169). The latter may promote fat storage in adipose and non-adipose tissue through effects on lipolysis and skeletal muscle fat oxidation. Animals studies showed an increase in body fat and less lean mass when fed a high GI diet compared with a matched low Gl diet over 18 weeks (171). As indicated above, the shift towards a higher fat oxidation may be of practical use for body weight control. A lower rate of adaptation to a high fat diet has been shown to lead to weight gain over time $(37,51)$.

Diets with low Gl foods reduce the risk of developing type 2 diabetes, cardiovascular disease, thereby improving insulin sensitivity, glycaemic control and blood lipid profile (173-175). In observational studies, increasing GI has been linked to higher prevalence of insulin resistance, metabolic syndrome, TAG concentrations and HDL concentrations (176, 177). Although many studies have been performed with variable results, many are confounded by dietary differences in the diets other than Gl (energy, macronutrient and fibre content) and are difficult to interpret.

\section{Green tea}

The role of polyphenols has been an active area of research for bioactive food ingredients in the past decades. Interest in the potential role of these polyphenols in fatty acid 


\section{Chapter 1}

metabolism, energy expenditure and obesity started only in the last decade. The most abundant of the catechin polyphenols are epicatechin, epigallocatechin, epicatechin-3gallate and epigallocatechin-3-gallate (EGCG). The latter being the most abundant and pharmacologically active (178). Catechins are thought to stimulate fat oxidation through direct inhibition of catechol-o-methyltransferase (COMT), an enzyme that degrades noradrenaline (179). This increase in CNS stimulation has been suggested to increase fatty acid mobilization and oxidation and energy expenditure. Although this mechanism is often referred to, there is no convincing human evidence yet.

In animal models, green tea seems to have a beneficial effect on body weight. Lee et al. demonstrated that EGCG supplementation resulted in a reduction in body weight and adipose tissues mass at various sites in a dose-dependent manner (180). The latter data indicate that chronic green tea supplementation may cause some adaptations in fat metabolism. These data are confirmed in human studies, where long-term green tea supplementation has been reported to have slight positive effects on reducing and maintaining body weight in humans (181-184). Although not all studies showed consistent results (185-187). Dulloo et al. showed that consumption of a green tea extract (GTE, 270 mg EGCG) in combination with $150 \mathrm{mg}$ caffeine has an acute effect on $24 \mathrm{~h}$ fat oxidation and $E E$ in healthy men (188). On the other hand, Gregersen et al. found no acute effect of GTE ingestion, with varying levels of active ingredients, on fat oxidation (189). Subjects received low doses (40-101 mg EGCG) intermittently throughout the day. A dosage below $100 \mathrm{mg}$ EGCG per administration could be beneath the threshold to elicit an effect on fat metabolism as seen in other studies. A number of studies have also addressed the question whether green tea catechins in the absence of caffeine can enhance $E E$ and fat oxidation $(190,191)$. Venables et al. has shown that consumption of a green tea extract (890 mg polyphenols + 366 mg EGCG) increased fat oxidation during moderate-intensity exercise (192). Literature is still inconclusive with respect to the most effective supplementation protocol, optimal catechin dosage and the impact of the addition of caffeine (193).

Mechanisms for effects on fat oxidation

Watanabe et al. has shown that EGCG inhibited acetyl CoA-carboxylase (ACC) in 3T3-L1 cells suggesting that EGCG may alter the partitioning of lipids from storage towards oxidation (194). In addition, chronic feeding of green tea extract to mice has been shown to elevate skeletal muscle gene expression of pathways involved in lipid transport and oxidation, such as FAT/CD36, medium-chain acyl-CoA dehydrogenase (MCAD) and uncoupling protein 3 (UCP3) $(195,196)$. Additionally, in this study, the green tea extract 
reduced malonyl-CoA in skeletal muscle and may thereby promote fatty acid transport into the mitochondria through a reduced inhibition of CPT-1 (197). In the epididymal white adipose tissue of EGCG-fed mice, mRNA levels of CPT-1, uncoupling protein 2 (UCP-2), hormone-sensitive lipase (HSL) and adipose triglyceride lipase (ATGL) were increased (180, 198). Nevertheless, this increased expression of genes involved in fat metabolism has not consistently been found (199). Whether the effects of EGCG and/or green tea extract on gene expression are acute, either through a direct regulatory action or due to the transient increase in free fatty acids (FFA) chronically, remains to be established.

\section{Pharmacological approach: Liraglutide}

Diet and life style modifications remain the first steps in obesity management but as these often fail to provide major and sustainable weight loss, the use of pharmaceutical agents might sometimes be needed to allow long-term weight loss maintenance $(200,201)$. Gastrointestinal hormones play important roles in the regulation of energy homeostasis and have been regarded as potential therapeutic targets for sustainable weight loss maintenance and glycaemic control $(202,203)$. Glucagon-like peptide-1 (GLP-1) is secreted from L-cells in the gut in a physiological and glucose-dependent manner and enhances glucose-induced insulin secretion. In addition, GLP-1 slows down gastric emptying, inhibits glucagon secretion, promotes satiety and reduces body weight and improves glycemic control in lean, obese subjects and type 2 diabetes mellitus subjects (204-209). However, due to the short half-life of endogenous GLP-1 (it is rapidly metabolised by dipeptidyl peptidase-4 (DPP-4)), a drug with protracted activity is required to obtain the full therapeutic potential. GLP-1 analogues are an important drug class for the treatment of type 2 diabetes mellitus and potentially also obesity (210).

Liraglutide is a GLP-1 analogue with $97 \%$ structural homology to human GLP-1 and has a half-life of about 13 hours and can be administered subcutaneously once daily (211). The effects of liraglutide have been studied extensively in subjects with type 2 diabetes mellitus. The LEAD trials showed an improvement in glycemic control and a reduction in body weight and $\mathrm{HbA}_{1 c}$ in subjects with type 2 diabetes mellitus (212-214). In minipigs, liraglutide reduced feeding frequency and meal size (215). The reduction in body weight is also observed in obese subjects and accompanied by reductions in waist circumference and systolic and diastolic blood pressure (216). The underlying mechanism that mediates the weight loss by liraglutide is not entirely clear. It is believed that this could be via a combination of effects on the gastrointestinal tract and the nervous system leading to satiety effects and increased energy expenditure (216-218). The GLP-1 receptor (GLP-1R) has been localized to the stomach, duodenum, brain, pancreas, heart, lung and kidney (219). Furthermore, GLP-1 binding sites have been found in muscle cell, adipocytes and 


\section{Chapter 1}

liver (220-222). The findings of GLP-1R outside the pancreas provide evidence that GLP-1 has many extra-pancreatic effects and corroborates other studies that show physiological effects of GLP-1 $(217,223,224)$. The effect of GLP-1 in adipose tissue has been poorly studied, only a few reports exist. Studies in isolated rat and human adipocytes have demonstrated that GLP-1 has the ability to induce both lipogenic and lipolytic pathways (225-227). The use of vildagliptin, a DPP-4 inhibitor, was found to decrease the rate of fasting lipolysis as indicated by a reduction of palmitate flux in obese subjects (228). However, extensive research is necessary to determine to effects of GLP-1R agonists on adipose tissue function in vivo.

\section{Outline of this thesis}

This thesis focuses on the modulation of fat oxidation by nutritional and pharmacological interventions in overweight/obese subjects. Chapter $\mathbf{2}$ A-B describes the role of slowly digestible carbohydrates, trehalose and isomaltulose, on insulinemic and glycemic responses, postprandial lipolysis and fat oxidation in healthy overweight subjects, respectively. The effects of trehalose and isomaltulose are investigated when ingested as a drink and in combination with a mixed meal. By labelling the carbohydrates by a tracer we were able to determine whole body substrate utilization as well as exogenous carbohydrate oxidation. It is not known whether the putative beneficial effect of isomaltulose and trehalose on fat oxidation also extend to IGT subjects, who show profound disturbances in the capacity to utilise fat as a substrate source during fasting conditions as well as the capacity to switch between fuels in the postprandial state. For this reason, chapter $\mathbf{3}$ describes a study with a similar protocol as chapter 2A-B but now in subjects with impaired glucose tolerance. In recent years there has been an increased interest in the health benefits of polyphenols in the prevention of obesity and type 2 diabetes mellitus. Green tea is rich in catechins, and beneficial effects have been attributed to the most abundant catechin, EGCG. Originally, the effects of polyphenols including EGCG were mainly ascribed to their anti-oxidant potential, but more recently it has become clear that the metabolic effects also extend to pathways of fatty acid metabolism. However, the exact underlying mechanisms of the effects of EGCG are still poorly understood. Chapter 4 describes the effects of a 3 day supplementation of $300 \mathrm{mg}$ EGCG on fat oxidation in overweight subjects. Local lipolysis, glucose metabolism and blood flow in adipose tissue and skeletal muscle were measured in a subgroup using microdialysis. Nutritional modifications have not always been successful, therefore in chapter 5, we investigated the effects of a pharmacological agent, liraglutide, in obese subjects on substrate oxidation, glucose metabolism, gastric emptying and food intake. Subjects were treated for 5 weeks with $1.8 \mathrm{mg}, 3.0 \mathrm{mg}$ liraglutide or placebo respectively. 
Substrate utilization was measured during a in the respiration chamber followed by a meal test to measure circulating metabolites and appetite by VAS scales. A fat biopsy was taken to determine the expression of genes in subcutaneous adipose tissue that are involved in the regulation of these metabolic pathways and adipose tissue function. In chapter 6 , the results are discussed in a broader perspective and implications for future research are given. 


\section{References}

1. Rankinen T, Zuberi A, Chagnon YC, et al. The human obesity gene map: the 2005 update. Obesity (Silver Spring) 2006;14:529-644.

2. Obesity: preventing and managing the global epidemic. Report of a WHO consultation. World Health Organ Tech Rep Ser 2000;894:i-xii, 1-253.

3. Must A, Spadano J, Coakley EH, Field AE, Colditz G, Dietz WH. The disease burden associated with overweight and obesity. JAM A 1999;282:1523-9.

4. Edelstein SL, Knowler WC, Bain RP, et al. Predictors of progression from impaired glucose tolerance to NIDDM: an analysis of six prospective studies. Diabetes 1997;46:701-10.

5. Reaven GM, Hollenbeck CB, Chen YD. Relationship between glucose tolerance, insulin secretion, and insulin action in non-obese individuals with varying degrees of glucose tolerance. Diabetologia 1989;32:52-5.

6. DeFronzo RA. Pathogenesis of type 2 diabetes mellitus. Med Clin North Am 2004;88:787-835, ix.

7. Saad M F, Knowler WC, Pettitt DJ, Nelson RG, Charles M A, Bennett PH. A tw o-step model for development of non-insulin-dependent diabetes. Am J Med 1991;90:229-35.

8. Weyer C, Bogardus C, Pratley RE. Metabolic characteristics of individuals with impaired fasting glucose and/or impaired glucose tolerance. Diabetes 1999;48:2197-203.

9. DeFronzo RA. Lilly lecture 1987. The triumvirate: beta-cell, muscle, liver. A collusion responsible for NIDDM . Diabetes 1988;37:667-87.

10. Bock G, Chittilapilly E, Basu R, et al. Contribution of hepatic and extrahepatic insulin resistance to the pathogenesis of impaired fasting glucose: role of increased rates of gluconeogenesis. Diabetes 2007;56:1703-11.

11. DECODE Study Group tEDEG. Glucose tolerance and cardiovascular mortality: comparison of fasting and 2-hour diagnostic criteria. Arch Intern Med 2001;161:397-405.

12. Hamman RF. Genetic and environmental determinants of non-insulin-dependent diabetes mellitus (NIDDM). Diabetes M etab Rev 1992;8:287-338.

13. Westerterp KR, Verboeket-van de Venne WP, Westerterp-Plantenga MS, Velthuiste Wierik EJ, de Graaf C, Weststrate JA. Dietary fat and body fat: an intervention study. Int J Obes Relat M etab Disord 1996;20:1022-6.

14. Hill JO, Peters JC. Environmental contributions to the obesity epidemic. Science 1998;280:1371-4.

15. West DB, York B. Dietary fat, genetic predisposition, and obesity: lessons from animal models. Am J Clin Nutr 1998;67:505S-512S.

16. Drewnowski A, Greenwood MR. Cream and sugar: human preferences for high-fat foods. Physiol Behav 1983;30:629-33.

17. Lissner L, Levitsky DA, Strupp BJ, Kalkwarf HJ, Roe DA. Dietary fat and the regulation of energy intake in human subjects. Am J Clin Nutr 1987;46:886-92. 
18. Stubbs RJ, Ritz P, Coward WA, Prentice AM. Covert manipulation of the ratio of dietary fat to carbohydrate and energy density: effect on food intake and energy balance in free-living men eating ad libitum. Am J Clin Nutr 1995;62:330-7.

19. Astrup A, Ryan L, Grunwald GK, et al. The role of dietary fat in body fatness: evidence from a preliminary meta-analysis of ad libitum low-fat dietary intervention studies. Br J Nutr 2000;83 Suppl 1:S25-32.

20. Yu-Poth S, Zhao G, Etherton T, Naglak M, Jonnalagadda S, Kris-Etherton PM. Effects of the National Cholesterol Education Program's Step I and Step II dietary intervention programs on cardiovascular disease risk factors: a meta-analysis. Am J Clin Nutr 1999;69:632-46.

21. Astrup A, Grunwald GK, M elanson EL, Saris WH, Hill JO. The role of low-fat diets in body weight control: a meta-analysis of ad libitum dietary intervention studies. Int J Obes Relat M etab Disord 2000;24:1545-52.

22. Avenell A, Brown TJ, M cGee MA, et al. What are the long-term benefits of weight reducing diets in adults? A systematic review of randomized controlled trials. J Hum Nutr Diet 2004;17:317-35.

23. Corpeleijn E, Saris WH, Blaak EE. Metabolic flexibility in the development of insulin resistance and type 2 diabetes: effects of lifestyle. Obes Rev 2009;10:17893.

24. Galgani JE, M oro C, Ravussin E. Metabolic flexibility and insulin resistance. Am J Physiol Endocrinol M etab 2008;295:E1009-17.

25. Galgani J, Ravussin E. Energy metabolism, fuel selection and body weight regulation. Int J Obes (Lond) 2008;32 Suppl 7:S109-19.

26. Weyer $\mathrm{C}$, Funahashi $\mathrm{T}$, Tanaka $\mathrm{S}$, et al. Hypoadiponectinemia in obesity and type 2 diabetes: close association with insulin resistance and hyperinsulinemia. J Clin Endocrinol M etab 2001;86:1930-5.

27. Clement K, Vaisse C, Lahlou N, et al. A mutation in the human leptin receptor gene causes obesity and pituitary dysfunction. Nature 1998;392:398-401.

28. Hill JO, Prentice AM. Sugar and body weight regulation. Am J Clin Nutr 1995;62:264S-273S; discussion 273S-274S.

29. Flatt JP, Ravussin E, Acheson KJ, Jequier E. Effects of dietary fat on postprandial substrate oxidation and on carbohydrate and fat balances. J Clin Invest 1985;76:1019-24.

30. Schutz Y, Flatt JP, Jequier E. Failure of dietary fat intake to promote fat oxidation: a factor favoring the development of obesity. Am J Clin Nutr 1989;50:307-14.

31. Schrauwen $P$, van Marken Lichtenbelt WD, Saris WH, Westerterp KR. Changes in fat oxidation in response to a high-fat diet. Am J Clin Nutr 1997;66:276-82.

32. van Dam RM, Seidell JC. Carbohydrate intake and obesity. Eur J Clin Nutr 2007;61 Suppl 1:S75-99.

33. Astrup A. The relevance of increased fat oxidation for body-weight management: metabolic inflexibility in the predisposition to weight gain. Obes Rev 2011;12:85965. 
34. Horton TJ, Drougas H, Brachey A, Reed GW, Peters JC, Hill JO. Fat and carbohydrate overfeeding in humans: different effects on energy storage. Am J Clin Nutr 1995;62:19-29.

35. Thomas CD, Peters JC, Reed GW, Abumrad NN, Sun M, Hill JO. Nutrient balance and energy expenditure during ad libitum feeding of high-fat and highcarbohydrate diets in humans. Am J Clin Nutr 1992;55:934-42.

36. Flatt JP. Dietary fat, carbohydrate balance, and weight maintenance: effects of exercise. Am J Clin Nutr 1987;45:296-306.

37. Flatt JP. The difference in the storage capacities for carbohydrate and for fat, and its implications in the regulation of body weight. Ann N Y Acad Sci 1987;499:10423.

38. Flatt JP. Importance of nutrient balance in body weight regulation. Diabetes M etab Rev 1988;4:571-81.

39. Astrup A, Buemann B, Western P, Toubro S, Raben A, Christensen NJ. Obesity as an adaptation to a high-fat diet: evidence from a cross-sectional study. Am J Clin Nutr 1994;59:350-5.

40. Blaak EE, Hul G, Verdich C, et al. Fat oxidation before and after a high fat load in the obese insulin-resistant state. J Clin Endocrinol M etab 2006;91:1462-9.

41. Nagy TR, Goran MI, Weinsier RL, Toth MJ, Schutz Y, Poehlman ET. Determinants of basal fat oxidation in healthy Caucasians. J Appl Physiol 1996;80:1743-8.

42. Astrup A, Buemann B, Christensen NJ, Toubro S. Failure to increase lipid oxidation in response to increasing dietary fat content in formerly obese women. Am J Physiol 1994;266:E592-9.

43. Heitmann BL, Lissner $\mathrm{L}$, Sorensen $\mathrm{TI}$, Bengtsson $\mathrm{C}$. Dietary fat intake and weight gain in women genetically predisposed for obesity. Am J Clin Nutr 1995;61:12137.

44. Blaak EE, Van Baak M A, Kemerink GJ, Pakbiers MT, Heidendal GA, Saris WH. Betaadrenergic stimulation of energy expenditure and forearm skeletal muscle metabolism in lean and obese men. Am J Physiol 1994;267:E306-15.

45. Blaak EE, Hul G, Verdich $\mathrm{C}$, et al. Impaired fat-induced thermogenesis in obese subjects: the NUGENOB study. Obesity (Silver Spring) 2007;15:653-63.

46. Buemann B, Toubro S, Astrup A. Substrate oxidation and thyroid hormone response to the introduction of a high fat diet in formerly obese women. Int J Obes Relat Metab Disord 1998;22:869-77.

47. Raben A, Andersen HB, Christensen NJ, Madsen J, Holst JJ, Astrup A. Evidence for an abnormal postprandial response to a high-fat meal in women predisposed to obesity. Am J Physiol 1994;267:E549-59.

48. Colberg SR, Simoneau JA, Thaete FL, Kelley DE. Skeletal muscle utilization of free fatty acids in women with visceral obesity. J Clin Invest 1995;95:1846-53.

49. Moors CC, van der Zijl NJ, Diamant M, Blaak EE, Goossens GH. Impaired insulin sensitivity is accompanied by disturbances in skeletal muscle fatty acid handling in subjects with impaired glucose metabolism. Int J Obes (Lond) 2011. 
50. Astrup A, Buemann B, Christensen NJ, Madsen J. 24-hour energy expenditure and sympathetic activity in postobese women consuming a high-carbohydrate diet. Am J Physiol 1992;262:E282-8.

51. Zurlo F, Lillioja S, Esposito-Del Puente A, et al. Low ratio of fat to carbohydrate oxidation as predictor of weight gain: study of 24-h RQ. Am J Physiol 1990;259:E650-7.

52. Seidell JC, M uller DC, Sorkin JD, Andres R. Fasting respiratory exchange ratio and resting metabolic rate as predictors of weight gain: the Baltimore Longitudinal Study on Aging. Int J Obes Relat M etab Disord 1992;16:667-74.

53. Falholt K, Jensen I, Lindkaer Jensen S, et al. Carbohydrate and lipid metabolism of skeletal muscle in type 2 diabetic patients. Diabet Med 1988;5:27-31.

54. Spriet LL. Regulation of skeletal muscle fat oxidation during exercise in humans. Med Sci Sports Exerc 2002;34:1477-84.

55. Holloway GP, Luiken JJ, Glatz JF, Spriet LL, Bonen A. Contribution of FAT/CD36 to the regulation of skeletal muscle fatty acid oxidation: an overview. Acta Physiol (Oxf) 2008;194:293-309.

56. Holloway GP, Bonen A, Spriet LL. Regulation of skeletal muscle mitochondrial fatty acid metabolism in lean and obese individuals. Am J Clin Nutr 2009;89:455S$62 \mathrm{~S}$.

57. Roden M. Muscle triglycerides and mitochondrial function: possible mechanisms for the development of type 2 diabetes. Int J Obes (Lond) 2005;29 Suppl 2:S111-5.

58. van Loon LJ, Goodpaster BH. Increased intramuscular lipid storage in the insulinresistant and endurance-trained state. Pflugers Arch 2006;451:606-16.

59. van Loon LJ, Manders RJ, Koopman R, et al. Inhibition of adipose tissue lipolysis increases intramuscular lipid use in type 2 diabetic patients. Diabetologia 2005;48:2097-107.

60. Bergman BC, Hunerdosse DM, Kerege A, Playdon MC, Perreault L. Localisation and composition of skeletal muscle diacylglycerol predicts insulin resistance in humans. Diabetologia 2012;55:1140-50.

61. Amati F, Dube JJ, Alvarez-Carnero $E$, et al. Skeletal muscle triglycerides, diacylglycerols, and ceramides in insulin resistance: another paradox in endurance-trained athletes? Diabetes 2011;60:2588-97.

62. Ahmed K, Tunaru S, Tang C, et al. An autocrine lactate loop mediates insulindependent inhibition of lipolysis through GPR81. Cell M etab 2010;11:311-9.

63. Jocken JW, Blaak EE. Catecholamine-induced lipolysis in adipose tissue and skeletal muscle in obesity. Physiol Behav 2008;94:219-30.

64. Danforth E, Jr. Failure of adipocyte differentiation causes type II diabetes mellitus? Nat Genet 2000;26:13.

65. Coppack SW, Evans RD, Fisher RM, et al. Adipose tissue metabolism in obesity: lipase action in vivo before and after a mixed meal. Metabolism 1992;41:264-72.

66. Laws A, Hoen HM, Selby JV, Saad MF, Haffner SM, Howard BV. Differences in insulin suppression of free fatty acid levels by gender and glucose tolerance status. Relation to plasma triglyceride and apolipoprotein B concentrations. 
Insulin Resistance Atherosclerosis Study (IRAS) Investigators. Arterioscler Thromb Vasc Biol 1997;17:64-71.

67. Groop LC, Bonadonna RC, DelPrato S, et al. Glucose and free fatty acid metabolism in non-insulin-dependent diabetes mellitus. Evidence for multiple sites of insulin resistance. J Clin Invest 1989;84:205-13.

68. Jocken JW, Goossens GH, van Hees AM, et al. Effect of beta-adrenergic stimulation on whole-body and abdominal subcutaneous adipose tissue lipolysis in lean and obese men. Diabetologia 2008;51:320-7.

69. van Hees AM, Jans A, Hul GB, Roche HM, Saris WH, Blaak EE. Skeletal muscle fatty acid handling in insulin resistant men. Obesity (Silver Spring) 2011;19:1350-9.

70. Karpe F, Dickmann JR, Frayn KN. Fatty acids, obesity, and insulin resistance: time for a reevaluation. Diabetes 2011;60:2441-9.

71. Jocken JW, Langin $D$, Smit $E$, et al. Adipose triglyceride lipase and hormonesensitive lipase protein expression is decreased in the obese insulin-resistant state. J Clin Endocrinol M etab 2007;92:2292-9.

72. Bickerton AS, Roberts R, Fielding BA, et al. Adipose tissue fatty acid metabolism in insulin-resistant men. Diabetologia 2008;51:1466-74.

73. Groop LC, Bonadonna RC, Simonson DC, Petrides AS, Shank M, DeFronzo RA. Effect of insulin on oxidative and nonoxidative pathways of free fatty acid metabolism in human obesity. Am J Physiol 1992;263:E79-84.

74. Lewis GF, Carpentier A, Adeli K, Giacca A. Disordered fat storage and mobilization in the pathogenesis of insulin resistance and type 2 diabetes. Endocr Rev 2002;23:201-29.

75. Potts JL, Coppack SW, Fisher RM, Humphreys SM , Gibbons GF, Frayn KN. Impaired postprandial clearance of triacylglycerol-rich lipoproteins in adipose tissue in obese subjects. Am J Physiol 1995;268:E588-94.

76. Sadur CN, Yost TJ, Eckel RH. Insulin responsiveness of adipose tissue lipoprotein lipase is delayed but preserved in obesity. J Clin Endocrinol M etab 1984;59:117682.

77. M CQuaid SE, Hodson L, Neville MJ, et al. Downregulation of adipose tissue fatty acid trafficking in obesity: a driver for ectopic fat deposition? Diabetes 2011;60:47-55.

78. Van Harmelen V, Reynisdottir S, Eriksson $P$, et al. Leptin secretion from subcutaneous and visceral adipose tissue in women. Diabetes 1998;47:913-7.

79. Abizaid A, Horvath TL. Brain circuits regulating energy homeostasis. Regul Pept 2008;149:3-10.

80. Wein S, Ukropec J, Gasperikova D, Klimes I, Sebokova E. Concerted action of leptin in regulation of fatty acid oxidation in skeletal muscle and liver. Exp Clin Endocrinol Diabetes 2007;115:244-51.

81. Muoio DM, Dohm GL, Fiedorek FT, Jr., Tapscott EB, Coleman RA. Leptin directly alters lipid partitioning in skeletal muscle. Diabetes 1997;46:1360-3.

82. Yildiz BO, Haznedaroglu IC. Rethinking leptin and insulin action: therapeutic opportunities for diabetes. Int J Biochem Cell Biol 2006;38:820-30. 
83. Dyck DJ, Heigenhauser GJ, Bruce CR. The role of adipokines as regulators of skeletal muscle fatty acid metabolism and insulin sensitivity. Acta Physiol (Oxf) 2006;186:5-16.

84. Jequier E, Tappy L. Regulation of body weight in humans. Physiol Rev 1999;79:451-80.

85. Heymsfield SB, Greenberg AS, Fujioka K, et al. Recombinant leptin for weight loss in obese and lean adults: a randomized, controlled, dose-escalation trial. JAM A 1999;282:1568-75.

86. Vatier C, Gautier JF, Vigouroux C. Therapeutic use of recombinant methionyl human leptin. Biochimie 2012.

87. Hotta K, Funahashi T, Arita $Y$, et al. Plasma concentrations of a novel, adiposespecific protein, adiponectin, in type 2 diabetic patients. Arterioscler Thromb Vasc Biol 2000;20:1595-9.

88. Cote M, M auriege P, Bergeron J, et al. Adiponectinemia in visceral obesity: impact on glucose tolerance and plasma lipoprotein and lipid levels in men. J Clin Endocrinol Metab 2005;90:1434-9.

89. Yamauchi T, Kamon J, Minokoshi $Y$, et al. Adiponectin stimulates glucose utilization and fatty-acid oxidation by activating AMP-activated protein kinase. Nat Med 2002;8:1288-95.

90. Tomas E, Tsao TS, Saha AK, et al. Enhanced muscle fat oxidation and glucose transport by ACRP30 globular domain: acetyl-CoA carboxylase inhibition and AM P-activated protein kinase activation. Proc Natl Acad Sci U S A 2002;99:1630913.

91. Civitarese AE, Ukropcova B, Carling $\mathrm{S}$, et al. Role of adiponectin in human skeletal muscle bioenergetics. Cell Metab 2006;4:75-87.

92. Guilherme A, Virbasius JV, Puri V, Czech MP. Adipocyte dysfunctions linking obesity to insulin resistance and type 2 diabetes. Nat Rev Mol Cell Biol 2008;9:367-77.

93. Hotamisligil GS. Inflammation and metabolic disorders. Nature 2006;444:860-7.

94. Schenk S, Saberi M, Olefsky JM. Insulin sensitivity: modulation by nutrients and inflammation. J Clin Invest 2008;118:2992-3002.

95. Olefsky JM, Glass CK. Macrophages, inflammation, and insulin resistance. Annu Rev Physiol 2010;72:219-46.

96. Kern PA, Ranganathan S, Li C, Wood L, Ranganathan G. Adipose tissue tumor necrosis factor and interleukin-6 expression in human obesity and insulin resistance. Am J Physiol Endocrinol M etab 2001;280:E745-51.

97. Saghizadeh M, Ong JM, Garvey WT, Henry RR, Kern PA. The expression of TNF alpha by human muscle. Relationship to insulin resistance. J Clin Invest 1996;97:1111-6.

98. Sell H, Eckel J, Dietze-Schroeder D. Pathways leading to muscle insulin resistance-the muscle--fat connection. Arch Physiol Biochem 2006;112:105-13.

99. Carey AL, Febbraio MA. Interleukin- 6 and insulin sensitivity: friend or foe? Diabetologia 2004;47:1135-42. 
100. Keller P, Keller C, Carey AL, et al. Interleukin- 6 production by contracting human skeletal muscle: autocrine regulation by IL- 6 . Biochem Biophys Res Commun 2003;310:550-4.

101. Bruce CR, Dyck DJ. Cytokine regulation of skeletal muscle fatty acid metabolism: effect of interleukin-6 and tumor necrosis factor-alpha. Am J Physiol Endocrinol Metab 2004;287:E616-21.

102. Sopasakis VR, Sandqvist M, Gustafson B, et al. High local concentrations and effects on differentiation implicate interleukin- 6 as a paracrine regulator. Obes Res 2004;12:454-60.

103. van Hall G, Steensberg A, Sacchetti M , et al. Interleukin-6 stimulates lipolysis and fat oxidation in humans. J Clin Endocrinol M etab 2003;88:3005-10.

104. Randle PJ, Garland PB, Hales CN, Newsholme EA. The glucose fatty-acid cycle. Its role in insulin sensitivity and the metabolic disturbances of diabetes mellitus. Lancet 1963;1:785-9.

105. Kelley DE, Simoneau JA. Impaired free fatty acid utilization by skeletal muscle in non-insulin-dependent diabetes mellitus. J Clin Invest 1994;94:2349-56.

106. Boden G, Jadali F, White J, et al. Effects of fat on insulin-stimulated carbohydrate metabolism in normal men. J Clin Invest 1991;88:960-6.

107. Boden G, Lebed B, Schatz M, Homko C, Lemieux S. Effects of acute changes of plasma free fatty acids on intramyocellular fat content and insulin resistance in healthy subjects. Diabetes 2001;50:1612-7.

108. Shulman Gl. Cellular mechanisms of insulin resistance. J Clin Invest 2000;106:1716.

109. Roden M, Krssak M, Stingl $\mathrm{H}$, et al. Rapid impairment of skeletal muscle glucose transport/phosphorylation by free fatty acids in humans. Diabetes 1999;48:35864.

110. Turpeinen AK, Takala TO, Nuutila $\mathrm{P}$, et al. Impaired free fatty acid uptake in skeletal muscle but not in myocardium in patients with impaired glucose tolerance: studies with PET and 14(R,S)-[18F]fluoro-6-thia-heptadecanoic acid. Diabetes 1999; 48:1245-50.

111. M cGarry JD. Glucose-fatty acid interactions in health and disease. Am J Clin Nutr 1998;67:500S-504S.

112. Goodpaster BH, Theriault R, Watkins SC, Kelley DE. Intramuscular lipid content is increased in obesity and decreased by weight loss. Metabolism 2000;49:467-72.

113. Kelley DE, Goodpaster BH. Skeletal muscle triglyceride. An aspect of regional adiposity and insulin resistance. Diabetes Care 2001;24:933-41.

114. Hajduch E, Balendran A, Batty IH, et al. Ceramide impairs the insulin-dependent membrane recruitment of protein kinase $B$ leading to a loss in downstream signalling in L6 skeletal muscle cells. Diabetologia 2001;44:173-83.

115. Montell $E$, Turini $M, M$ arotta $M$, et al. DAG accumulation from saturated fatty acids desensitizes insulin stimulation of glucose uptake in muscle cells. Am J Physiol Endocrinol M etab 2001;280:E229-37. 
116. Pinnamaneni SK, Southgate RJ, Febbraio MA, Watt MJ. Stearoyl CoA desaturase 1 is elevated in obesity but protects against fatty acid-induced skeletal muscle insulin resistance in vitro. Diabetologia 2006;49:3027-37.

117. Listenberger $\mathrm{LL}$, Han $\mathrm{X}$, Lewis $\mathrm{SE}$, et al. Triglyceride accumulation protects against fatty acid-induced lipotoxicity. Proc Natl Acad Sci U S A 2003;100:3077-82.

118. Ellis BA, Poynten A, Lowy AJ, et al. Long-chain acyl-CoA esters as indicators of lipid metabolism and insulin sensitivity in rat and human muscle. Am J Physiol Endocrinol M etab 2000;279:E554-60.

119. Chalkley SM, Hettiarachchi M, Chisholm DJ, Kraegen EW. Five-hour fatty acid elevation increases muscle lipids and impairs glycogen synthesis in the rat. Metabolism 1998;47:1121-6.

120. Hulver MW, Berggren JR, Cortright RN, et al. Skeletal muscle lipid metabolism with obesity. Am J Physiol Endocrinol Metab 2003;284:E741-7.

121. Dohm GL, Tapscott EB, Pories WJ, et al. An in vitro human muscle preparation suitable for metabolic studies. Decreased insulin stimulation of glucose transport in muscle from morbidly obese and diabetic subjects. J Clin Invest 1988;82:48694.

122. Turinsky J, O'Sullivan DM, Bayly BP. 1,2-Diacylglycerol and ceramide levels in insulin-resistant tissues of the rat in vivo. J Biol Chem 1990;265:16880-5.

123. Adams JM , 2nd, Pratipanawatr T, Berria R, et al. Ceramide content is increased in skeletal muscle from obese insulin-resistant humans. Diabetes 2004;53:25-31.

124. Straczkowski M, Kowalska I, Baranowski M, et al. Increased skeletal muscle ceramide level in men at risk of developing type 2 diabetes. Diabetologia 2007;50:2366-73.

125. Yu C, Chen Y, Cline GW, et al. Mechanism by which fatty acids inhibit insulin activation of insulin receptor substrate-1 (IRS-1)-associated phosphatidylinositol 3-kinase activity in muscle. J Biol Chem 2002;277:50230-6.

126. Itani SI, Ruderman NB, Schmieder F, Boden G. Lipid-induced insulin resistance in human muscle is associated with changes in diacylglycerol, protein kinase $C$, and IkappaB-alpha. Diabetes 2002;51:2005-11.

127. Glatz JF, Luiken JJ, Bonen A. Involvement of membrane-associated proteins in the acute regulation of cellular fatty acid uptake. J Mol Neurosci 2001;16:123-32; discussion 151-7.

128. Bonen A, Chabowski A, Luiken JJ, Glatz JF. Is membrane transport of FFA mediated by lipid, protein, or both? Mechanisms and regulation of proteinmediated cellular fatty acid uptake: molecular, biochemical, and physiological evidence. Physiology (Bethesda) 2007;22:15-29.

129. Abumrad NA, el-Maghrabi MR, Amri EZ, Lopez E, Grimaldi PA. Cloning of a rat adipocyte membrane protein implicated in binding or transport of long-chain fatty acids that is induced during preadipocyte differentiation. Homology with human CD36. J Biol Chem 1993;268:17665-8.

130. Stremmel W, Lotz G, Strohmeyer G, Berk PD. Identification, isolation, and partial characterization of a fatty acid binding protein from rat jejunal microvillous membranes. J Clin Invest 1985;75:1068-76. 
131. Schaffer JE, Lodish HF. Expression cloning and characterization of a novel adipocyte long chain fatty acid transport protein. Cell 1994;79:427-36.

132. Goldberg IJ, Eckel RH, Abumrad NA. Regulation of fatty acid uptake into tissues: lipoprotein lipase- and CD36-mediated pathways. J Lipid Res 2009;50 Suppl:S8690.

133. Coburn CT, Knapp FF, Jr., Febbraio M, Beets AL, Silverstein RL, Abumrad NA. Defective uptake and utilization of long chain fatty acids in muscle and adipose tissues of CD36 knockout mice. J Biol Chem 2000;275:32523-9.

134. Ibrahimi A, Bonen A, Blinn WD, et al. Muscle-specific overexpression of FAT/CD36 enhances fatty acid oxidation by contracting muscle, reduces plasma triglycerides and fatty acids, and increases plasma glucose and insulin. J Biol Chem 1999;274:26761-6.

135. Bonen A, Benton CR, Campbell SE, et al. Plasmalemmal fatty acid transport is regulated in heart and skeletal muscle by contraction, insulin and leptin, and in obesity and diabetes. Acta Physiol Scand 2003;178:347-56.

136. Corpeleijn E, Pelsers MM, Soenen S, et al. Insulin acutely upregulates protein expression of the fatty acid transporter CD36 in human skeletal muscle in vivo. J Physiol Pharmacol 2008;59:77-83.

137. Bonen A, Parolin ML, Steinberg GR, et al. Triacylglycerol accumulation in human obesity and type 2 diabetes is associated with increased rates of skeletal muscle fatty acid transport and increased sarcolemmal FAT/CD36. FASEB J 2004;18:11446.

138. Bezaire V, Bruce CR, Heigenhauser GJ, et al. Identification of fatty acid translocase on human skeletal muscle mitochondrial membranes: essential role in fatty acid oxidation. Am J Physiol Endocrinol Metab 2006;290:E509-15.

139. Blaak EE, Wagenmakers AJ, Glatz JF, et al. Plasma FFA utilization and fatty acidbinding protein content are diminished in type 2 diabetic muscle. Am J Physiol Endocrinol M etab 2000;279:E146-54.

140. Kim JK, Fillmore JJ, Chen Y, et al. Tissue-specific overexpression of lipoprotein lipase causes tissue-specific insulin resistance. Proc Natl Acad Sci U S A 2001;98:7522-7.

141. Lithell H, Boberg J, Hellsing K, Lundqvist G, Vessby B. Lipoprotein-lipase activity in human skeletal muscle and adipose tissue in the fasting and the fed states. Atherosclerosis 1978;30:89-94.

142. Glatz JF, Bonen A, Luiken JJ. Exercise and insulin increase muscle fatty acid uptake by recruiting putative fatty acid transporters to the sarcolemma. Curr Opin Clin Nutr M etab Care 2002;5:365-70.

143. M CGarry JD, Brown NF. The mitochondrial carnitine palmitoyltransferase system. From concept to molecular analysis. Eur J Biochem 1997;244:1-14.

144. Rasmussen BB, Holmback UC, Volpi E, M orio-Liondore B, Paddon-Jones D, Wolfe RR. Malonyl coenzyme $A$ and the regulation of functional carnitine palmitoyltransferase-1 activity and fat oxidation in human skeletal muscle. J Clin Invest 2002;110:1687-93. 
145. Blaak EE. Basic disturbances in skeletal muscle fatty acid metabolism in obesity and type 2 diabetes mellitus. Proc Nutr Soc 2004;63:323-30.

146. Koves TR, Ussher JR, Noland RC, et al. Mitochondrial overload and incomplete fatty acid oxidation contribute to skeletal muscle insulin resistance. Cell M etab 2008;7:45-56.

147. Phielix E, Schrauwen-Hinderling VB, Mensink $M$, et al. Lower intrinsic ADPstimulated mitochondrial respiration underlies in vivo mitochondrial dysfunction in muscle of male type 2 diabetic patients. Diabetes 2008;57:2943-9.

148. Kelley DE, He J, Menshikova EV, Ritov VB. Dysfunction of mitochondria in human skeletal muscle in type 2 diabetes. Diabetes 2002;51:2944-50.

149. Petersen KF, Dufour S, Befroy D, Garcia R, Shulman Gl. Impaired mitochondrial activity in the insulin-resistant offspring of patients with type 2 diabetes. N Engl J Med 2004;350:664-71.

150. Holloway GP, Thrush AB, Heigenhauser GJ, et al. Skeletal muscle mitochondrial FAT/CD36 content and palmitate oxidation are not decreased in obese women. Am J Physiol Endocrinol Metab 2007;292:E1782-9.

151. Boushel R, Gnaiger E, Schjerling P, Skovbro M, Kraunsoe R, Dela F. Patients with type 2 diabetes have normal mitochondrial function in skeletal muscle. Diabetologia 2007;50:790-6.

152. Hickey MS, Carey JO, Azevedo JL, et al. Skeletal muscle fiber composition is related to adiposity and in vitro glucose transport rate in humans. Am J Physiol 1995;268:E453-7.

153. Tanner CJ, Barakat HA, Dohm GL, et al. Muscle fiber type is associated with obesity and weight loss. Am J Physiol Endocrinol M etab 2002;282:E1191-6.

154. Gray RE, Tanner CJ, Pories WJ, MacDonald KG, Houmard JA. Effect of weight loss on muscle lipid content in morbidly obese subjects. Am J Physiol Endocrinol M etab 2003;284:E726-32.

155. Houmard JA, Tanner C , Yu C, et al. Effect of weight loss on insulin sensitivity and intramuscular long-chain fatty acyl-CoAs in morbidly obese subjects. Diabetes 2002;51:2959-63.

156. Kelley DE, Goodpaster B, Wing RR, Simoneau JA. Skeletal muscle fatty acid metabolism in association with insulin resistance, obesity, and weight loss. Am J Physiol 1999;277:E1130-41.

157. Corpeleijn E, Mensink M, Kooi ME, Roekaerts PM, Saris WH, Blaak EE. Impaired skeletal muscle substrate oxidation in glucose-intolerant men improves after weight loss. Obesity (Silver Spring) 2008;16:1025-32.

158. Perseghin G, Bonfanti R, Magni S, et al. Insulin resistance and whole body energy homeostasis in obese adolescents with fatty liver disease. Am J Physiol Endocrinol M etab 2006;291:E697-703.

159. De Pergola G, Pannacciulli N, M inenna A, Martina RA, Cannito F, Giorgino R. Fuel metabolism in adult individuals with a wide range of body mass index: effect of a family history of type 2 diabetes. Diabetes Nutr M etab 2003;16:41-7. 
160. Lattuada G, Costantino F, Caumo A, et al. Reduced whole-body lipid oxidation is associated with insulin resistance, but not with intramyocellular lipid content in offspring of type 2 diabetic patients. Diabetologia 2005;48:741-7.

161. Mensink M, Blaak EE, van Baak M A, Wagenmakers AJ, Saris WH. Plasma free Fatty Acid uptake and oxidation are already diminished in subjects at high risk for developing type 2 diabetes. Diabetes 2001;50:2548-54.

162. Reaven GM. The fourth musketeer--from Alexandre Dumas to Claude Bernard. Diabetologia 1995;38:3-13.

163. Blaak EE, van Aggel-Leijssen DP, Wagenmakers AJ, Saris WH, van Baak MA. Impaired oxidation of plasma-derived fatty acids in type 2 diabetic subjects during moderate-intensity exercise. Diabetes 2000;49:2102-7.

164. Goodpaster BH, Katsiaras A, Kelley DE. Enhanced fat oxidation through physical activity is associated with improvements in insulin sensitivity in obesity. Diabetes 2003;52:2191-7.

165. Simoneau JA, Veerkamp JH, Turcotte LP, Kelley DE. M arkers of capacity to utilize fatty acids in human skeletal muscle: relation to insulin resistance and obesity and effects of weight loss. FASEBJ 1999;13:2051-60.

166. Blaak EE, Wolffenbuttel BH, Saris WH, Pelsers MM, Wagenmakers AJ. Weight reduction and the impaired plasma-derived free fatty acid oxidation in type 2 diabetic subjects. J Clin Endocrinol M etab 2001;86:1638-44.

167. M onnier L, Lapinski H, Colette C. Contributions of fasting and postprandial plasma glucose increments to the overall diurnal hyperglycemia of type 2 diabetic patients: variations with increasing levels of $\mathrm{HbA}(1 \mathrm{c})$. Diabetes Care 2003;26:8815.

168. Monnier L, Colette C. Target for glycemic control: concentrating on glucose. Diabetes Care 2009;32 Suppl 2:S199-204.

169. Brand-M iller JC, Holt SH, Pawlak DB, M cM illan J. Glycemic index and obesity. Am J Clin Nutr 2002;76:281S-5S.

170. Isken F, Weickert MO, Tschop MH, et al. Metabolic effects of diets differing in glycaemic index depend on age and endogenous glucose-dependent insulinotrophic polypeptide in mice. Diabetologia 2009;52:2159-68.

171. Pawlak DB, Kushner JA, Ludwig DS. Effects of dietary glycaemic index on adiposity, glucose homoeostasis, and plasma lipids in animals. Lancet 2004;364:778-85.

172. Scribner KB, Pawlak DB, Aubin CM, Majzoub JA, Ludwig DS. Long-term effects of dietary glycemic index on adiposity, energy metabolism, and physical activity in mice. Am J Physiol Endocrinol M etab 2008;295:E1126-31.

173. Hodge AM, English DR, O'Dea K, Giles GG. Glycemic index and dietary fiber and the risk of type 2 diabetes. Diabetes Care 2004;27:2701-6.

174. Dickinson S, Brand-Miller J. Glycemic index, postprandial glycemia and cardiovascular disease. Curr Opin Lipidol 2005;16:69-75.

175. Rizkalla SW, Taghrid L, Laromiguiere M, et al. Improved plasma glucose control, whole-body glucose utilization, and lipid profile on a low-glycemic index diet in 
type 2 diabetic men: a randomized controlled trial. Diabetes Care 2004;27:186672.

176. M cKeown NM, M eigs JB, Liu S, Saltzman E, Wilson PW, Jacques PF. Carbohydrate nutrition, insulin resistance, and the prevalence of the metabolic syndrome in the Framingham Offspring Cohort. Diabetes Care 2004;27:538-46.

177. Liu S, Manson JE, Stampfer MJ, et al. Dietary glycemic load assessed by foodfrequency questionnaire in relation to plasma high-density-lipoprotein cholesterol and fasting plasma triacylglycerols in postmenopausal women. Am J Clin Nutr 2001;73:560-6.

178. Sano M, Tabata M, Suzuki M, Degawa M, M iyase T, Maeda-Yamamoto M. Simultaneous determination of twelve tea catechins by high-performance liquid chromatography with electrochemical detection. Analyst 2001;126:816-20.

179. Borchardt RT, Huber JA. Catechol 0-methyltransferase. 5. Structure-activity relationships for inhibition by flavonoids. J Med Chem 1975;18:120-2.

180. Lee MS, Kim CT, Kim Y. Green tea (-)-epigallocatechin-3-gallate reduces body weight with regulation of multiple genes expression in adipose tissue of dietinduced obese mice. Ann Nutr Metab 2009;54:151-7.

181. Nagao T, Komine $\mathrm{Y}$, Soga $\mathrm{S}$, et al. Ingestion of a tea rich in catechins leads to a reduction in body fat and malondialdehyde-modified LDL in men. Am J Clin Nutr 2005;81:122-9.

182. Tsuchida T, Itakura H, Nakamura H. Reduction of body fat in humans by long-term ingestion of catechins. Prog M ed 2002;22:2189-2203.

183. Wang $\mathrm{H}$, Wen $\mathrm{Y}$, Du Y, et al. Effects of catechin enriched green tea on body composition. Obesity (Silver Spring) 2010;18:773-9.

184. Nagao T, Hase T, Tokimitsu I. A green tea extract high in catechins reduces body fat and cardiovascular risks in humans. Obesity (Silver Spring) 2007;15:1473-83.

185. Chan CC, Koo M W, Ng EH, Tang OS, Yeung WS, Ho PC. Effects of Chinese green tea on weight, and hormonal and biochemical profiles in obese patients with polycystic ovary syndrome--a randomized placebo-controlled trial. J Soc Gynecol Investig 2006;13:63-8.

186. Hill AM, Coates AM, Buckley JD, Ross R, Thielecke F, Howe PR. Can EGCG reduce abdominal fat in obese subjects? J Am Coll Nutr 2007;26:396S-402S.

187. Fukino $\mathrm{Y}$, Shimbo M, Aoki N, Okubo T, Iso H. Randomized controlled trial for an effect of green tea consumption on insulin resistance and inflammation markers. J Nutr Sci Vitaminol (Tokyo) 2005;51:335-42.

188. Dulloo AG, Duret C, Rohrer D, et al. Efficacy of a green tea extract rich in catechin polyphenols and caffeine in increasing 24-h energy expenditure and fat oxidation in humans. Am J Clin Nutr 1999;70:1040-5.

189. Gregersen NT, Bitz C, Krog-Mikkelsen I, et al. Effect of moderate intakes of different tea catechins and caffeine on acute measures of energy metabolism under sedentary conditions. Br J Nutr 2009;102:1187-94.

190. Thielecke F, Rahn G, Bohnke J, et al. Epigallocatechin-3-gallate and postprandial fat oxidation in overweight/obese male volunteers: a pilot study. Eur J Clin Nutr 2010;64:704-13. 
191. Lonac MC, Richards JC, Schweder MM, Johnson TK, Bell C. Influence of ShortTerm Consumption of the Caffeine-Free, Epigallocatechin-3-Gallate Supplement, Teavigo, on Resting Metabolism and the Thermic Effect of Feeding. Obesity (Silver Spring) 2011;19:298-304.

192. Venables MC, Hulston CJ, Cox HR, Jeukendrup AE. Green tea extract ingestion, fat oxidation, and glucose tolerance in healthy humans. Am J Clin Nutr 2008;87:77884.

193. Thavanesan $\mathrm{N}$. The putative effects of green tea on body fat: an evaluation of the evidence and a review of the potential mechanisms. Br J Nutr 2011;106:1297-309.

194. Watanabe J, Kawabata J, Niki R. Isolation and identification of acetyl-CoA carboxylase inhibitors from green tea (Camellia sinensis). Biosci Biotechnol Biochem 1998;62:532-4.

195. Murase T, Haramizu S, Shimotoyodome A, Nagasawa A, Tokimitsu I. Green tea extract improves endurance capacity and increases muscle lipid oxidation in mice. Am J Physiol Regul Integr Comp Physiol 2005;288:R708-15.

196. Sae-Tan S, Grove KA, Kennett MJ, Lambert JD. (-)-Epigallocatechin-3-gallate increases the expression of genes related to fat oxidation in the skeletal muscle of high fat-fed mice. Food Funct 2011;2:111-6.

197. Murase T, Haramizu S, Shimotoyodome A, Tokimitsu I, Hase T. Green tea extract improves running endurance in mice by stimulating lipid utilization during exercise. Am J Physiol Regul Integr Comp Physiol 2006;290:R1550-6.

198. Chen N, Bezzina R, Hinch E, et al. Green tea, black tea, and epigallocatechin modify body composition, improve glucose tolerance, and differentially alter metabolic gene expression in rats fed a high-fat diet. Nutr Res 2009;29:784-93.

199. Kim HJ, Jeon SM, Lee M K, Jung UJ, Shin SK, Choi MS. Antilipogenic effect of green tea extract in C57BL/ 6J-Lep ob/ob mice. Phytother Res 2009;23:467-71.

200. Roumen C, Corpeleijn E, Feskens EJ, M ensink M, Saris WH, Blaak EE. Impact of 3year lifestyle intervention on postprandial glucose metabolism: the SLIM study. Diabet Med 2008;25:597-605.

201. Bays HE. Current and investigational antiobesity agents and obesity therapeutic treatment targets. Obes Res 2004;12:1197-211.

202. Badman MK, Flier JS. The gut and energy balance: visceral allies in the obesity wars. Science 2005;307:1909-14.

203. Wren AM. Gut and hormones and obesity. Front Horm Res 2008;36:165-81.

204. Holst JJ. Enteroglucagon. Annu Rev Physiol 1997;59:257-71.

205. Wettergren A, Schjoldager B, Mortensen PE, Myhre J, Christiansen J, Holst JJ. Truncated GLP-1 (proglucagon 78-107-amide) inhibits gastric and pancreatic functions in man. Dig Dis Sci 1993;38:665-73.

206. Flint A, Raben A, Astrup A, Holst JJ. Glucagon-like peptide 1 promotes satiety and suppresses energy intake in humans. J Clin Invest 1998;101:515-20.

207. Gutzwiller JP, Drewe J, Goke B, et al. Glucagon-like peptide-1 promotes satiety and reduces food intake in patients with diabetes mellitus type 2. Am J Physiol 1999;276:R1541-4. 
208. Flint A, Raben A, Ersboll AK, Holst JJ, Astrup A. The effect of physiological levels of glucagon-like peptide-1 on appetite, gastric emptying, energy and substrate metabolism in obesity. Int J Obes Relat M etab Disord 2001;25:781-92.

209. M eier JJ, Gallwitz B, Salmen S, et al. Normalization of glucose concentrations and deceleration of gastric emptying after solid meals during intravenous glucagonlike peptide 1 in patients with type 2 diabetes. J Clin Endocrinol Metab 2003;88:2719-25.

210. Drucker DJ, Nauck MA. The incretin system: glucagon-like peptide-1 receptor agonists and dipeptidyl peptidase-4 inhibitors in type 2 diabetes. Lancet 2006;368:1696-705.

211. Agerso H, Jensen LB, Elbrond B, Rolan P, Zdravkovic M. The pharmacokinetics, pharmacodynamics, safety and tolerability of NN2211, a new long-acting GLP-1 derivative, in healthy men. Diabetologia 2002;45:195-202.

212. Vilsboll T, Zdravkovic M, Le-Thi T, et al. Liraglutide, a long-acting human glucagonlike peptide-1 analog, given as monotherapy significantly improves glycemic control and lowers body weight without risk of hypoglycemia in patients with type 2 diabetes. Diabetes Care 2007;30:1608-10.

213. Garber A, Henry R, Ratner R, et al. Liraglutide versus glimepiride monotherapy for type 2 diabetes (LEAD-3 Mono): a randomised, 52-week, phase III, double-blind, parallel-treatment trial. Lancet 2009;373:473-81.

214. Marre $M$, Shaw J, Brandle $M$, et al. Liraglutide, a once-daily human GLP-1 analogue, added to a sulphonylurea over 26 weeks produces greater improvements in glycaemic and weight control compared with adding rosiglitazone or placebo in subjects with Type 2 diabetes (LEAD-1 SU). Diabet M ed 2009;26:268-78.

215. Raun K, von Voss P, Knudsen LB. Liraglutide, a once-daily human glucagon-like peptide-1 analog, minimizes food intake in severely obese minipigs. Obesity (Silver Spring) 2007;15:1710-6.

216. Astrup A, Rossner S, Van Gaal L, et al. Effects of liraglutide in the treatment of obesity: a randomised, double-blind, placebo-controlled study. Lancet 2009;374:1606-16.

217. Holst JJ. The physiology of glucagon-like peptide 1. Physiol Rev 2007;87:1409-39.

218. Barrera JG, Sandoval DA, D'Alessio DA, Seeley RJ. GLP-1 and energy balance: an integrated model of short-term and long-term control. Nat Rev Endocrinol 2011;7:507-16.

219. Ahren B. GLP-1 and extra-islet effects. Horm M etab Res 2004;36:842-5.

220. Villanueva-Penacarrillo ML, Alcantara Al, Clemente F, Delgado E, Valverde I. Potent glycogenic effect of GLP-1(7-36)amide in rat skeletal muscle. Diabetologia 1994;37:1163-6.

221. Galera C, Clemente F, Alcantara A, et al. Inositolphosphoglycans and diacyglycerol are possible mediators in the glycogenic effect of GLP-1(7-36)amide in BC3H-1 myocytes. Cell Biochem Funct 1996;14:43-8. 


\section{Chapter 1}

222. Wheeler MB, Lu M, Dillon JS, Leng XH, Chen $C$, Boyd AE, 3rd. Functional expression of the rat glucagon-like peptide-I receptor, evidence for coupling to both adenylyl cyclase and phospholipase-C. Endocrinology 1993;133:57-62.

223. Dardevet D, M oore M C, Neal D, DiCostanzo CA, Snead W, Cherrington AD. Insulinindependent effects of GLP-1 on canine liver glucose metabolism: duration of infusion and involvement of hepatoportal region. Am J Physiol Endocrinol Metab 2004;287:E75-81.

224. Nikolaidis LA, Mankad S, Sokos GG, et al. Effects of glucagon-like peptide-1 in patients with acute myocardial infarction and left ventricular dysfunction after successful reperfusion. Circulation 2004;109:962-5.

225. Majumdar ID, Weber HC. Gastrointestinal regulatory peptides and their effects on fat tissue. Curr Opin Endocrinol Diabetes Obes 2010;17:51-6.

226. Ruiz-Grande C, Alarcon C, Merida E, Valverde I. Lipolytic action of glucagon-like peptides in isolated rat adipocytes. Peptides 1992;13:13-6.

227. Perea A, Vinambres C, Clemente F, Villanueva-Penacarrillo ML, Valverde I. GLP-1 (7-36) amide: effects on glucose transport and metabolism in rat adipose tissue. Horm Metab Res 1997;29:417-21.

228. Azuma K, Radikova Z, Mancino J, et al. Measurements of islet function and glucose metabolism with the dipeptidyl peptidase 4 inhibitor vildagliptin in patients with type 2 diabetes. J Clin Endocrinol M etab 2008;93:459-64. 


\section{Chapter 2A}

\section{Reduced glycemic and insulinemic responses following trehalose ingestion: implications for postprandial substrate use}

Judith GP van Can, Herman IJzerman, LuC JC van Loon, Fred Brouns and Ellen E Blaak.

Reduced glycemic and insulinemic responses following trehalose ingestion: implications for postprandial substrate use.

British J of Nutr 2009; 102: 1395-1399. 


\section{Abstract}

Introduction: The proposed impact of slowly digestible sources of dietary carbohydrate in reducing the risk of developing obesity and related metabolic disorders remains unclear. The aim of the present study is to compare the postprandial metabolic response to the ingestion of glucose (GLUC) vs trehalose (TRE).

Aim: We hypothesized that the reduced digestion and absorption rate of TRE is accompanied by an attenuated glycemic and insulinemic response, leading to a less inhibited postprandial fat oxidation rate.

Design: In a randomized, single blind, cross-over study, 10 overweight subjects ingested 2 carbohydrate drinks (75 g CHO equivalents of TRE or GLUC) following an overnight fast (8.40 AM) and together with a standardized mixed meal (12.30 PM , 25 en\% of total energy content was provided as either GLUC or TRE). Blood samples were collected prior to ingestion and every 30 min thereafter for a period of $3 \mathrm{~h}$, substrate use was assessed by indirect calorimetry and expired breath samples were collected.

Results: Ingestion of carbohydrates with a mixed meal resulted in a lower peak glucose response and a lower $\triangle A U C$ following TRE when compared with GLUC. Differences in peak insulin response and $\triangle A U C$ were observed with TRE when compared with GLUC during AM and PM. These differences were accompanied with a reduced carbohydrate oxidation after TRE when ingested as a drink, whilst no significant differences in fat oxidation between drink were observed. 


\section{Introduction}

Over the last 2 decades the prevalence of obesity and obesity-related disorders has increased rapidly (1). Both genetic and environmental factors (physical activity and diet) play an important role in the etiology of these chronic metabolic diseases. Obesity develops as a result of an imbalance between energy intake and energy expenditure, resulting in a positive energy balance. Although many factors promote a positive energy balance, there is sound evidence that a high fat/low carbohydrate $(\mathrm{CHO})$ diet may increase the risk for weight gain largely because of excess energy intake (2). On the other hand, high carbohydrate-low fat diets containing a large amount of rapidly available carbohydrates (cooked starches) and added refined sugars (sucrose, high fructose corn syrup) which may be counter-productive to body weight control and glycemic control. The latter because they markedly increase postprandial glycemia and insulinemia, thereby inhibiting adipose tissue lipolysis and/or muscle fat oxidation and, as such may promote fat storage in both adipose and non-adipose tissue. Greater postprandial fat storage in non-adipose tissue, such as skeletal muscle and liver tissue, has been associated with the development of insulin resistance, whilst postprandial hyperglycemia per se is a strong risk factor for the development of type 2 diabetes mellitus and cardiovascular comorbidities $(3,4)$. Finally, hyperinsulinemia might affect triacylglycerol (TAG) clearance and liver TAG production, thereby increasing plasma TAG concentrations. Therefore, the recommendation to ingest a carbohydrate rich diet, containing a large amount of high glycemic carbohydrates may actually have less favourable effects on blood lipid profile (5, $6)$.

Potential negative side effects of high carbohydrate diets may be counteracted by the use of low glycemic index (GI) foods. Prolonged use of low Gl foods has been reported to prevent the risk profile for developing obesity, diabetes and cardiovascular disease (7). Brand-Miller et al. hypothesized that the ingestion of slowly digestible carbohydrates attenuates postprandial glycemia, reduces insulinemia, and enhances fat oxidation, all of which may assist to prevent body weight gain and insulin resistance (7). The latter may be of relevance in dietary strategies to modulate body weight and improve insulin sensitivity.

The present study compares the postprandial metabolic response following ingestion of glucose (GLUC) vs. trehalose (TRE). We hypothesized that the ingestion of trehalose is accompanied by an attenuated glycemic and/or insulinemic response, a reduced inhibition of postprandial fat oxidation rate and a lower plasma triacylglycerol concentration when compared with glucose ingestion. 


\section{Chapter 2A}

\section{Methods}

\section{Subjects}

Ten healthy, overweight men $(n=8)$ and women $(n=2)$ were recruited to participate study (age $31 \pm 4$ yrs, BMI $27.7 \pm 0.8 \mathrm{~kg} / \mathrm{m}^{2}$, fasting glucose $5.1 \pm 0.1 \mathrm{mmol} / \mathrm{L}$, fasting insulin $14 \pm 1.9$ $\mu \mathrm{U} / \mathrm{ml}$ ). Subjects with cardiovascular or metabolic disorders, and those using medication were excluded from the study. The study was reviewed and approved by the Medical Ethics Committee of Maastricht University. All subjects provided written informed consent.

\section{Study design}

All subjects were studied following an overnight fast at $8.00 \mathrm{AM}$ on 2 occasions with an interval of at least 1 wk. At the beginning of the experimental day, a Teflon cannula was inserted into an antecubital vein. Two different carbohydrate drinks were ingested (glucose or trehalose), during 2 different trials, performed in a single blind, randomized cross-over design. GLUC and TRE were derived from corn, a natural carbohydrate source with a high natural abundance of ${ }^{13} \mathrm{C}$. The carbohydrate load consisted of $75 \mathrm{~g}$ carbohydrate equivalents and was dissolved in $400 \mathrm{ml}$ water, to assess the metabolic response. After baseline measurements all experimental beverages were consumed within $15 \mathrm{~min}$. Blood samples were taken prior to the consumption of the drinks/meals ( $t=5 \mathrm{~min}$ ) and at $t=30,60,90,120,150$ and $180 \mathrm{~min}$ after ingestion to determine circulating metabolite and hormone concentrations. Energy expenditure and substrate use were measured, immediately before and for $3 \mathrm{~h}$ after carbohydrate ingestion (8.40 AM), using a ventilated hood system. Expired breath samples were collected every $h$ to determine ${ }^{13} \mathrm{CO}_{2}$ enrichment. These procedures were repeated at the same day before consuming a standardized lunch together with a beverage containing either GLUC or TRE and for $3 \mathrm{~h}$ after lunch (12.30 PM). Lunch had a total energy content equivalent to $50 \%$ of calculated $24 \mathrm{~h}$ resting energy expenditure. Lunch macronutrient composition represented 55 energy percentage (En\%) CHO, $30 \mathrm{En} \%$ fat and $15 \mathrm{En} \%$ protein; $25 \mathrm{En} \%$ of the total energy content of the meal was provided in the form of a beverage containing either TRE or GLUC. Lunch was consumed within $15 \mathrm{~min}$.

Test products

Trehalose (TRE)

TRE is a disaccharide of glucose with an $\alpha 1,1$ glycoside linkage. It is a non-reducing sugar that is naturally present in honey, bread, mushrooms and fermented drinks. TRE is 
produced industrially by enzymatic conversion using starch as base material. Its sweetness is $40-45 \%$ compared to that of SUC. When ingested, trehalose is enzymatically hydrolyzed in the small intestine by trehalose into $2 \mathrm{D}$-glucose molecules, which are subsequently absorbed and metabolized $(8,9)$. It appears that ingestion, hydrolysis, absorption and metabolism of trehalose is essentially identical to all other digestible disaccharides (8).

\section{Exogenous carbohydrate oxidation}

As indicated above, all carbohydrates were derived from naturally ${ }^{13} \mathrm{C}$ enriched sources: GLUC $\left({ }^{13} \mathrm{C}\right.$ enrichment $=-11.17$ delta per mil v PDB $(\delta \%)$ and TRE $\left({ }^{13} \mathrm{C}\right.$ enrichment $=-17.86$ $\delta \%$ ). The ${ }^{13} \mathrm{C}$-enrichment of the experimental beverages was determined by elemental analyser isotope ratio mass spectrometry (IRM S; Carlo Erba-Finnigan M AT 252, Bremen, Germany). Subjects were instructed not to consume any food products with a high ${ }^{13} \mathrm{C}$ natural abundance for at least $1 \mathrm{wk}$ prior to and during the experimental period. In European countries the consumption of native carbohydrate sources with a high natural ${ }^{13} \mathrm{C}$ abundance is low (10).

Biochemical analyses

At all time points, $8 \mathrm{ml}$ blood was collected in pre-chilled tubes with $200 \mu \mathrm{L} 0.2 \mathrm{M}$ EDTA (Sigma, Dorset, UK). After collection, blood samples were centrifuged immediately at $4^{\circ} \mathrm{C}$ for $10 \mathrm{~min}$ at $1000 \mathrm{~g}$ and frozen at $-80^{\circ} \mathrm{C}$ until analysis. Plasma glucose and free fatty acid (FFA) concentration were determined enzymatically: (glucose: ABX Diagnostics, Montpellier, France and NEFA: NEFA-NEFA C kit, Wako, Neuss, Germany) on a semiautomatic analyzer (COBAS FARA, Roche Diagnostics, Basel, Switzerland). Insulin was analyzed by radioimmunoassay (Human Insulin RIA Kit, LINCO Research Inc, M O). Breath samples were analyzed for ${ }^{13} \mathrm{C} /{ }^{12} \mathrm{C}$ ratio by gas chromatography isotope ratio mass spectrometry (GC-IRM S) (Finnigan M AT 252).

\section{Calculations}

Metabolic rate was calculated from $\mathrm{VO}_{2}(\mathrm{~L} / \mathrm{min})$ and $\mathrm{VCO}_{2}(\mathrm{~L} / \mathrm{min})$ according to the equations of Frayn (11). Nitrogen (N) excretion was calculated based on the assumption that protein oxidation represents $15 \%$ of total energy expenditure. Energy expenditure was calculated using the formula of Weir (12). 
Carbohydrate oxidation $=\left(4.55 \cdot \mathrm{VCO}_{2}\right)-\left(3.21 \cdot \mathrm{VO}_{2}\right)-(2.87 \cdot \mathrm{N})$

Fat oxidation $=\left(1.67 \cdot \mathrm{VO}_{2}\right)-\left(1.67 \cdot \mathrm{VCO}_{2}\right)-(1.92 \cdot \mathrm{N})$

$\mathrm{N}(\mathrm{g} / \mathrm{min})=((0.15 \cdot \mathrm{EE}) / 17) / 6.25$

Energy expenditure $(\mathrm{KJ} / \mathrm{min})=4.187 \cdot\left(3.9 \cdot \mathrm{VO}_{2}+1.1 \cdot \mathrm{VCO}_{2}\right)$

The isotopic enrichment was expressed as $\delta \%$ difference between ${ }^{13} \mathrm{C} /{ }^{12} \mathrm{C}$ ratio of the sample and a known laboratory reference standard according to the formula of Craig (13):

$$
\delta^{13} \mathrm{C}=\left[\left[\frac{{ }^{13} \mathrm{C} /{ }^{12} \mathrm{C} \text { sample }}{{ }^{13} \mathrm{C} /{ }^{12} \mathrm{Cstandard}}\right]-1\right] \bullet 10^{3} \text { permil }
$$

The $\delta^{13} \mathrm{C}$ was then related to an international standard Pee Dee Bellemnite (PDB).

Exogenous $\mathrm{CHO}$ oxidation was estimated using the following formula (14):

$$
\text { Exo } \mathrm{CHO} \text { oxidation }=\mathrm{VCO}_{2} \bullet\left[\frac{\delta E x p-\delta E x p_{b k g}}{\delta \operatorname{lng}-\delta E x p_{b k g}}\right]\left(\frac{1}{\mathrm{k}}\right)
$$

in which $\mathrm{VCO}_{2}$ is the volume of expired $\mathrm{CO}_{2}$ per $\mathrm{min}(\mathrm{L} / \mathrm{min}), \delta$ Exp is the ${ }^{13} \mathrm{C}$ enrichment of expired air with $\mathrm{CHO}$ ingestion at different time-points, $\delta$ Ing is the enrichment of the $\mathrm{CHO}$ in the experimental beverages, $\delta \operatorname{Exp}_{\text {bkg }}$ is the ${ }^{13} \mathrm{C}$ enrichment in expired breath before the intervention (background) and $\mathrm{k}$ is the amount of $\mathrm{CO}_{2}$ (in Liters) produced by the oxidation of $1 \mathrm{~g}$ glucose ( $\mathrm{k}=0.7467$ liter of $\mathrm{CO}_{2}$ per $\mathrm{g}$ glucose). This represents a minimal estimate of exogenous carbohydrate oxidation, as part of the ${ }^{13} \mathrm{C}$ will be temporarily fixated in the bicarbonate pool and in the tricarboxylic acid cycle intermediates $(14,15)$.

\section{Statistics}

A computerized statistics program, SPSS 11 for Macintosh, was used to perform all calculations. All data are expressed as means with their standard errors. The total response of metabolic parameters after $\mathrm{CHO}$ ingestion was expressed as the incremental area under the curve (minus baseline values, $\triangle A \cup C$ ) and calculated by the trapezoid method. Response is defined in the result section as $\triangle A U C$, unless mentioned otherwise. Differences between responses to GLUC vs TRE were analyzed by means of student's 44 
paired t-test. Student's paired t-test was used to compare differences in peak response between the different carbohydrates.

\section{Results}

Plasma glucose, insulin, FFA and triacylglycerol

Fasting plasma glucose, insulin and FFA concentrations did not differ between experiments (Figure 1A-C). Peak plasma glucose concentrations were significantly lower after ingestion of TRE when compared with GLUC (Figure 1A). The glycemic response was not significantly lower after intake of TRE compared with GLUC following an overnight fast $(P=0.08)$, whilst there was a significant difference between TRE and GLUC when ingested in combination with a mixed meal $(P \varangle 0.02$, Table 1$)$.
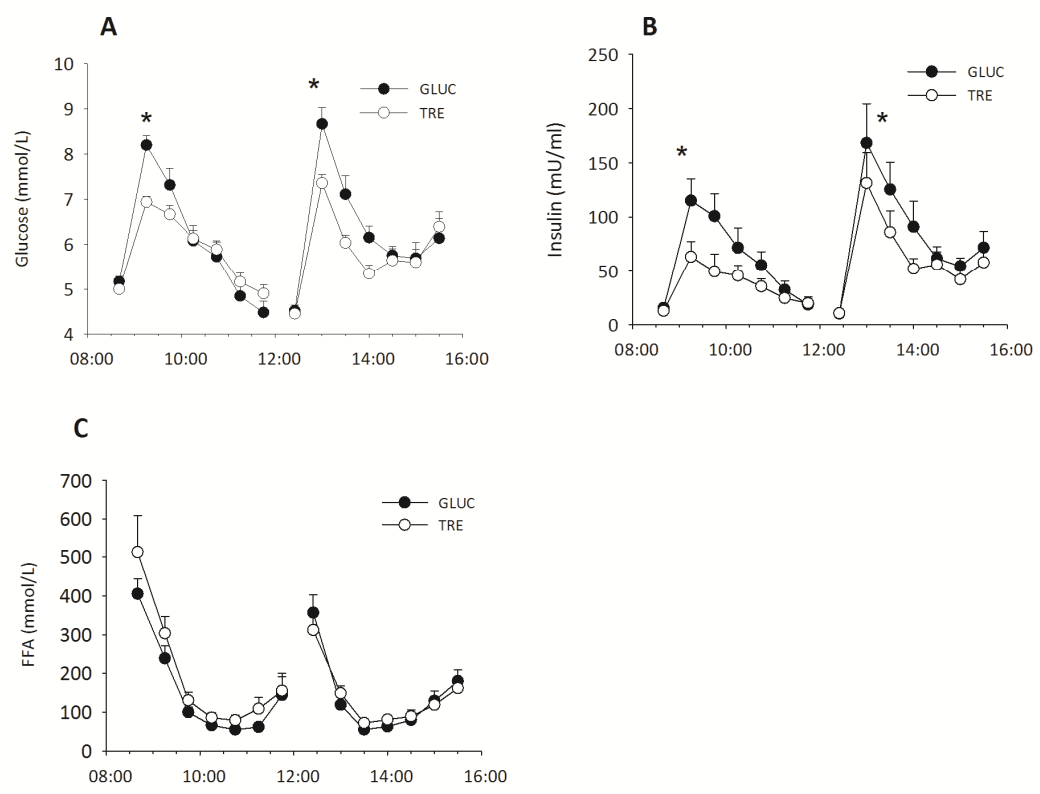

Figuur 1 Plasma glucose (A), insulin (B) and FFA (C) concentrations following glucose (-๑-) and trehalose (-o-) ingestion. Values are means, with their standard error represented as vertical bars. * $\mathrm{P} \varangle 0.05$

Peak insulin concentrations and the total response were significantly lower after ingestion of TRE compared with GLUC during AM and PM (Figure 1B, Table 1). During AM, there were no differences in circulating FFA concentrations between TRE and GLUC, whilst there was a trend towards less suppression of FFA with TRE during PM ( $P=0.09$ ) (Figure $1 C$, Table 1). The intake of trehalose resulted in a lower increase in TAG concentrations compared 


\section{Chapter 2A}

with glucose during the morning $(P<0.02)$ and a higher increase during the afternoon $(P<$ 0.05) (Table 1).

Thermogenesis and respiratory quotient

There were no significant differences in the thermogenic response $(\triangle \mathrm{AUC})$ between TRE vs. GLUC during AM and PM. There was a tendency towards a lower increase of the respiratory quotient (RQ) after intake of TRE compared to GLUC during $A M(P=0.09)$, but no significant differences were observed between TRE and GLUC during PM (Table 1).

Total fat oxidation

There was a trend towards an attenuated suppression of fat oxidation with ingestion of TRE when compared with GLUC during AM $(P=0.1)$, whereas values were not different during PM (Figure 2A).
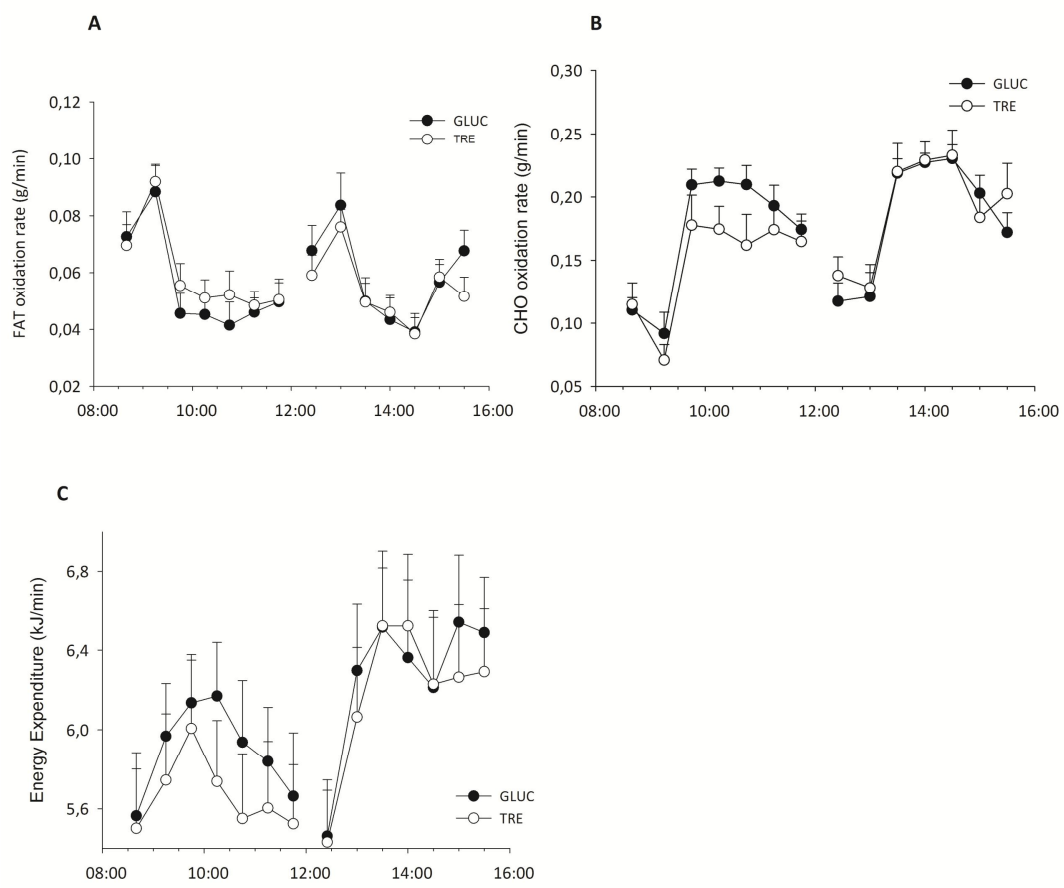

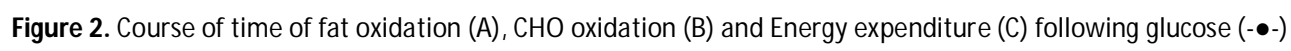
and trehalose (-o-) ingestion. Values are means, with their standard error represented as vertical bars. * $\mathrm{P} \varangle .05$ 
Total carbohydrate oxidation

After intake of TRE the increment in total $\mathrm{CHO}$ oxidation was significantly lower as compared with GLUC during AM ( $P=0.02)$. No significant changes were observed during PM (Figure 2B, Table 1).

Exogenous carbohydrate oxidation

No significant differences were observed in the minimal estimates of exogenous $\mathrm{CHO}$ oxidation rates between experiments. The mean percentage of the enriched sugar recovered in breath carbon dioxide excretion averaged at least $7-10 \%$ in all trials during AM.

Table 1. Overview of metabolic responses, expressed as $\triangle A U C$, after ingestion of TRE and GLUC. $* P \varangle .05 * *$ $\mathrm{P} \diamond .01$

\begin{tabular}{|c|c|c|}
\hline & $\begin{array}{l}\triangle A \text { AUC AM over } 3 \mathrm{~h} \\
\text { TRE vs. GLUC }\end{array}$ & $\begin{array}{l}\triangle A \text { AUC PM over } 3 \mathrm{~h} \\
\text { TRE vs. GLUC }\end{array}$ \\
\hline Glucose (mmol/L) & 178 vs. 188 & 274 vs. $360^{*}$ \\
\hline Insulin $(\mu \mathrm{U} / \mathrm{ml})$ & 4868vs. $9264 * *$ & 10693 vs. 14634 ** \\
\hline FFA (mmol/L) & -61372 vs. -49332 & -32263 vs. -41182 \\
\hline Triacylglycerol (mmol/L) & -6759 vs. $16102 *$ & 62761 vs. $40076 *$ \\
\hline Fat oxidation ( $\mathrm{g} / \mathrm{min})$ & -0.99 vs. -3.21 & -0.88 vs. -1.95 \\
\hline $\mathrm{CHO}$ oxidation ( $\mathrm{g} / \mathrm{min})$ & 5.18 vs. $11.86 *$ & 10.1 vs. 13.27 \\
\hline RQ & 7.7 vs. 3.8 & 6.3 vs. 4.3 \\
\hline Energy Expenditure $(\mathrm{KJ} / \mathrm{min})$ & 69.5 vs. 48.9 & 156 vs. 147.9 \\
\hline
\end{tabular}

\section{Discussion}

The present study provides evidence that attenuated postprandial glycemic and insulinemic responses following TRE ingestion shifts postprandial substrate use towards a lower $\mathrm{CHO}$ oxidation in overweight subjects after ingestion of a $\mathrm{CHO}$ drink, but not when ingested as part of a mixed meal. No significant effects were observed on postprandial fat oxidation. The attenuated glycemic and insulinemic responses following TRE are attributed to the slower rates at which TRE is digested and/or absorbed. Several studies have shown that the absorption rate of TRE is slower than GLUC (16). An attenuated rise in blood glucose and insulin levels after intake of TRE were observed in trained athletes and healthy subjects $(17,18)$. The present study is the first to show that TRE ingestion 


\section{Chapter 2A}

attenuates the rise in plasma glucose and insulin levels in overweight subjects. Although, there were no significant differences in the total integrated glycemic responses following ingestion of different carbohydrates after an overnight fast (AM), there was a clearly attenuated rise in peak plasma glucose concentration after ingestion of TRE compared with GLUC. The differences in the duration of elevated glycemia and the absence of a strong rebound effect may explain the lack of difference when considering the $\triangle A U C$.

\section{Substrate use}

The postprandial hyperglycemia with ingestion of GLUC increases insulin secretion, and higher insulin levels would promote glucose uptake in insulin-sensitive tissues, like the skeletal muscle, and inhibit adipose tissue lipolysis (19). Through these mechanisms, interindividual differences in substrate use may play a role in the development of obesity and subsequently type 2 diabetes mellitus. Additionally, a shift towards a greater postprandial fat oxidation rate may attenuate lipid accumulation in non-adipose tissues leading to reduced insulin resistance $(20,21)$. Lower glucose and insulin levels were observed after ingestion of TRE and no significant effects on postprandial fat oxidation were observed, whilst there was a slightly lower increase in $\mathrm{CHO}$ oxidation. Thus, the trehalose-induced lower glycemic and insulinemic response did not promote fat oxidation in the postprandial period.

\section{Postprandial TAG concentration}

Hyperinsulinemia may be accompanied by a greater increase in plasma triacylglycerol concentrations, which are considered to be risk factors for the development of cardiovascular disease (5). Low glycemic, low insulinemic carbohydrate sources may be used to attenuate the postprandial rise in TAG concentrations, but there is no clear consensus. In the present study, we observed that TRE resulted in reduced TAG concentrations during AM, whilst during PM postprandial TAG was slightly increased when compared with GLUC.

In conclusion, ingestion of TRE versus GLUC attenuates the postprandial glycemic and insulinemic responses. Attenuated blood glucose and insulin concentrations tended to shift postprandial substrate use towards a reduced carbohydrate oxidation when TRE was ingested as a drink during AM, but had no significant effects on postprandial fat oxidation or postprandial FFA concentrations. 


\section{References}

1. Seidell JC. Obesity, insulin resistance and diabetes--a worldwide epidemic. $\mathrm{Br}$ J Nutr 2000;83 Suppl 1:S5-8.

2. Saris WH. Glycemic carbohydrate and body weight regulation. Nutr Rev 2003;61:S10-6.

3. Blaak EE, Hul G, Verdich C, et al. Fat oxidation before and after a high fat load in the obese insulin-resistant state. J Clin Endocrinol M etab 2006;91:1462-9.

4. Blaak EE. Basic disturbances in skeletal muscle fatty acid metabolism in obesity and type 2 diabetes mellitus. Proc Nutr Soc 2004;63:323-30.

5. Sparks LM, Pasarica M, Sereda O, et al. Effect of adipose tissue on the sexual dimorphism in metabolic flexibility. Metabolism 2009;58:1564-71.

6. Chong MF, Fielding BA, Frayn KN. M echanisms for the acute effect of fructose on postprandial lipemia. Am J Clin Nutr 2007;85:1511-20.

7. Brand-M iller JC, Holt SH, Pawlak DB, M cMillan J. Glycemic index and obesity. Am J Clin Nutr 2002;76:281S-5S.

8. Richards AB, Krakowka S, Dexter LB, et al. Trehalose: a review of properties, history of use and human tolerance, and results of multiple safety studies. Food Chem Toxicol 2002;40:871-98.

9. Dahlqvist A. Specificity of the human intestinal disaccharidases and implications for hereditary disaccharide intolerance. J Clin Invest 1962;41:463-70.

10. Wagenmakers AJ, Rehrer NJ, Brouns F, Saris WH, Halliday D. Breath $13 \mathrm{CO} 2$ background enrichment during exercise: diet-related differences between Europe and America. J Appl Physiol 1993;74:2353-7.

11. Frayn KN. Calculation of substrate oxidation rates in vivo from gaseous exchange. J Appl Physiol 1983;55:628-34.

12. Weir JB. New methods for calculating metabolic rate with special reference to protein metabolism. J Physiol 1949;109:1-9.

13. Craig $\mathrm{H}$. Isotopic standards for carbon and oxygen and correction factors for mass-spectrometric analysis of carbon dioxide. Geochim Cosmochim Acta 1957; 12:133-149.

14. Irving CS, Wong WW, Shulman RJ, Smith EO, Klein PD. [13C]bicarbonate kinetics in humans: intra- vs. interindividual variations. Am J Physiol 1983;245:R190-202.

15. Leijssen DP, Elia M. Recovery of $13 \mathrm{CO} 2$ and $14 \mathrm{CO} 2$ in human bicarbonate studies: a critical review with original data. Clin Sci (Lond) 1996;91:665-77.

16. Dahlqvist A, Thomson DL. The Digestion and Absorption of M altose and Trehalose by the Intact Rat. Acta Physiol Scand 1963;59:111-25.

17. Livesey $\mathrm{G}$. Tolerance of low-digestible carbohydrates: a general view. $\mathrm{Br}$ J Nutr 2001;85 Suppl 1:S7-16.

18. Jentjens $\mathrm{RL}$, Jeukendrup $\mathrm{AE}$. Effects of pre-exercise ingestion of trehalose, galactose and glucose on subsequent metabolism and cycling performance. Eur J Appl Physiol 2003;88:459-65. 
19. Wolever TM. Carbohydrate and the regulation of blood glucose and metabolism. Nutr Rev 2003;61:S40-8.

20. Flatt JP. Carbohydrate balance and body-weight regulation. Proc Nutr Soc 1996;55:449-65.

21. Eckel RH, Hernandez TL, Bell M L, et al. Carbohydrate balance predicts weight and fat gain in adults. Am J Clin Nutr 2006;83:803-8. 


\section{Chapter 2B}

\section{Reduced glycemic and insulinemic responses following isomaltulose ingestion: implications for postprandial substrate use}

Judith GP van Can, Herman IJ zerman, LuC JC van Loon, Fred Brouns and Ellen E Blaak.

Reduced glycemic and insulinemic responses following isomaltulose ingestion: implications for postprandial substrate use.

British J of Nutr 2009; 102: 1408-1413. 


\section{Chapter 2B}

Abstract

Introduction: The impact of slow digestible sources of dietary carbohydrate in reducing the risk of developing obesity and related metabolic disorders is unclear. The aim of the present study was to compare the postprandial metabolic response to the ingestion of sucrose (SUC) vs. isomaltulose (IMU).

Aim: We hypothesized that the reduced digestion and absorption rate of IMU would result in lower glycemic and insulinemic responses when compared with the ingestion of SUC, leading to greater postprandial fat oxidation rates.

Design: In a randomized, single blind, cross-over study, 10 overweight subjects ingested 2 different carbohydrate drinks (SUC and IMU, $75 \mathrm{~g}$ CHO equivalents) following an overnight fast (8.40 AM) and with a standardized meal (12.30 PM, 25 en\% of total energy content was provided as either SUC or IMU drink). Blood samples were taken before ingestion and every 30 min thereafter for a period of $3 \mathrm{~h}$, substrate use was assessed by indirect calorimetry and breath samples were collected.

Results: Ingestion of carbohydrates with a mixed meal resulted in a lower peak glucose and insulin response and a lower $\triangle A U C$ following IMU when compared with SUC. Together with the lower glucose and insulin responses, postprandial fat oxidation rates were higher (14\%) with IMU when compared with SUC when ingested with a mixed meal $(P=0.02)$. The attenuated rise in glucose and insulin concentrations following IMU results in reduced inhibition of postprandial fat oxidation.

Conclusion: The metabolic response to IMU co-ingestion suggests that this may represent an effective nutritional strategy to counteract overweight induced metabolic disturbances. 


\section{Introduction}

Over the last 2 decades the prevalence of obesity and obesity-related disorders has increased rapidly (1). Both genetic and environmental factors play an important role in the etiology of these chronic metabolic diseases. Obesity develops as a result of an imbalance between energy intake and energy expenditure, resulting in a positive energy balance. Although many factors promote a positive energy balance, there is sound evidence that a high fat/low carbohydrate $(\mathrm{CHO})$ diet increases the risk of weight gain due to excess energy intake (2). On the other hand, high carbohydrate-low fat diets containing a large amount of rapidly available carbohydrates (cooked starches) and added refined sugars (sucrose, high fructose corn syrup) may be counter-productive to body weight control because they markedly increase postprandial glycemia and insulinemia. The latter may promote fat storage in both adipose and non-adipose tissue, through an inhibitory effect on adipose tissue lipolysis and/or muscle fat oxidation. Greater postprandial fat storage in non-adipose tissue, such as skeletal muscle and liver tissue, has been associated with the development of insulin resistance, whilst postprandial hyperglycemia per se represents a strong risk factor for the development of type 2 diabetes mellitus and cardiovascular comorbidities $(3,4)$. Finally, hyperinsulinemia may negatively impact on triacylglycerol (TAG) clearance, resulting in higher plasma TAG concentrations. Therefore, the recommendation to ingest a carbohydrate rich diet, containing a large amount of high glycemic carbohydrates may be less favourable effects on blood lipid profile $(5,6)$.

Potential negative side effects of high carbohydrate diets may be counteracted by the use of low glycemic index (Gl) foods. Prolonged use of low $\mathrm{Gl}$ foods has been reported to prevent the risk profile for developing obesity, diabetes and cardiovascular disease (7). Brand-Miller et al. hypothesized that the ingestion of slowly digestible carbohydrates attenuates the postprandial rise in glycemia and insulinemia, and enhances fat oxidation rates. The latter may assist in preventing body weight gain and insulin resistance (7). As such, slowly digestible carbohydrates may be of relevance in dietary strategies to modulate body weight and improve insulin sensitivity.

The aim of the present study was to compare postprandial hormonal and metabolic responses following ingestion of sucrose (SUC) vs. isomaltulose (IMU). We hypothesized that the ingestion of isomaltulose is accompanied by a lower glycemic and/or insulinemic response, a greater increase in satiety regulating peptides, less inhibition of postprandial fat oxidation rate and a lower plasma triacylglycerol response when compared with sucrose. 


\section{Chapter 2B}

\section{Methods}

\section{Subjects}

Ten healthy, overweight men $(n=8)$ and women $(n=2)$ were recruited for this study (age $31 \pm 4 \mathrm{yrs}, \mathrm{BMI} 27.7 \pm 0.8 \mathrm{~kg} / \mathrm{m}^{2}$, fasting glucose $5.1 \pm 0.1 \mathrm{mmol} / \mathrm{L}$, fasting insulin $14 \pm 1.9$ $\mu \mathrm{U} / \mathrm{ml}$ ). Subjects with cardiovascular or metabolic disorders, and those using medication were excluded from the study. The study was reviewed and approved by the Medical Ethics Committee of Maastricht University. All subjects provided written informed consent.

\section{Study design}

All subjects were studied following an overnight fast at $8.00 \mathrm{AM}$ on 2 occasions with an interval of at least $1 \mathrm{wk}$. At the beginning of the experimental day, a teflon cannula was inserted into an antecubital vein. Two different carbohydrate drinks were ingested (glucose or trehalose), during 2 different trials, performed in a single blind, randomized cross-over design. SUC and IMU were derived from cane sugar, a natural carbohydrate source with a high natural abundance of ${ }^{13} \mathrm{C}$. The carbohydrate load consisted of $75 \mathrm{~g}$ carbohydrate and was dissolved in $400 \mathrm{ml}$ water, to assess the metabolic response. After baseline measurements all experimental beverages were consumed within $15 \mathrm{~min}$. Blood samples were taken prior to the consumption of the drinks/meals ( $t=5 \mathrm{~min}$ ) and at $t=30$, $60,90,120,150$ and 180 min after ingestion to determine circulating metabolite and hormone concentrations. Energy expenditure and substrate use were measured, immediately before and for $3 \mathrm{~h}$ after carbohydrate ingestion (8.40 AM), using a ventilated hood system. Expired breath samples were collected every $h$ to determine ${ }^{13} \mathrm{CO}_{2}$ enrichment. These procedures were repeated at the same day before consuming a standardized lunch and for $3 \mathrm{~h}$ after lunch (12.30 PM). Lunch had a total energy content equivalent to $50 \%$ of calculated $24 \mathrm{~h}$ resting energy expenditure. Lunch macronutrient composition represented 55 energy percentage (En\%) $\mathrm{CHO}, 30 \mathrm{En} \%$ fat and $15 \mathrm{En} \%$ protein; 25 En\% of the total energy content of the meal was provided in the form of a beverage containing either IMU or SUC. Lunch was consumed within $15 \mathrm{~min}$.

Test products

Isomaltulose (IMU)

[6-0-( $\propto-$-D-glucopyranosyl)-D-fructofuranose, Chemical Abstract Service $n^{\circ} .1371$ 8-94-0] is a reducing disaccharide produced by an enzymatic conversion of SUC, whereby the 1,2glycosidic linkage between GLUC and fructose is rearranged to a 1,6-glycosidic linkage. The 
sucrase-isomaltase complex located on the brush border membrane of the small intestinal epithelial cells hydrolyzes both isomaltulose and sucrose. The resulting monosaccharides, glucose and fructose, are taken up into the portal blood (8).

Exogenous carbohydrate oxidation

As indicated above, all carbohydrates were derived from naturally ${ }^{13} \mathrm{C}$ enriched sources: SUC $\left({ }^{13} \mathrm{C}\right.$ enrichment $=-12.23 \delta \%$ ), IMU $\left({ }^{13} \mathrm{C}\right.$ enrichment $=-11.26 \delta \%$ ). The ${ }^{13} \mathrm{C}$-enrichment of the experimental drinks was determined by elemental analyser isotope ratio mass spectrometry (IRMS; Carlo Erba-Finnigan MAT 252, Bremen, Germany). Subjects were instructed not to consume any food products with a high natural abundance of ${ }^{13} \mathrm{C}$ at least 1 wk prior to and during the experimental period. In European countries the consumption of native carbohydrate sources with high natural ${ }^{13} \mathrm{C}$ abundance is low (9).

Biochemical analyses

At all time points, $8 \mathrm{ml}$ blood was collected in pre-chilled tubes with $200 \mu \mathrm{L} 0.2 \mathrm{M}$ EDTA (Sigma, Dorset, UK). After collection, blood samples were centrifuged immediately at $4^{\circ} \mathrm{C}$ for $10 \mathrm{~min}$ at $1000 \mathrm{~g}$ and frozen at $-80^{\circ} \mathrm{C}$ until further analysis. Plasma glucose and free fatty acid (NEFA) concentration were determined enzymatically: (glucose: ABX Diagnostics, Montpellier, France and NEFA: NEFA-NEFA C kit, Wako, Neuss, Germany) on a semiautomatic analyzer (COBAS FARA centrifugal spectrophotometer, Roche Diagnostics, Basel, Switzerland). Insulin was analyzed by radioimmunoassay (Human Insulin RIA Kit, LINCO Research Inc, St. Charles, MO), as was total ghrelin (Total Ghrelin RIA kit, LINCO Research Inc, MO). Plasma active GLP-1 concentration was analyzed by enzyme-linked immunoradiometric assay (EGLP-35K; Linco Research Inc, MO). Breath samples were analyzed for ${ }^{13} \mathrm{C} /{ }^{12} \mathrm{C}$ ratio by gas chromatography isotope ratio mass spectrometry (GCIRM S) (Finnigan MAT 252).

\section{Calculations}

Metabolic rate was calculated from $\mathrm{VO}_{2}(\mathrm{~L} / \mathrm{min})$ and $\mathrm{VCO}_{2}(\mathrm{~L} / \mathrm{min})$ according to the equations of Frayn (10). Nitrogen (N) excretion was calculated based on the assumption that protein oxidation represents $15 \%$ of total energy expenditure. Energy expenditure was calculated using the formula of Weir (11). 


\section{Chapter 2B}

$\mathrm{CHO}$ oxidation $=\left(4.55 \cdot \mathrm{VCO}_{2}\right)-\left(3.21 \cdot \mathrm{VO}_{2}\right)-(2.87 \cdot \mathrm{N})$

Fat oxidation $=\left(1.67 \cdot \mathrm{VO}_{2}\right)-\left(1.67 \cdot \mathrm{VCO}_{2}\right)-(1.92 \cdot \mathrm{N})$

$\mathrm{N}(\mathrm{g} / \mathrm{min})=((0.15 \cdot \mathrm{EE}) / 17) / 6.25$

Energy expenditure $(\mathrm{KJ} / \mathrm{min})=4.187 \cdot\left(3.9 \cdot \mathrm{VO}_{2}+1.1 \cdot \mathrm{VCO}_{2}\right)$

The isotopic enrichment was expressed as $\delta \%$ difference between ${ }^{13} \mathrm{C} /{ }^{12} \mathrm{C}$ ratio of the sample and a known laboratory reference standard according to the formula of Craig (12) :

$$
\delta^{13} \mathrm{C}=\left[\left[\frac{{ }^{13} \mathrm{C} /{ }^{12} \mathrm{Csample}}{{ }^{13} \mathrm{C} /{ }^{12} \mathrm{C} \text { standard }}\right]-1\right] \bullet 10^{3} \text { permil }
$$

The $\delta^{13} \mathrm{C}$ was then related to an international standard Pee Dee Bellemnite (PDB).

Exogenous $\mathrm{CHO}$ oxidation was estimated using the following formula (13):

$$
\text { Exo } \mathrm{CHO} \text { oxidation }=\mathrm{VCO}_{2} \bullet\left[\frac{\delta E x p-\delta E x p_{b k g}}{\delta \operatorname{lng}-\delta E x p_{b k g}}\right]\left(\frac{1}{\mathrm{k}}\right)
$$

in which $\mathrm{VCO}_{2}$ is the volume of expired $\mathrm{CO}_{2}$ per $\min (\mathrm{L} / \mathrm{min}), \delta$ Exp is the ${ }^{13} \mathrm{C}$ enrichment of expired air with $\mathrm{CHO}$ ingestion at different time-points, slng is the enrichment of the $\mathrm{CHO}$ in the experimental drinks, $\delta$ Exp $_{\text {bkg }}$ is the ${ }^{13} \mathrm{C}$ enrichment of expired breath before the intervention (background) and $\mathrm{k}$ is the amount of $\mathrm{CO}_{2}$ (in Liters) produced by the oxidation of $1 \mathrm{~g}$ of glucose ( $\mathrm{k}=0.7467$ liter of $\mathrm{CO}_{2}$ per $\mathrm{g}$ of glucose). Endogenous $\mathrm{CHO}$ oxidation was calculated as the difference between total $\mathrm{CHO}$ oxidation and exogenous $\mathrm{CHO}$ oxidation. This represents a minimal estimate of exogenous carbohydrate oxidation, as part of the ${ }^{13} \mathrm{C}$ will be temporarily fixated in the bicarbonate pool and in the tricarboxylic acid cycle intermediates $(14,15)$.

Statistics

A computerized statistics program, SPSS 11 for Macintosh, was used to perform all calculations. All data are expressed as means with their standard errors. The total response of parameters after $\mathrm{CHO}$ ingestion was expressed as the incremental area under the curve (minus baseline values, $\triangle A \cup C$ ) and calculated by the trapezoid method. Response is defined in the result section as $\triangle A U C$, unless mentioned otherwise. Differences between responses to SUC vs. IMU were analyzed by means of student's 56 
paired t-test. Student's paired t-test was used to compare differences in peak response between the different carbohydrates.

\section{Results}

Plasma glucose, insulin, FFA and triacylglycerol

Fasting plasma glucose, insulin and FFA concentration did not differ between experiments (Figure $1 \mathrm{~A}-\mathrm{C}$ ). Peak plasma glucose concentrations were lower after ingestion of IMU when compared with SUC both when ingested as a drink (AM) as well as with a meal (PM) (Figure 1A). The glycemic response was lower after intake of IMU when compared with SUC during PM ( $P \varangle 0.01$ ) (Table 1$)$.
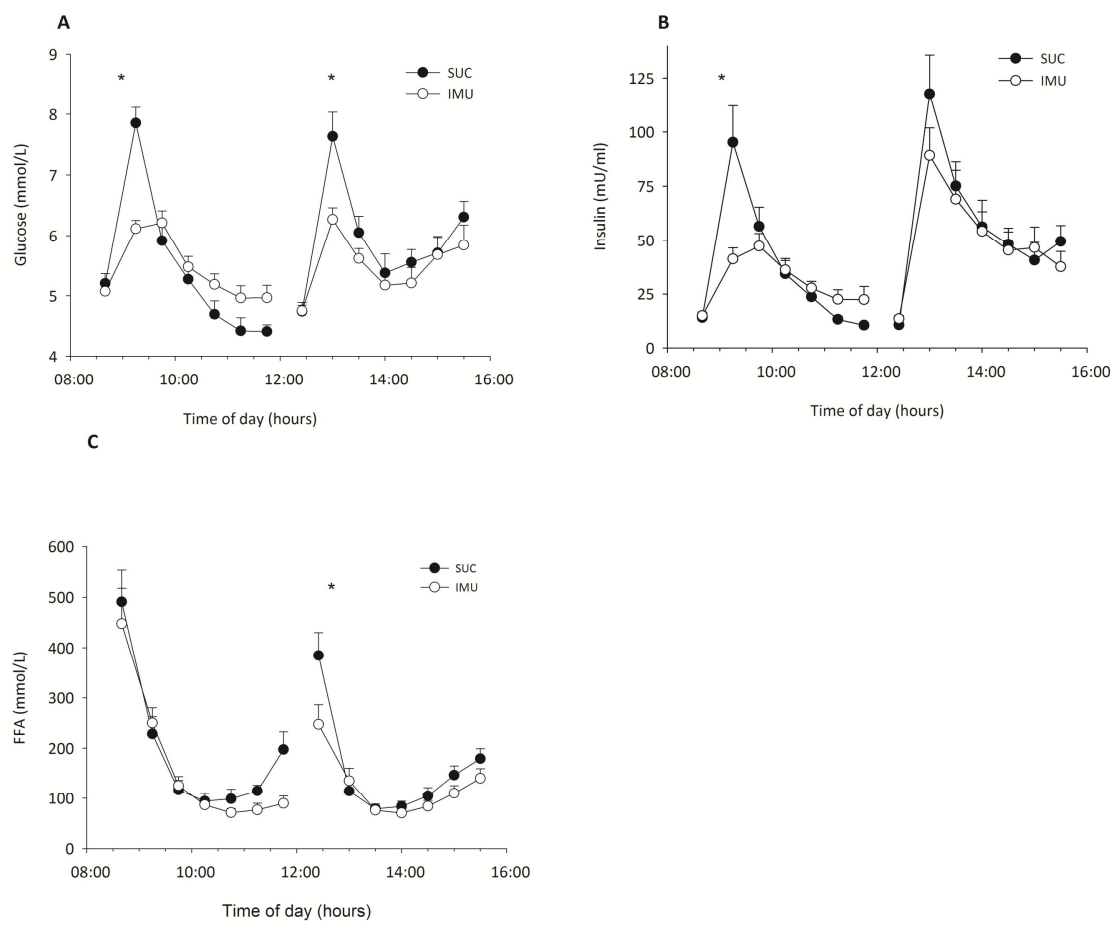

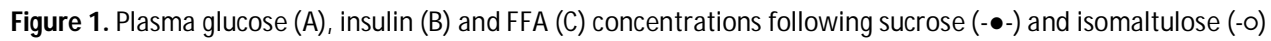
ingestion. Values are means, with their standard error represented as vertical bars. *P $\triangleleft .05$ 
Peak insulin concentrations were lower after ingestion of IMU compared with SUC during AM $(P<0.02)$ (Figure $1 B)$. Intake of IMU resulted in a lower insulin response as compared with SUC both during AM $(P=0.03)$ as well as $P M(P \varangle 0.01)$ (Table 1). Ingestion of IMU resulted in less suppression of NEFA concentrations when compared with SUC during PM $(P=0.01)$ (figure $1 C$, Table 1$)$. TAG concentrations were equal between IMU and SUC (Table 1).

\section{$\underline{\text { Total fat oxidation }}$}

The suppression of fat oxidation tended to be lower with IMU compared with SUC during AM $(P=0.10)$, reaching statistical significance during $P M(P=0.018)$ (Figure $2 A$, Table 1$)$.
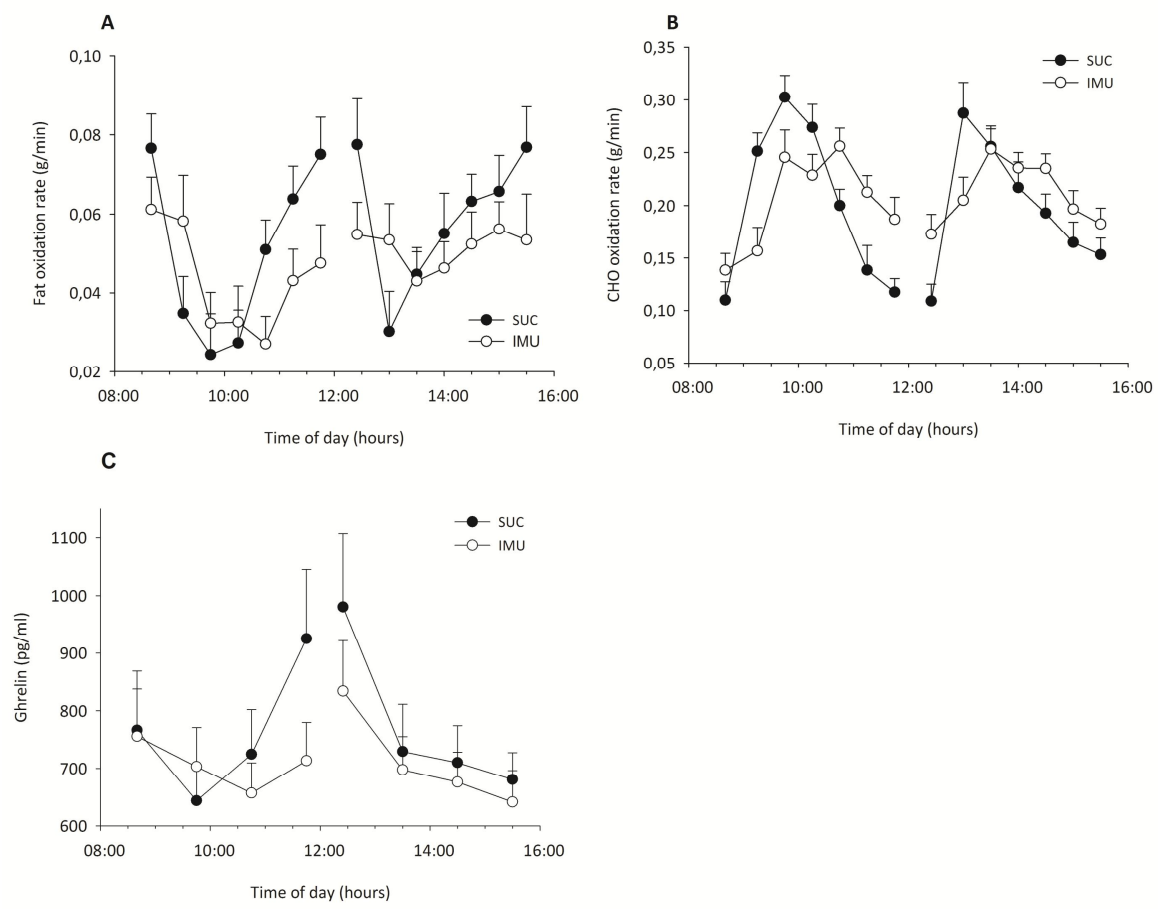

Figure 2. Fat oxidation rate (A), $\mathrm{CHO}$ oxidation rate (B) and plasma ghrelin concentration (C) following sucrose $(-\bullet-)$ and isomaltulose (-o-) ingestion. Values are means, with their standard error represented as vertical bars. * $P \varangle 0.05$ 


\section{$\underline{\text { Total carbohydrate oxidation }}$}

The $\mathrm{CHO}$ oxidation rates were different after ingestion of IMU or SUC during AM, but were not significant. Intake of IMU resulted in a lower increase of $\mathrm{CHO}$ oxidation compared with SUC during PM ( $\mathrm{P} \varangle .01$ ) (Figure 2B, Table 1).

$\underline{\text { Thermogenesis and respiratory quotient }}$

The thermogenic response was equal between IMU vs. SUC during AM and PM , (Table 1).

Table 1. Overview over metabolic responses, expressed as $\triangle A U C$, after ingestion of IMU and SUC. * $P \varangle 0.05 * *$ $P \triangleleft 0.01$

\begin{tabular}{|c|c|c|}
\hline & $\begin{array}{l}\triangle A U C A M \text { over } 3 \text { hours } \\
\text { IMU vs. SUC }\end{array}$ & $\begin{array}{l}\triangle A U C \text { PM over } 3 \text { hours } \\
\text { IMU vs. SUC }\end{array}$ \\
\hline Glucose (mmol/L) & 79 vs. 59 & 149 vs. $239^{* *}$ \\
\hline Insulin $(\mu \mathrm{U} / \mathrm{ml})$ & 3176 vs. $4726^{*}$ & 10693 vs. $14634^{* *}$ \\
\hline NEFA (mmol/L) & -54730 vs. -59122 & -22743 vs. $-43370 *$ \\
\hline Triacylglycerol (mmol/L) & -7418 vs. 9740 & 61386 vs. 66804 \\
\hline Fat oxidation (g/min) & -3.59 vs. -5.58 & -0.56 vs. $-3.99 *$ \\
\hline $\mathrm{CHO}$ oxidation (g/min) & 12.99 vs. 18.96 & 8.06 vs. $18.3 *$ \\
\hline $\mathrm{RQ}$ & 8.9 vs. 13.0 & 3.2 vs. $9.5 *$ \\
\hline Energy Expenditure $(\mathrm{KJ} / \mathrm{min})$ & 72.1 vs. 89.3 & 124 vs. 153 \\
\hline Ghrelin (pg/ml) & -16177 vs. -14326 & -21700 vs. -34678 \\
\hline GLP-1 (mmol/L) & 188 vs. 43 & 642 vs. 464 \\
\hline
\end{tabular}




\section{Chapter 2B}

\section{Exogenous carbohydrate oxidation}

No differences were observed in the minimal estimates of exogenous $\mathrm{CHO}$ oxidation rates between experiments. The mean percentage of the enriched sugar recovered in breath carbon dioxide excretion was at least $7-10 \%$ in all trials during AM.

\section{Satiety peptides responses}

Intake of IMU resulted in lower peak values of ghrelin when compared to SUC during AM $(P=0.045$, Figure $2 C)$. Differences were observed between plasma concentrations and $\triangle A U C$ of the satiety peptides, ghrelin and GLP-1, during PM which were not significant (Table 1).

\section{Discussion}

The present study provides evidence that an attenuated rise in glycemic and insulinemic responses following IMU may shift postprandial substrate utilization towards greater fat use in overweight subjects.

The attenuated glycemic and insulinemic responses following IMU are attributed to the slower rates at which IMU is digested and absorbed. Several studies have shown that IMU absorption rates are slower than $\operatorname{SUC}(16,17)$. The present study is the first to show that IMU intake attenuates the postprandial rise in plasma glucose and insulin levels in overweight subjects. Although, there were no significant differences in the total integrated glycemic responses following the ingestion of different carbohydrates after an overnight fast (AM), a lower peak plasma glucose concentration was evident after ingestion of IMU compared with SUC. The different duration of elevated glycemia and the absence of a strong rebound effect may explain the lack of difference when considering the $\triangle A U C$. The rebound effect induced hypoglycemia and low levels of insulin during AM, which resulted in an increase in FFA concentrations after intake of SUC as compared with IMU.

\section{Substrate use}

Intake of IMU in combination with a mixed meal resulted in an attenuated rise in the plasma glucose and insulin responses when compared with SUC and subsequently less inhibition of postprandial fat oxidation. The greater postprandial fat use was accompanied by higher circulating plasma FFA concentrations. The latter is likely attributed to a greater supply of plasma FFA, resulting from a reduced insulin mediated suppression of lipolysis (18). These data seem consistent with two other papers, which highlighted the stimulating effect of isomaltulose ingestion on fat oxidation and/or lipid deposition when compared 
to sucrose, in rats and healthy men. Sato et al. observed significant reductions in visceral fat mass, adipocyte cell size, hyperglycemia, and hyperlipidemia after 8 weeks of isomaltulose feeding compared with sucrose feeding in Zucker fatty (fa/fa) rats (19). Arai et al. showed that peak plasma glucose and insulin levels were lower $30 \mathrm{~min}$ after ingestion of the IMU containing liquid meal when compared with the control formula ingestion in healthy men. Postprandial fat oxidation rates following ingestion of the IMU meal group were higher when compared with the control formula group (20).

The present study shows that IMU is of benefit to stimulate postprandial fat oxidation when compared to SUC. The observation implies that substitution of IMU for SUC may support body weight control in obesity. A shift towards a greater postprandial fat use may attenuate fat accumulation in non-adipose tissues leading to reduced insulin resistance (21-23). Further studies are needed to investigate the long term physiological significance of our findings.

\section{Satiety regulatory peptides}

Contact of nutrients with the small intestine is postulated to be an important mechanism inducing satiety and it has been suggested that a slower carbohydrate digestion rate extends this contact (24). Circulating ghrelin concentrations rise with fasting and decline following meal ingestion and this primary regulation by food intake is in accordance with suggested role of ghrelin as a 'hunger hormone' (25). In the present study, peak ghrelin levels following IMU were significantly lower when compared with SUC during AM. The observation that ghrelin responses following IMU were much less pronounced when ingested as part of a mixed meal indicates that either the total quantity of carbohydrates consumed within the meal, or the interaction with other macronutrients in the meal may be more important in the overall satiety response.

In conclusion, ingestion of IMU attenuates the postprandial glycemic and insulinemic responses when compared with SUC ingestion. Lower postprandial plasma glucose and insulin concentrations shift postprandial substrate use towards greater fat use, which in the case of IMU was most pronounced when provided in combination with a mixed meal. Additionally, IMU ingestion has an impact on the postprandial ghrelin response. We speculate that exchanging high glycemic/insulinemic carbohydrates in the diet for slowly digestible carbohydrate sources may represent an effective nutritional strategy to counteract overweight induced metabolic disturbances like reducing insulin resistance and ectopic fat accumulation. 


\section{References}

1. Seidell JC. Obesity, insulin resistance and diabetes--a worldwide epidemic. $\mathrm{Br} \mathrm{J}$ Nutr 2000;83 Suppl 1:S5-8.

2. Saris WH. Glycemic carbohydrate and body weight regulation. Nutr Rev 2003;61:S10-6.

3. Blaak EE, Hul G, Verdich $\mathrm{C}$, et al. Fat oxidation before and after a high fat load in the obese insulin-resistant state. J Clin Endocrinol Metab 2006;91:1462-9.

4. Blaak EE. Basic disturbances in skeletal muscle fatty acid metabolism in obesity and type 2 diabetes mellitus. Proc Nutr Soc 2004;63:323-30.

5. Sparks JD, Sparks CE. Insulin regulation of triacylglycerol-rich lipoprotein synthesis and secretion. Biochim Biophys Acta 1994;1215:9-32.

6. Chong MF, Fielding BA, Frayn KN. Mechanisms for the acute effect of fructose on postprandial lipemia. Am J Clin Nutr 2007;85:1511-20.

7. Brand-M iller JC, Holt SH, Pawlak DB, M cMillan J. Glycemic index and obesity. Am J Clin Nutr 2002;76:281S-5S.

8. Lina BA, Jonker D, Kozianowski G. Isomaltulose (Palatinose): a review of biological and toxicological studies. Food Chem Toxicol 2002;40:1375-81.

9. Wagenmakers AJ, Rehrer NJ, Brouns F, Saris WH, Halliday D. Breath $13 \mathrm{CO} 2$ background enrichment during exercise: diet-related differences between Europe and America. J Appl Physiol 1993;74:2353-7.

10. Frayn KN. Calculation of substrate oxidation rates in vivo from gaseous exchange. J Appl Physiol 1983;55:628-34.

11. Weir JB. New methods for calculating metabolic rate with special reference to protein metabolism. J Physiol 1949;109:1-9.

12. Craig H. Isotopic standards for carbon and oxygen and correction factors for mass-spectrometric analysis of carbon dioxide. Geochim Cosmochim Acta 1957;12:133-49.

13. Pirnay F, Crielaard JM, Pallikarakis N, et al. Fate of exogenous glucose during exercise of different intensities in humans. J Appl Physiol 1982;53:1620-4.

14. Irving CS, Wong WW, Shulman RJ, Smith EO, Klein PD. [13C]bicarbonate kinetics in humans: intra- vs. interindividual variations. Am J Physiol 1983;245:R190-202.

15. Leijssen DP, Elia M. Recovery of $13 \mathrm{CO} 2$ and $14 \mathrm{CO} 2$ in human bicarbonate studies: a critical review with original data. Clin Sci (Lond) 1996;91:665-77.

16. Dahlqvist A, Auricchio S, Semenza G, Prader A. Human intestinal disaccharidases and hereditary disaccharide intolerance. The hydrolysis of sucrose, isomaltose, palatinose (isomaltulose), and a 1,6-alpha-oligosaccharide (isomaltooligosaccharide) preparation. J Clin Invest 1963;42:556-62.

17. Kawai K, Okuda Y, Yamashita K. Changes in blood glucose and insulin after an oral palatinose administration in normal subjects. Endocrinol Jpn 1985;32:933-6.

18. Wolever TM. Carbohydrate and the regulation of blood glucose and metabolism. Nutr Rev 2003;61:S40-8. 
19. Sato K, Arai H, Mizuno A, et al. Dietary palatinose and oleic acid ameliorate disorders of glucose and lipid metabolism in Zucker fatty rats. J Nutr 2007;137:1908-15.

20. Arai $H$, Mizuno A, Sakuma $M$, et al. Effects of a palatinose-based liquid diet (Inslow) on glycemic control and the second-meal effect in healthy men. Metabolism 2007;56:115-21.

21. Flatt JP. Carbohydrate balance and body-weight regulation. Proc Nutr Soc 1996;55:449-65.

22. Eckel RH, Hernandez TL, Bell ML, et al. Carbohydrate balance predicts weight and fat gain in adults. Am J Clin Nutr 2006;83:803-8.

23. Weiss R, Dufour S, Taksali SE, et al. Prediabetes in obese youth: a syndrome of impaired glucose tolerance, severe insulin resistance, and altered myocellular and abdominal fat partitioning. Lancet 2003;362:951-7.

24. Read N, French $\mathrm{S}$, Cunningham $\mathrm{K}$. The role of the gut in regulating food intake in man. Nutr Rev 1994;52:1-10.

25. Cummings DE, Purnell JQ, Frayo RS, Schmidova K, Wisse BE, Weigle DS. A preprandial rise in plasma ghrelin levels suggests a role in meal initiation in humans. Diabetes 2001;50:1714-9. 
Chapter 2B 


\section{Chapter 3}

\section{Reduced glycemic and insulinemic responses following trehalose and isomaltulose ingestion: implications for postprandial substrate use in impaired glucose tolerant subjects}

Judith GP van Can, LuC JC van Loon, Fred Brouns and Ellen E Blaak.

Reduced glycemic and insulinemic responses following trehalose and isomaltulose ingestion: implications for postprandial substrate use in impaired glucose tolerant subjects.

British J of Nutr 2011; dec 15: 1-8. 


\section{Chapter 3}

\section{Abstract}

Introduction: The impact of slowly digestible sugars in reducing the risk of developing obesity and related metabolic disorders remains unclear.

Aim: We hypothesized that such carbohydrates, resulting in a lower glycemic and insulinemic response, may lead to greater postprandial fat oxidation rates in subject with impaired glucose tolerance (IGT).

Design: This study intends to compare the postprandial metabolic responses to the ingestion of glucose (GLUC) vs trehalose (TRE) and sucrose (SUC) vs isomaltulose (IMU). In a randomized single-blind cross-over design, 10 overweight IGT subjects were studied 4 times, following ingestion of different carbohydrate drinks either at breakfast or in combination with a mixed meal at lunch. Before and $3 \mathrm{~h}$ after $\mathrm{CHO}$ ingestion, energy expenditure, substrate utilization and circulating metabolite concentrations were determined.

Results: Ingestion of carbohydrate drinks with a meal resulted in an attenuated rise in glucose (-33\%) and insulin (-14\%) concentration following TRE when compared with GLUC and following IMU, an attenuation of $43 \%$ and $34 \%$ when compared with SUC ingestion, respectively. Additionally, there was less inhibition of the rise in free fatty acid concentrations and less decline in postprandial fat oxidation (22\%) after IMU when compared with SUC, whereas TRE did not differ from GLUC.

Conclusion: The attenuated rise in glucose and insulin concentrations following IMU ingestion, attenuated the postprandial inhibition of fat oxidation compared to SUC when co-ingested with a meal. This suggests that exchange of SUC in the diet for IMU may result in a more favourable metabolic response and may help to reduce the risks associated with obesity and type 2 diabetes. 


\section{Introduction}

The increasing prevalence of obesity and obesity-related disorders like type 2 diabetes has become the greatest health problems of the present and coming decades (1). According to the physiological state where abnormalities in glucose metabolism are present but below the cut-off point for the diagnosis of type 2 diabetes, individuals can be grouped into those who suffer from 1. impaired fasting glucose (IFG) or 2. impaired glucose tolerance (IGT). Individuals with isolated IGT show a moderate to severe muscle insulin resistance and suffer from a defect in both the early-and late-phase insulin secretory response to an oral glucose load. Patients with IGT have a 2- to 5 -fold greater risk of developing cardiovascular disease, compared with age-matched normoglycemic controls (2). Each year, about $10 \%$ of the subjects with IFG and IGT progress to develop type 2 diabetes (3). Lifestyle intervention, directed towards a healthy diet, i.e a reduction in saturated fat intake, an increase in low glycemic carbohydrate intake, and an increase in habitual physical activity level has proven effective in preventing or delaying the onset of type 2 diabetes in subjects with IGT $(4,5)$. Interventions to reduce the glycemic index $(G I)$ and glycemic load (GL) of the daily diet have received much interest in nutritional research (6, 7). So far, numerous studies have reported that diets low in $\mathrm{Gl}$ or glycemic load can have beneficial effects on weight loss and/or reduce the risk of developing of chronic metabolic disease in humans $(6,8-10)$. Whereas some suggest that diets high in carbohydrate may have an adverse effect on triglyceride concentrations and HDL cholesterol (11), other fail to confirm those findings. The apparent discrepancy between studies is likely attributed to differences in the duration of the intervention, gender, and the use of different type of sugars between studies (12-14).

It has been hypothesized that low Gl foods may affect body weight control and insulin sensitivity by promoting satiety and stimulating fat oxidation at the expense of carbohydrate oxidation (15). This increased fat oxidation may reduce fat storage in adipose and non-adipose tissues, thereby promoting insulin sensitivity and an improved metabolic profile. Indeed, animal studies show that a reduced GI can shift substrate use in favour of fat oxidation, independent of diet-induced changes in body composition or energy intake (16-18). We recently showed that a reduced glycemic response after a mixed meal containing TRE or IMU may improve fat oxidation rates at the expense of carbohydrate oxidation in overweight subjects $(19,20)$. Similar findings were also observed during exercise conditions (21).

So far, it is not known whether these beneficial effects on fat oxidation also extend to impaired glucose tolerant subjects who show profound disturbances in the capacity to 


\section{Chapter 3}

utilise fat as a substrate source during basal fasting conditions as well as in the capacity to switch between carbohydrate and fat oxidation during postprandial conditions (22). The fact that disturbances in fatty acid uptake and oxidation are already present in the prediabetic state, suggests a key role in the progression towards type 2 diabetes (23). Consequently, more work is warranted to assess the impact of low $\mathrm{Gl}$ carbohydrates on postprandial substrate use in an obese group with impaired glucose tolerance. Therefore, we examined the metabolic response to the ingestion of 2 slowly digestible carbohydrate sources, trehalose (TRE) and isomaltulose (IMU), respectively. TRE is a glucose disaccharide with an $\alpha 1.1$ glycoside linkage, whereas IMU is a dissacharide and produced by an enzymatic conversion of sucrose (SUC).

We hypothesized that the ingestion of trehalose and isomaltulose will be accompanied by a lower glycemic and/or insulinemic response, an attenuated inhibition of postprandial lipolysis and fat oxidation rate and a lower plasma triacylglycerol response when compared with glucose and sucrose, respectively.

\section{Methods}

Subjects

Ten overweight men $(n=6)$ and women $(n=4)$, of which 2 were post-menopausal, with impaired glucose tolerance were recruited for this study. Subjects' characteristics are presented in table 1 . Subjects with type 2 diabetes and/or overt cardiovascular complications, and those using medication for digestive disorders were excluded from the study. All subjects were screened with a standard $75 \mathrm{~g}$ OGTT after an overnight fast. Impaired glucose tolerance was diagnosed based on the WHO criteria. This study was conducted according to the guidelines laid down in the Declaration of Helsinki and all procedures involving human subjects/patients were approved by the Medical Ethical Committee of the Maastricht University Medical Centre ${ }^{+}$. All subjects gave written informed consent.

Study design

Each subject participated in 4 trials, separated by a 1-wk washout period, in which the metabolic response was measured after ingestion of 4 different carbohydrate drinks. Carbohydrate drinks were ingested after an overnight fast (breakfast drink) and in combination with a standardized mixed meal (lunch). The carbohydrate drinks (glucose, trehalose, sucrose and isomaltulose) were provided in a single-blind, randomized order. 
Table 1. Subjects' characteristics

\begin{tabular}{ll}
\hline & $\begin{array}{l}\text { Subjects (female } \mathrm{n}=4 \text {, male } \mathrm{n}=6 \text { ) } \\
\text { Mean } \pm \mathrm{SD}\end{array}$ \\
\hline Age (years) & $56 \pm 8$ \\
Weight $(\mathrm{kg})$ & $91.3 \pm 20.3$ \\
BMI $\left(\mathrm{kg} / \mathrm{m}^{2}\right)$ & $30.8 \pm 4.9$ \\
Fasting glucose (mmol/L) & $5.63 \pm 0.64$ \\
2h glucose (mmol/L) & $8.78 \pm 0.96$ \\
Fasting insulin $(\mu \mathrm{U} / \mathrm{ml})$ & $18 \pm 8.9$ \\
HOM A-IR & $4.63 \pm 2.53$ \\
HbA $\mathrm{I}_{1 \mathrm{C}}(\%)$ & $5.85 \pm 0.19$ \\
Fasting free fatty acids ( $\mu \mathrm{mol} / \mathrm{L})$ & $402 \pm 101$ \\
Fasting triacylglycerol (mmol/L) & $1.15 \pm 0.47$ \\
ALAT (U/L) & $30 \pm 9.7$ \\
Creatinine ( $\mu$ mol/L) & $79 \pm 15.2$ \\
\hline
\end{tabular}

\section{Protocol}

At the beginning of the experimental day, after an overnight fast, a cannula was inserted into an antecubital vein. The carbohydrate load consisted of $75 \mathrm{~g}$ carbohydrate equivalents and was dissolved in $400 \mathrm{ml}$ water. The carbohydrate drink was consumed after an overnight fast at breakfast (8.45AM) or in combination with a mixed meal at lunch (12.30 PM) within a period of $15 \mathrm{~min}$. Energy expenditure and substrate utilization were measured, before and for $3 \mathrm{~h}$ after ingestion of the meal and/or drink using a ventilated hood system (Omnical, Maastricht University, The Netherlands) (24). Gas analyses, which are performed every min, are performed by dual paramagnetic $\mathrm{O}_{2}$ analysers and dual infrared $\mathrm{CO}_{2}$ analysers (type 1156, 1507, 1520; Servomex, Cowborough, Sussex, UK), similar to the analysis system described by Schoffelen et al. (25). Blood samples were 


\section{Chapter 3}

taken before consumption of the meal/drinks ( $t=-5 \mathrm{~min}$ ) and then at $t=30,60,90,120$, 150 and $180 \mathrm{~min}$ after carbohydrate ingestion to determine circulating metabolites and hormone concentrations. Expired breath samples were collected each $\mathrm{h}$ to determine ${ }^{13} \mathrm{CO}_{2}$ enrichment. Energy expenditure and substrate use were calculated using the formulas of Weir and Frayn $(26,27)$.

Lunch had a total energy content equivalent of $50 \%$ of calculated $24 \mathrm{~h}$ resting energy expenditure based upon the formula of Harris and Benedict (28). Lunch macronutrient composition represented $55 \mathrm{En} \% \mathrm{CHO}, 30 \mathrm{En} \%$ fat and $15 \mathrm{En} \%$ protein; $25 \mathrm{En} \%$ of the total energy content of the meal was provided in the form of a beverage containing either TRE, IMU, GLUC or SUC.

Test products

Trehalose (TRE)

TRE is a disaccharide of glucose with an $\alpha 1,1$ glycoside linkage. It is a non-reducing sugar that is naturally present in honey, bread, mushrooms and fermented drinks. For our experimentation ${ }^{13} \mathrm{C}$ enriched TRE was produced by enzymatic conversion using corn starch as base material. In the human intestine TRE is exclusively digested by epithelial trehalase into two D-glucose molecules, which are subsequently absorbed and metabolised $(29,30)$. Apart from the trehalase action, it appears that ingestion, hydrolysis, absorption and metabolism of trehalose is essentially identical to all other digestible disaccharides (29).

Isomaltulose (IMU)

Isomaltulose is a disaccharide produced by an enzymatic conversion of SUC, whereby the 1,2-glycosidic linkage between glucose and fructose is rearranged to a 1,6-glycosidic linkage. For our experiment ${ }^{13} \mathrm{C}$ enriched IMU was produced by enzymatic conversion using cane sugar as base material. The sucrase-isomaltase complex located on the brush border membrane of the small intestinal epithelial cells hydrolyzes both isomaltulose and sucrose. The resulting monosaccharides, glucose and fructose, are taken up into the portal blood (31).

Biochemical analyses

At all time points, $8 \mathrm{ml}$ blood was collected in pre-chilled tubes with $200 \mu \mathrm{L}$ of $0.2 \mathrm{M}$ EDTA (Sigma, Dorset, UK). After collection, blood samples were centrifuged immediately at $4^{\circ} \mathrm{C}$ 
for $10 \mathrm{~min}$ at $1000 \mathrm{~g}$ and frozen at $-80^{\circ} \mathrm{C}$ until further analysis. The plasma was used for the enzymatic colorimetric quantification of fatty acids (NEFA C kit; Wako Chemicals, Neuss, Germany), TAG (Sigma, St.Louis, MO, USA) on a COBAS FARA centrifugal spectrophotometer (Roche Diagnostica, Basel, Switserland). Plasma glucose concentration (ABX Diagnostics, Montpellier, France) was measured enzymatically on a COBAS MIRA automated spectrophotometer (Roche Diagnostica). Plasma insulin was measured with a double antibody radioimmunoassay (Linco research, St. Charles, M O,USA). Breath samples were analyzed for ${ }^{13} \mathrm{C} /{ }^{12} \mathrm{C}$ ratio by gas chromatography isotope ratio mass spectrometry (GC-IRM S) (Finnigan M AT 252) as described in van Can et al. (19, 20).

Statistics

A computerized statistics program, SPSS 15 for Windows, was used to perform all calculations. All data are expressed as means \pm SEM. The total response of parameters after $\mathrm{CHO}$ ingestion was expressed as the incremental area under the curve (iAUC) and calculated by the trapezoid method. Response is defined in the result section as iAUC, unless mentioned otherwise. Differences between responses to GLUC vs TRE and SUC vs IMU were analyzed by means of student's paired t-test. Student's paired t-test was used to compare differences in peak response between the different carbohydrates. The 4 carbohydrates were not compared with each other due to the fact that they are made out of different carbohydrate sources. Therefore TRE is compared with GLUC and IMU compared with SUC.

\section{Results}

\section{Circulating metabolites}

Glucose response

Ingestion of TRE resulted in lower peaks in glucose concentrations when compared with GLUC both during breakfast drinks $(P<0.01)$ and lunch $(P=0.001)$ (Figure $1 A)$. This did, however not result in a significant difference in glycemic response, expressed as iAUC (Table 2). Glucose peaks were lower after ingestion of IMU compared with SUC during breakfast $(P=0.01)$ and lunch $(P=0.001)$ (Figure $1 B)$. There was a reduced incremental glycemic response after ingestion of IMU when combined with a mixed meal $(P<0.001$; Table 3). 


\section{Chapter 3}

Insulin response

TRE resulted in lower peak insulin concentrations when compared with GLUC following breakfast $(P=0.003)$ and lunch $(P=0.025$; Figure $1 C)$. The iAUC was lower after ingestion of TRE compared with GLUC during breakfast $(P=0.009)$ but not when TRE was ingested with a mixed meal during lunch (Table 2). Insulin responses were reduced after ingestion of IMU compared with SUC following breakfast (iAUC, $P \varangle 0.05$ ) and lunch (iAUC, $P=0.001$; Figure 1D, table 3).

FFA response

As expected, plasma FFA concentrations decreased after carbohydrate ingestion. Ingestion of either TRE or GLUC resulted in a similar FFA response pattern, also when ingested in combination with a mixed meal (Figure 1E). There were no significant differences in the integrated decrement between TRE and GLUC (Table 2). Ingestion of IMU in combination with a mixed meal during lunch, resulted in a less inhibition of the decline in plasma FFA concentrations when compared with SUC ( $P \varangle 0.0001$; Figure $1 F$, Table 3 ).

TAG response

TAG concentrations increased after ingestion of the different carbohydrate drinks and when the drinks were ingested in combination with a mixed meal. There were no differences in incremental TAG AUC after ingestion of TRE compared with GLUC during breakfast and lunch (Figure $2 \mathrm{~A}$ and Table 2). There was a trend towards a lower incremental $A U C$ when IMU was ingested in combination with a mixed meal $(P=0.06$; Figure 2B,Table3). 

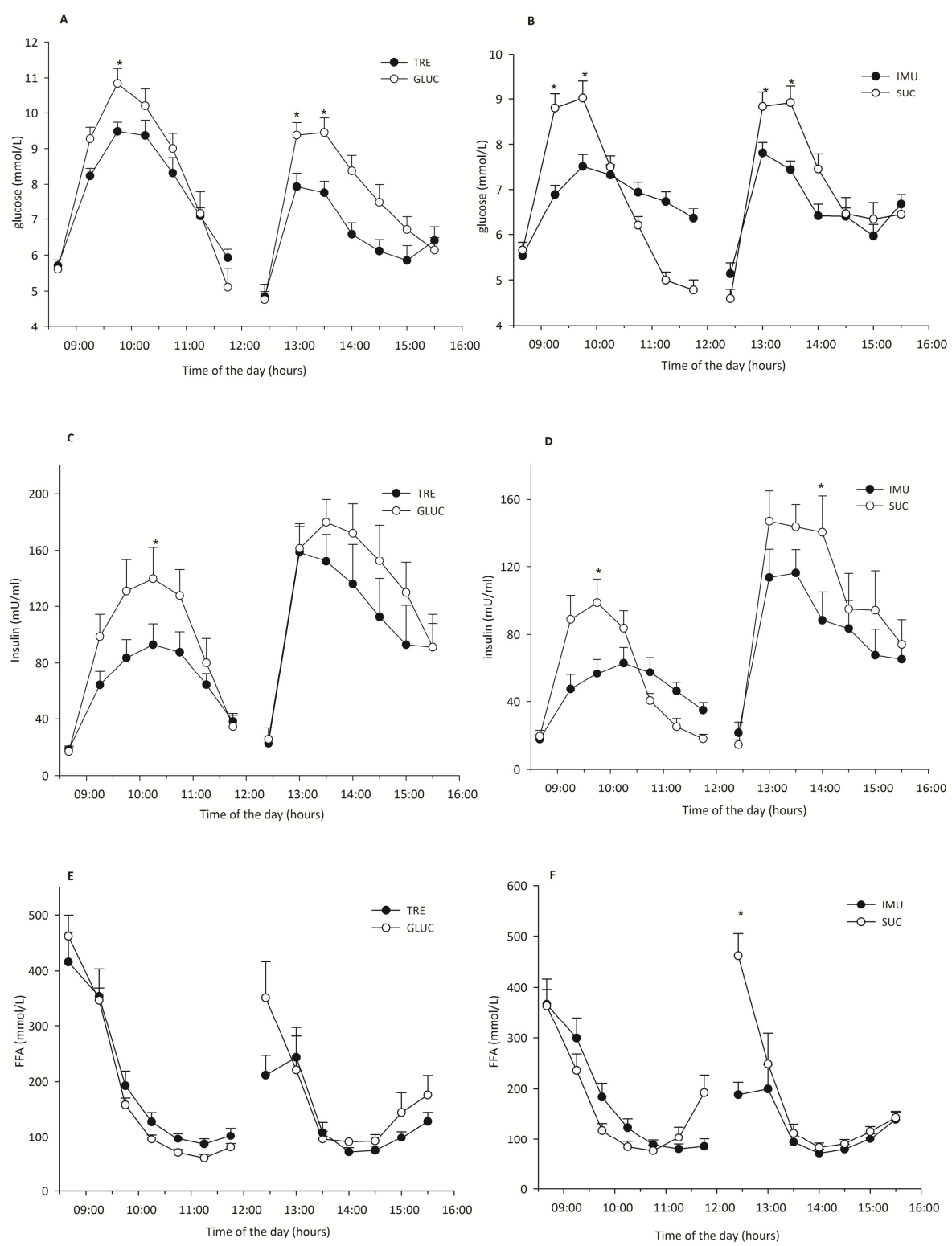

Figure 1. Time course of the glycemic response after intake of trehalose (-•-) and glucose (-o-) (A) and

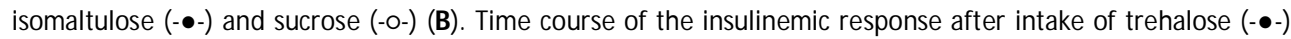
and glucose (-o-) (C) and isomaltulose (- $\bullet-)$ and sucrose (-o-) (D). Time course of the FFA concentrations after

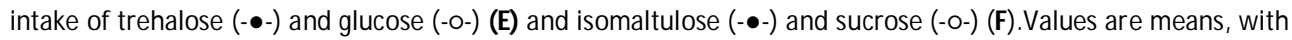
their standard error represented as vertical bars. * $\mathrm{P} \varangle .05$ 


\section{Chapter 3}

Thermogenesis and substrate oxidation

There were no differences in the thermogenic response between carbohydrate drinks during breakfast or when ingested with a mixed meal (Table 2-3).

There were no differences in the incremental AUC of the respiratory quotient (RQ) after TRE ingestion compared with GLUC during breakfast and lunch (Table 2). Intake of IMU did not result in differences in RQ response compared with SUC during breakfast, whereas IMU ingested in combination with a mixed meal resulted in a reduced RQ response compared with SUC ( $P=0.034$; Table 3 ).

There were no significant differences in the decrement in fat oxidation rates between TRE and GLUC during breakfast and lunch (Figure 2B, Table 2). Fat oxidation did not differ between IMU and SUC during breakfast, interestingly fat oxidation was significantly less suppressed after IMU when compared with SUC following lunch ( $P \varangle 0.05$; Figure $2 \mathrm{C}$, Table $3)$.

There were no significant differences in carbohydrate oxidation between TRE and GLUC during breakfast and lunch (Figure 2D, table 2). Intake of IMU did not result in significant differences following breakfast when compared with SUC, whereas the increment in $\mathrm{CHO}$ oxidation was lower after ingestion of IMU when compared with SUC during lunch $(\mathrm{P}=0.036$; Figure $2 \mathrm{E}$, table 3 ).

No differences were observed in the minimal estimates of exogenous $\mathrm{CHO}$ oxidation rates between experiments. The mean percentage of the enriched carbohydrate oxidized, as calculated by the recovery of ${ }^{13} \mathrm{CO}_{2}$ in the expired breath, was $11 \%$ for TRE, $12 \%$ for GLUC, $15 \%$ for IMU and $19 \%$ for SUC respectively. 

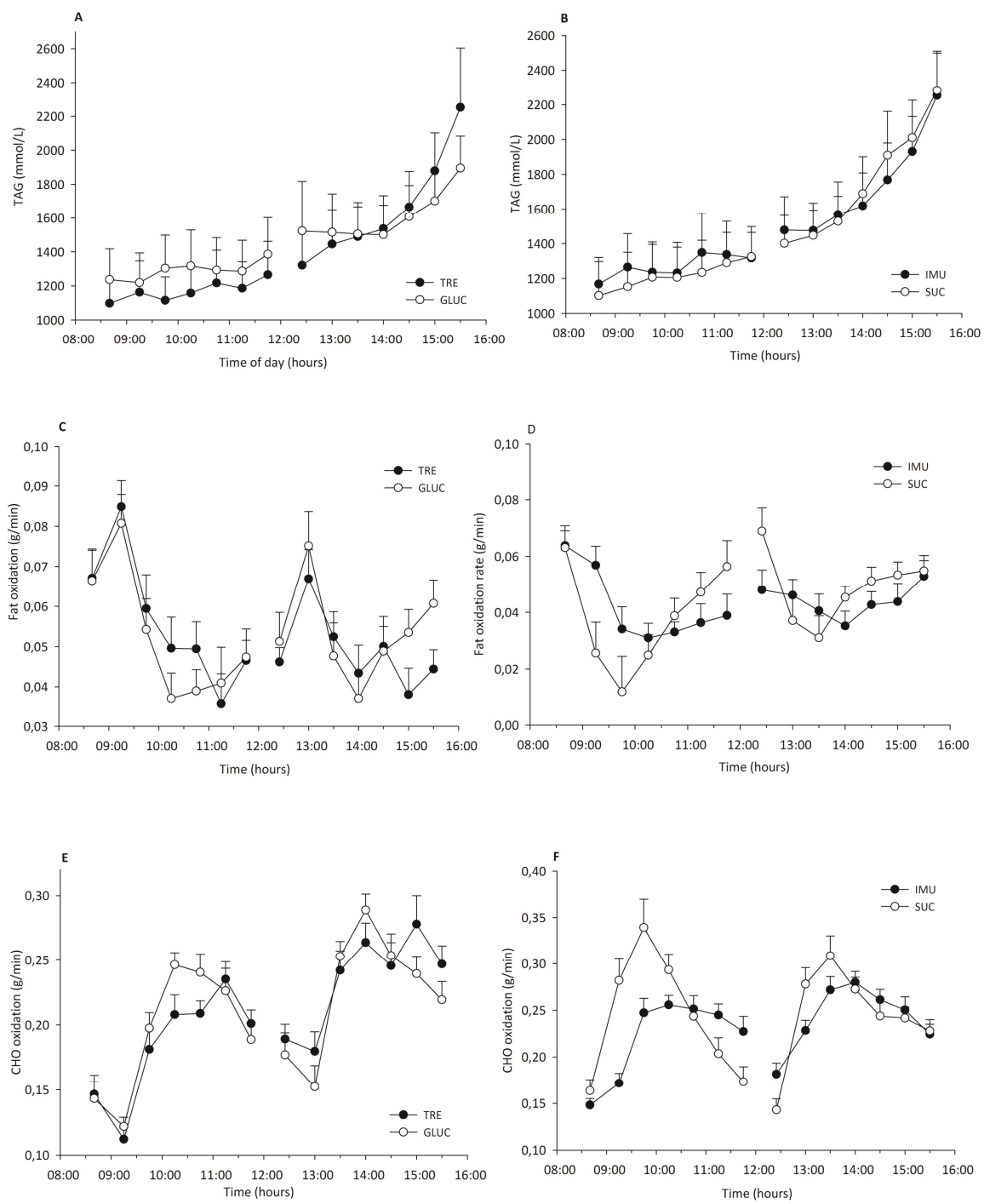

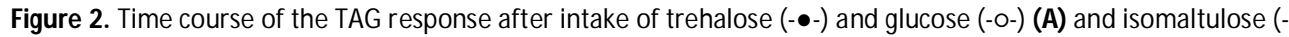
-) and sucrose (-o-) (B). Time course of the fat oxidation rate after intake of trehalose (- $\bullet-)$ and glucose (-o-) (C)

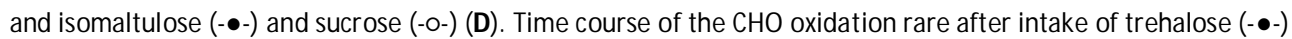
and glucose (-o-) (E) and isomaltulose (- $\bullet-)$ and sucrose (-o-) (F).Values are means, with their standard error represented as vertical bars. * $\mathrm{P} \varangle .05$ 


\section{Chapter 3}

Table 2. M etabolic responses, expressed as change in area under the curve (iAUC), after ingestion of trehalose and glucose.

\begin{tabular}{|c|c|c|c|c|}
\hline & \multicolumn{2}{|c|}{ iAUC breakfast over $3 \mathrm{~h}$} & \multicolumn{2}{|c|}{ iAUC lunch over $3 \mathrm{~h}$} \\
\hline & Trehalose & Glucose & Trehalose & Glucose \\
\hline Glucose (mmol/L over 3h) & 428 & 554 & 374 & 559 \\
\hline Insulin ( $\mu \mathrm{U} / \mathrm{ml}$ over 3h) & $9425^{* *}$ & 15216 & 17934 & 20875 \\
\hline FFA (mmol/L over 3h) & -41527 & -52838 & -15200 & -55284 \\
\hline TAG (mmol/L over 3h) & 13182 & 9158 & 56566 & 6863 \\
\hline Fat oxidation (g over 3h) & -1.32 & -2.66 & 0.62 & 0.38 \\
\hline CHO oxidation (g over 3h) & 6.55 & 10.11 & 8.72 & 9.6 \\
\hline Energy Expenditure (kJ over 3h) & 33 & 53 & 144 & 166 \\
\hline Respiratory Quotient (over 3h) & 5.47 & 7.60 & 1.77 & 2.68 \\
\hline
\end{tabular}

Mean value was significantly different from that for glucose: $* \mathrm{P}, 0 \cdot 05, * * \mathrm{P}, 0 \cdot 01$.

Table 3. Metabolic responses, expressed as change in area under the curve (iAUC), after ingestion of isomaltulose and sucrose.

\begin{tabular}{lllll}
\hline & \multicolumn{2}{l}{ iAUC breakfast over 3h } & \multicolumn{2}{l}{ iAUC lunch over 3h } \\
\cline { 2 - 5 } & Isomaltulose & Sucrose & Isomaltulose & Sucrose \\
\hline Glucose (mmol/L over 3h) & 248 & 266 & $279^{* *}$ & 489 \\
Insulin $(\mu \mathrm{U} / \mathrm{ml}$ over 3h) & $5779^{*}$ & 7326 & $11726^{* *}$ & 17658 \\
FFA (mmol/L over 3h) & -36137 & -38869 & $-12880^{* *}$ & -55284 \\
TAG (mmol/Lover 3h) & 19802 & 20896 & 40787 & 60680 \\
Fat oxidation (g over 3h) & -4.22 & -5.20 & $-0.89^{*}$ & -4.08 \\
CHO oxidation (g over 3h) & 14.14 & 16.19 & $12.27^{*}$ & 23.16 \\
Energy Expenditure (kJ over 3h) & 54 & 55 & 156 & 158 \\
Respiratory Quotient (over 3h) & 11.14 & 13.18 & $4.89^{*}$ & 12.24 \\
\hline
\end{tabular}

M ean value was significantly different from that for sucrose: $* P, 0 \cdot 05, * * P, 0 \cdot 01$. 


\section{Discussion}

\section{Substrate utilization}

The main finding of the present study is that intake of IMU in combination with a mixed meal resulted in an attenuated rise in postprandial plasma glucose and insulin concentrations and a lesser inhibition of circulating FFA concentration and fat oxidation compared to SUC ingestion. The reduced inhibition of postprandial fat oxidation could be attributed to a greater supply of FFA to the fat-oxidizing tissue, secondary to a reduced insulin mediated suppression of lipolysis (32). Our results seem consistent with other work, highlighting the stimulating effects of isomaltulose ingestion on postprandial fat oxidation and/or lipid deposition when compared with sucrose, in rats, healthy and overweight subjects $(19,33,34)$. This study shows that IMU ingestion in exchange for SUC has beneficial effects in subjects with impaired glucose tolerance and, as such, may help to prevent progression into type 2 diabetes.

The attenuated postprandial decline in fat oxidation induced by ingestion of IMU may have implications for body weight control. Flatt proposed that subjects who continue to oxidize carbohydrate in the postabsorptive state deplete their endogenous glycogen stores; thereby stimulating food intake. Through this mechanism, inter-individual differences in substrate selection may play a key role in the development of obesity (35). A lower decrement in circulating FFA and fat oxidation following the ingestion of more slowly digestible carbohydrates may favour fat oxidation above storage, resulting in less fat accumulation in non-adipose tissues with a favourable effect on insulin sensitivity by preventing late hypoglycaemia and the accompanying increase in plasma FFA concentrations (36). High FFA concentrations may be linked with insulin resistance and cardiovascular disease by increasing muscle ectopic fat promoting lipotoxicity which may reduce insulin action (37).

\section{Glycemic and insulinemic responses}

The attenuated glycemic and insulinemic responses following TRE and IMU are attributed to the slower rates at which TRE and IMU are digested and absorbed. Several studies have shown that the absorption rate of TRE and IMU are slower than GLUC and SUC, respectively $(38,39)$. TRE as well as IMU are absorbed and tolerated well in humans (29, 31). Reduced glucose and insulin concentrations after intake of TRE or IMU have been observed in trained athletes, healthy subjects, as well as in overweight subjects (19, 20, $40,41)$. This study is the first to show that intake of TRE and IMU attenuated the 


\section{Chapter 3}

postprandial rise in plasma glucose and insulin concentrations in subjects with IGT. Although, there were no significant differences in the integrated glycemic responses following the ingestion of different carbohydrates after an overnight fast (breakfast), there was a clearly attenuated rise in peak plasma glucose concentration after ingestion of IMU compared with SUC and after ingestion of TRE compared with GLUC (see Figure 1).

\section{Postprandial TAG concentration}

High concentrations of plasma triacylglycerol concentrations are considered to be risk factors for the development of cardiovascular disease (42). Low glycemic, low insulinemic carbohydrate sources may be used to attenuate the postprandial rise in TAG concentrations. However, data show no consensus regarding higher postprandial TAG concentrations following the ingestion of fructose $(43,44)$. In the present study, we observed a trend towards reduced TAG concentrations with ingestion of IMU in combination with a mixed meal compared with SUC, whereas no such differences were observed for TRE. In contrast, in healthy overweight subjects TRE resulted in reduced TAG concentrations during breakfast (20). This discrepancy could be explained by the higher age of the subjects in the present study. Animal as well as human studies generally observed more pronounced effects in younger subjects $(45,46)$.

A limitation of the present study is that the number of subjects is rather small. We cannot rule out gender differences, although the cross-over design limits inter-individual variation. The set-up of the study provides a proof of principle on the impact of trehalose and isomaltulose in the breakfast setting and under more physiological conditions where the drink is consumed in combination with a mixed meal. Further studies are warranted to investigate the overall response and physiological significance of the observed differences.

In conclusion, ingestion of TRE and IMU result in an attenuated postprandial rise in plasma glucose and insulin concentrations when compared with GLU and SUC, respectively. Coingestion of IMU with a mixed meal resulted in an attenuated decline in plasma FFA concentrations and postprandial fat oxidation rate when compared with SUC, which may reduce ectopic fat accumulation and improve insulin sensitivity. Thus, exchanging SUC for IMU may be favourable to prevent metabolic disturbances, thereby potentially slowing down the progression to type 2 diabetes. M ore studies are needed to determine the longterm effects of exchanging rapid for more slowly digestible sugars on body weight control and the prevention of type 2 diabetes in subjects with IGT. 


\section{References}

1. Zimmet P, Alberti KG, Shaw J. Global and societal implications of the diabetes epidemic. Nature 2001;414:782-7.

2. DECODE Study Group tEDEG. Glucose tolerance and cardiovascular mortality: comparison of fasting and 2-hour diagnostic criteria. Arch Intern Med 2001;161:397-405.

3. Knowler WC, Barrett-Connor E, Fowler SE, et al. Reduction in the incidence of type 2 diabetes with lifestyle intervention or metformin. $\mathrm{N}$ Engl J Med 2002;346:393-403.

4. Unwin N, Shaw J, Zimmet P, Alberti KG. Impaired glucose tolerance and impaired fasting glycaemia: the current status on definition and intervention. Diabet Med 2002;19:708-23.

5. Roumen C, Corpeleijn E, Feskens EJ, M ensink M, Saris WH, Blaak EE. Impact of 3year lifestyle intervention on postprandial glucose metabolism: the SLIM study. Diabet Med 2008;25:597-605.

6. Brand-Miller JC. Postprandial glycemia, glycemic index, and the prevention of type 2 diabetes. Am J Clin Nutr 2004;80:243-4.

7. Livesey G. Low-glycaemic diets and health: implications for obesity. Proc Nutr Soc 2005;64:105-13.

8. Ludwig DS. The glycemic index: physiological mechanisms relating to obesity, diabetes, and cardiovascular disease. JAM A 2002;287:2414-23.

9. Brand-Miller J, Hayne S, Petocz P, Colagiuri S. Low-glycemic index diets in the management of diabetes: a meta-analysis of randomized controlled trials. Diabetes Care 2003;26:2261-7.

10. Larsen TM, Dalskov SM, van Baak M, et al. Diets with high or low protein content and glycemic index for weight-loss maintenance. N Engl J Med 2010;363:2102-13.

11. Chong MF, Fielding BA, Frayn KN. Mechanisms for the acute effect of fructose on postprandial lipemia. Am J Clin Nutr 2007;85:1511-20.

12. Swanson JE, Laine DC, Thomas W, Bantle JP. M etabolic effects of dietary fructose in healthy subjects. Am J Clin Nutr 1992;55:851-6.

13. Bantle JP, Raatz SK, Thomas W, Georgopoulos A. Effects of dietary fructose on plasma lipids in healthy subjects. Am J Clin Nutr 2000;72:1128-34.

14. Bossetti BM, Kocher LM, M oranz JF, Falko JM. The effects of physiologic amounts of simple sugars on lipoprotein, glucose, and insulin levels in normal subjects. Diabetes Care 1984;7:309-12.

15. Brand-M iller JC, Holt SH, Pawlak DB, M cM illan J. Glycemic index and obesity. Am J Clin Nutr 2002;76:281S-5S.

16. Pawlak DB, Kushner JA, Ludwig DS. Effects of dietary glycaemic index on adiposity, glucose homoeostasis, and plasma lipids in animals. Lancet 2004;364:778-85. 
17. Scribner KB, Pawlak DB, Aubin CM, Majzoub JA, Ludwig DS. Long-term effects of dietary glycemic index on adiposity, energy metabolism, and physical activity in mice. Am J Physiol Endocrinol M etab 2008;295:E1126-31.

18. Isken F, Klaus S, Petzke KJ, Loddenkemper C, Pfeiffer AF, Weickert MO. Impairment of fat oxidation under high- vs. low-glycemic index diet occurs before the development of an obese phenotype. Am J Physiol Endocrinol Metab 2010;298:E287-95.

19. van Can JG, Ijzerman TH, van Loon LJ, Brouns F, Blaak EE. Reduced glycaemic and insulinaemic responses following isomaltulose ingestion: implications for postprandial substrate use. Br J Nutr 2009;102:1408-13.

20. van Can JG, ljzerman TH, van Loon LJ, Brouns F, Blaak EE. Reduced glycaemic and insulinaemic responses following trehalose ingestion: implications for postprandial substrate use. Br J Nutr 2009;102:1395-9.

21. Stevenson EJ, Thelwall PE, Thomas K, Smith F, Brand-Miller J, Trenell MI. Dietary glycemic index influences lipid oxidation but not muscle or liver glycogen oxidation during exercise. Am J Physiol Endocrinol M etab 2009;296:E1140-7.

22. Corpeleijn E, Mensink M, Kooi ME, Roekaerts PM, Saris WH, Blaak EE. Impaired skeletal muscle substrate oxidation in glucose-intolerant men improves after weight loss. Obesity (Silver Spring) 2008;16:1025-32.

23. M ensink M, Blaak EE, van Baak M A, Wagenmakers AJ, Saris WH. Plasma free Fatty Acid uptake and oxidation are already diminished in subjects at high risk for developing type 2 diabetes. Diabetes 2001;50:2548-54.

24. Adriaens MP, Schoffelen PF, Westerterp KR. Intra-individual variation of basal metabolic rate and the influence of daily habitual physical activity before testing. Br J Nutr 2003;90:419-23.

25. Schoffelen PF, Westerterp KR, Saris WH, Ten Hoor F. A dual-respiration chamber system with automated calibration. J Appl Physiol 1997;83:2064-72.

26. Weir JB. New methods for calculating metabolic rate with special reference to protein metabolism. J Physiol 1949;109:1-9.

27. Frayn KN. Calculation of substrate oxidation rates in vivo from gaseous exchange. J Appl Physiol 1983;55:628-34.

28. Harris J, Benedict F. A biometric study of basal metabolism in man. Washington, DC: Carnegie Institute of Washington, 1919:1-266.

29. Richards $A B$, Krakowka $S$, Dexter LB, et al. Trehalose: a review of properties, history of use and human tolerance, and results of multiple safety studies. Food Chem Toxicol 2002;40:871-98.

30. Dahlqvist A. Specificity of the human intestinal disaccharidases and implications for hereditary disaccharide intolerance. J Clin Invest 1962;41:463-70.

31. Lina BA, Jonker D, Kozianowski G. Isomaltulose (Palatinose): a review of biological and toxicological studies. Food Chem Toxicol 2002;40:1375-81.

32. Wolever TM, Mehling C. Long-term effect of varying the source or amount of dietary carbohydrate on postprandial plasma glucose, insulin, triacylglycerol, and free fatty acid concentrations in subjects with impaired glucose tolerance. Am J Clin Nutr 2003;77:612-21. 
33. Sato K, Arai H, Mizuno A, et al. Dietary palatinose and oleic acid ameliorate disorders of glucose and lipid metabolism in Zucker fatty rats. J Nutr 2007;137:1908-15.

34. Arai $H$, Mizuno A, Sakuma $M$, et al. Effects of a palatinose-based liquid diet (Inslow) on glycemic control and the second-meal effect in healthy men. Metabolism 2007;56:115-21.

35. Flatt JP. Carbohydrate balance and body-weight regulation. Proc Nutr Soc 1996;55:449-65.

36. Jenkins DJ, Wolever TM, Ocana AM, et al. Metabolic effects of reducing rate of glucose ingestion by single bolus versus continuous sipping. Diabetes 1990;39:775-81.

37. Bays $H, M$ andarino L, DeFronzo RA. Role of the adipocyte, free fatty acids, and ectopic fat in pathogenesis of type 2 diabetes mellitus: peroxisomal proliferatoractivated receptor agonists provide a rational therapeutic approach. J Clin Endocrinol Metab 2004;89:463-78.

38. Dahlquist A, Thomson DL. The Digestion and Absorption of M altose and Trehalose by the Intact Rat. Acta Physiol Scand 1963;59:111-25.

39. Dahlqvist A, Auricchio S, Semenza G, Prader A. Human intestinal disaccharidases and hereditary disaccharide intolerance. The hydrolysis of sucrose, isomaltose, palatinose (isomaltulose), and a 1,6-alpha-oligosaccharide (isomaltooligosaccharide) preparation. J Clin Invest 1963;42:556-62.

40. Kawai K, Okuda Y, Yamashita K. Changes in blood glucose and insulin after an oral palatinose administration in normal subjects. Endocrinol Jpn 1985;32:933-6.

41. Jentjens RL, Jeukendrup AE. Effects of pre-exercise ingestion of trehalose, galactose and glucose on subsequent metabolism and cycling performance. Eur J Appl Physiol 2003;88:459-65.

42. Sparks JD, Sparks CE. Insulin regulation of triacylglycerol-rich lipoprotein synthesis and secretion. Biochim Biophys Acta 1994;1215:9-32.

43. Bouche C, Rizkalla SW, Luo J, et al. Five-week, low-glycemic index diet decreases total fat mass and improves plasma lipid profile in moderately overweight nondiabetic men. Diabetes Care 2002;25:822-8.

44. Teff KL, Elliott SS, Tschop M, et al. Dietary fructose reduces circulating insulin and leptin, attenuates postprandial suppression of ghrelin, and increases triglycerides in women. J Clin Endocrinol M etab 2004;89:2963-72.

45. Isken $\mathrm{F}$, Weickert MO, Tschop MH, et al. Metabolic effects of diets differing in glycaemic index depend on age and endogenous glucose-dependent insulinotrophic polypeptide in mice. Diabetologia 2009;52:2159-68.

46. van Dam RM, Visscher AW, Feskens EJ, Verhoef P, Kromhout D. Dietary glycemic index in relation to metabolic risk factors and incidence of coronary heart disease: the Zutphen Elderly Study. Eur J Clin Nutr 2000;54:726-31. 
Chapter 3 


\section{Chapter 4}

\section{A 3 day EGCG supplementation reduces interstitial lactate concentration in skeletal muscle in overweight subjects}

Judith GP van Can, Jan-Willen van Dijk, Gijs G Goossens, Johan Jocken, Jeannette J Hospers, Igor Bendik and Ellen E Blaak (submitted). 


\section{Abstract}

Introduction: Green tea, particularly the catechin epigallocatechin-3-gallate (EGCG), may affect body weight and composition. The underlying mechanism may relate to an enhanced lipolysis and fat oxidation.

Aim: To investigate the effects of a 3 day supplementation of $300 \mathrm{mg}$ EGCG on fat oxidation in overweight subjects.

Design: In a double-blind randomized, cross-over study, 24 subjects $(9 \mathrm{M} / 15 \mathrm{~F}$, age $=30 \pm 2$ $y, B M I=27.7 \pm 0.3 \mathrm{~kg} / \mathrm{m}^{2}$ ) received $300 \mathrm{mg} /$ day EGCG or placebo for 3 days. Energy expenditure, substrate metabolism and circulating metabolites, were determined at baseline and for 6 hours after ingestion of a mixed meal (energy content was $40 \%$ of calculated energy expenditure). After $6 \mathrm{~h}$, a fat biopsy was collected to examine gene expression of factors involved in fatty acid handling. In 12 subjects, adipose tissue and skeletal muscle glycerol, glucose and lactate concentrations were determined by the microdialysis technique.

Results: EGCG supplementation had no effects on energy expenditure, fat and carbohydrate oxidation compared to placebo. Although EGCG reduced circulating glycerol concentrations, no differences in adipose tissue and skeletal muscle lipolysis were observed. Fasting $(P=0.001)$ and postprandial $(P=0.003)$ skeletal muscle lactate concentration were reduced after EGCG supplementation compared to placebo, despite similar tissue blood flow. Adipose tissue leptin expression was increased $(P=0.05)$ and FAT/CD36 expression tended to be increased after EGCG as compared with placebo $(P=0.08)$.

Conclusions: Although whole body fat oxidation was unaltered, skeletal muscle lactate concentration was reduced after EGCG supplementation, suggesting a reduced glycolytic flux and a shift towards a more oxidative muscle phenotype. The underlying mechanism needs to be examined more extensively. 


\section{Introduction}

The prevalence of obesity has become an epidemic problem during the last few decades (1). Being overweight or obese is considered to be the most important risk factor for the onset of type 2 diabetes mellitus (2).

In recent years there has been an increased interest in the health benefits of polyphenols in the prevention of obesity and type 2 diabetes mellitus. Green tea is rich in polyphenols, especially catechins. These catechins are comprised primarily of epigallocatechin gallate (EGCG), epigallocatechin (EGC), and epicatechin (EC) (3). Many of the beneficial health effects of green tea have been attributed to the most abundant catechin, EGCG and were initially mainly related to their anti-oxidant activity (4-7). More recently, interest has increased in the anti-obesity effect of green tea. Consumption of green tea extracts (270 mg EGCG) in combination with caffeine supplementation (150-600 mg caffeine) has been shown to increase fat oxidation and energy expenditure in an acute manner, and to reduce body weight in normal to overweight subjects (8-12). Moreover, Venables et al. has shown that consumption of a green tea extract ( $890 \mathrm{mg}$ polyphenols + $366 \mathrm{mg}$ EGCG) increased fat oxidation during moderate-intensity exercise (13). Furthermore, green tea may increase insulin sensitivity, possibly by increasing fat oxidation and reducing ectopic fat accumulation, thereby reducing the risk of developing type 2 diabetes. A crosssectional study showed an inverse association between green tea consumption and fasting glucose concentrations (14). Additionally, 12 day supplementation of green tea in Sprague-Dawley rats increased insulin sensitivity (15). Results of human intervention studies are not consistent yet $(16,17)$.

The underlying mechanisms behind the possible effect of green tea components on energy expenditure and fat oxidation are not well studied in humans yet. One of the putative mechanisms is that EGCG may modulate energy expenditure by inhibiting catechol-o-methyltransferase (COMT), an enzyme involved in the degradation of norepinephrine. As a consequence there is a prolonged stimulation of the adrenergic receptors, thereby increasing lipolysis and fat oxidation (18). Another mechanism may involve activation of sirtuins, especially sirtuin1 (SIRT1) and its transcriptional co-factor Peroxisome proliferator-activated receptor- $\gamma$ coactivator 1 alpha (PGC-1 $\alpha$ ), although data are not consistent yet and few human intervention data are available (19-22).

Watanabe et al. has shown that EGCG inhibited acetyl CoA-carboxylase (ACC) in 3T3-L1 cells suggesting that EGCG could alter the partitioning of lipids from storage towards oxidation (23). In addition, chronic feeding of green tea extract to mice has been shown to elevate skeletal muscle gene expression of factors involved in lipid transport and 


\section{Chapter 4}

oxidation, such as FAT/CD36, medium-chain acyl-CoA dehydrogenase (MCAD) and uncoupling protein 3 (UCP3) $(24,25)$. In a similar study, green tea extract reduced malonyl-CoA in skeletal muscle, which is an inhibitor of carnitine palmitoyl transferase (CPT), an enzyme involved in fatty acid transportation into the mitochondria (26). Whether the effects of EGCG and/or green tea extract on gene expression are acute, either through a direct regulatory action or due to the transient increase in free fatty acids (FFA) chronically, remains to be established.

We hypothesized that a 3 day supplementation of $300 \mathrm{mg} /$ day EGCG would increase postprandial fat oxidation accompanied by stimulation of postprandial lipolysis. In a subset of 12 subjects local adipose tissue and skeletal muscle metabolism was investigated by the microdialysis technique. Finally, molecular pathways were studied in adipose tissue by determining gene expression of enzymes involved in lipolysis and fatty acid partitioning.

\section{Methods}

\section{Ethics Statement}

The study was reviewed and approved by the Medical Ethical Committee of the Maastricht University Medical Centre ${ }^{+}$and all subjects gave written informed consent before participation.

Subjects

Twenty-four overweight men $(n=9)$ and women $(n=15)$ with a low habitual caffeine intake $(<300 \mathrm{mg} /$ day) were recruited for this study. Subjects' characteristics are presented in table 1. Subjects with type 2 diabetes and/or overt cardiovascular complications, and those using medication for digestive disorders were excluded from participation. All subjects tolerated the EGCG capsules well and no adverse effects were observed on liver enzymes ALAT and ASAT.

\section{Study design}

The effects of EGCG and placebo on postprandial fat oxidation were studied in a double blind, randomised cross-over design, with a washout of at least 4 days between both treatments. Subjects consumed the capsules during 2 days with breakfast and dinner (at both occasions 1 capsule of $150 \mathrm{mg}$ ). At day 3 , subjects came to the university for a postprandial test (test day). At this day the 2 capsules were ingested simultaneously, $1 \mathrm{~h}$ before the ingestion of a liquid mixed meal. 
Table 1. Subjects' characteristic's

\begin{tabular}{ll}
\hline & Mean \pm SEM $(\mathrm{N}=24,9 \mathrm{M} / 15 \mathrm{~F})$ \\
\hline Age (years) & $30 \pm 2$ \\
BMI (kg/ $\left.\mathrm{m}^{2}\right)$ & $27.7 \pm 0.3$ \\
Waist circumference $(\mathrm{cm})$ & $89 \pm 1.7$ \\
Hip circumference $(\mathrm{cm})$ & $99 \pm 1.1$ \\
WHR & $0.9 \pm 0.01$ \\
Fat mass $(\%)$ & $28.8 \pm 1.9$ \\
Fat free mass (\%) & $71.2 \pm 1.9$ \\
Glucose $(\mathrm{mmol} / \mathrm{L})$ & $5.2 \pm 0.06$ \\
Insulin $(\mu \mathrm{U} / \mathrm{mL})$ & $12.5 \pm 0.7$ \\
HOM A-IR & $2.9 \pm 0.2$ \\
Systolic blood pressure $(\mathrm{mmHg})$ & $114 \pm 2$ \\
Diastolic blood pressure $(\mathrm{mmHg})$ & $75 \pm 1$ \\
\hline
\end{tabular}

Test product

The test product EGCG (Teavigo TG Lot: UT05080001) was provided by DSM Nutritional Products Ltd to Temmler Werke GmbH (M unchen, Germany). All capsules supplied by Temmler Werke $\mathrm{GmbH}$ were manufactured, tested and released according to Good Manufacturing Practice (GMP) guidelines. Teavigo TG ${ }^{\mathrm{TM}}$ contains $>90 \%$ EGCG on a dry weight basis. The placebo capsules were made from cellulose. The capsules were of identical appearance containing either $150 \mathrm{mg}$ EGCG or placebo. The dose of $300 \mathrm{mg}$ EGCG per day has been shown to be safe and well tolerated. This applied to single doses as well as repeated dosing $(27,28)$.

Protocol Test day

All subjects were asked to refrain from drinking alcohol, smoking and doing strenuous exercise for a period of $24 \mathrm{~h}$ before the test day. Subjects came to the laboratory by car or bus in the morning after an overnight fast. At the beginning of the test day (day 3), a cannula was inserted into an antecubital vein for blood sampling. The EGCG or placebo capsules were consumed $1 \mathrm{~h}$ before metabolic testing and a fasting blood sample was drawn to determine baseline values of EGCG ( $t=-65 \mathrm{~min}$ ). A liquid test meal was consumed 60 min after ingestion of EGCG/placebo capsules. Blood samples were taken before ingestion of the liquid meal ( $t=-5 \mathrm{~min}$ ) and for $6 \mathrm{~h}$ after meal ingestion at $\mathrm{t}=30,60$, $90,120,180,240,300$ and 360 min after EGCG/placebo ingestion to determine circulating 


\section{Chapter 4}

metabolites and hormone concentrations. Energy expenditure and substrate utilization were measured, before and for $6 \mathrm{~h}$ after ingestion of the liquid test meal, using a ventilated hood system (Omnical, Maastricht University, The Netherlands) (29). Gas analyses, which occurred every minute, are performed by dual paramagnetic $\mathrm{O}_{2}$ analysers and dual infrared $\mathrm{CO}_{2}$ analysers (type 1156, 1507, 1520; Servomex, Cowborough, Sussex, UK), similar to the analysis system described by Schoffelen et al (30).

The liquid meal had a total energy content equivalent of $40 \%$ of calculated $24 \mathrm{~h}$ resting energy expenditure based upon the formula of Harris and Benedict (31). The energy content of the test meal was accounted for $49 \mathrm{En} \% \mathrm{CHO}, 35 \mathrm{En} \%$ FAT and $16 \mathrm{En} \%$ protein and was consumed within 20 minutes. A fat biopsy was taken at the end of the $6 \mathrm{~h}$ postprandial period in each condition $(t=360 \mathrm{~min}$ ). Blood samples and fat biopsy were snap frozen in liquid nitrogen and stored at $-80^{\circ} \mathrm{C}$ until analysis.

\section{Fat biopsy}

A small amount (about $1 \mathrm{~g}$ ) of abdominal subcutaneous adipose tissue was collected under local anesthesia using a needle biopsy technique and snap frozen in liquid nitrogen. Total RNA was isolated, using the total RNA stabilization and purification kit for human samples Qiagen (Qiagen, Hombrechtikon, Switzerland). Gene expression of hormonesensitive lipase (HSL), adipose triglyceride lipase (ATGL), CPT-1, ACC-1, fatty acid translocase (FAT/CD36) and leptin was measured by the Taqman multiplex method using the ABI 7900 quantitative real-time RT-PCR instrument (Applied Biosystems, Rotkreuz, Switzerland) as described by Heim (32). All probe and primer sets were designed with the Primer Express program version 1.0 (Applied Biosystems) and initially tested to have comparable ( $>90 \%)$ efficiency in multiplex assays using $18 \mathrm{~S}$ rRNA as an internal control. An overview of the primers and probes is listed in table 2 .

\section{Microdialysis}

In a subset of 12 subjects, the lipolytic effects of EGCG in adipose tissue and skeletal muscle were determined by the microdialysis technique.

On arrival, four microdialysis probes (CM A 60, CM A microdialysis AB, Stockholm Sweden) were inserted. Two microdialysis probes were placed in the abdominal subcutaneous adipose tissue under sterile conditions $6-8 \mathrm{~cm}$ left and right from the umbilicus. One hour before insertion of these probes, the skin was anesthesized by means of a cream containing lidocaine $(25 \mathrm{mg} / \mathrm{g})$ and prilocaine $(25 \mathrm{mg} / \mathrm{g}$ ) (EMLA, Astra Zeneca, Sweden). Furthermore, two microdialysis probes were inserted in the medial portion of the $\mathrm{m}$. gastrocnemius of both legs after anesthesia (xylocaine $2 \%$ without adrenalin, Astra 88 
Zeneca). Thereafter, 90 min was allowed for recovery of adipose tissue and muscle from insertion trauma.

In both adipose tissue and skeletal muscle, one probe in both adipose tissue and skeletal muscle was perfused with Ringer's solution (147 mM sodium, 4mM potassium, $2.25 \mathrm{mM}$ calcium and $156 \mathrm{mM}$ chloride, Baxter BV, Utrecht, The Netherlands) at a rate of $0.3 \mu \mathrm{l} / \mathrm{min}$ to obtain a near $100 \%$ recovery. Microdialysate was collected from these probes in $30 \mathrm{~min}$ fractions during the baseline period and during the early postprandial period (0-120 $\mathrm{min})$ and at $60 \mathrm{~min}$ fractions during the last $4 \mathrm{~h}$ postprandially (120-360 $\mathrm{min}$ ), to determine glycerol, glucose and lactate concentrations. Baseline concentrations of glycerol, lactate and glucose were determined by the average of three baseline samples. The second microdialysis probe in adipose tissue and in skeletal muscle was used for determining tissue blood flow using the ethanol dilution technique $(33,34)$. For this, the probes were perfused with Ringer's solution supplemented with $50 \mathrm{mM}$ ethanol, at a flow rate of 5 $\mu \mathrm{l} / \mathrm{min}$ (Harvard microinfusion pump, Plato BV, Diemen, The Netherlands).

Ethanol concentrations were determined both in the ingoing and outgoing perfusion solvent to assess the ethanol inflow/outflow ratio as an indicator for local nutritive blood flow. Ethanol concentrations were determined at the same day, whereas microdialysate samples for measurement of glycerol, glucose and lactate concentrations were immediately frozen and stored at $-80^{\circ} \mathrm{C}$ until analysis.

\section{Biochemical analyses}

At all time points, $8 \mathrm{ml}$ blood was collected in pre-chilled tubes with $200 \mu \mathrm{l}$ of $0.2 \mathrm{M}$ EDTA (Sigma, Dorset, UK). After collection, blood samples were centrifuged immediately at $4^{\circ} \mathrm{C}$ for $10 \mathrm{~min}$ at $1000 \mathrm{~g}$ and frozen at $-80^{\circ} \mathrm{C}$ until analysis. Additionally, 500 $\mu$ l of the cell free plasma supernatant was combined with exactly 500 ul stabilization buffer at ambient temperature for the determination of EGCG concentration by HPLC. Plasma glucose (Uni Kit III, Roche, Basel, Switzerland), lactate, FFA (NEFA-C, Wako Chemicals, Neuss, Germany), triacylglycerol and free glycerol (148270, Roche Diagnostics, Indianapolis, IN, USA) concentrations will be analyzed with a COBAS FARA semi-automatic analyzer (Roche). Insulin will be analyzed by radioimmunoassay (Human Insulin RIA Kit, LINCO Research Inc, St. Charles, MO).

Glycerol, glucose and lactate concentrations from the microdialysates were measured by bioluminescence (35). Ethanol concentrations were measured spectrophotometrically using a standard enzymatic technique (R-Biopharm AG, Darmstadt, Germany). 


\section{Chapter 4}

\section{Calculations}

Substrate oxidation was calculated from $\mathrm{VO}_{2}(\mathrm{~L} / \mathrm{min})$ and $\mathrm{VCO}_{2}(\mathrm{~L} / \mathrm{min})$ according to the equations of Frayn (36). Nitrogen excretion was calculated based on the assumption that protein oxidation represents $\sim 15 \%$ of total energy expenditure. Energy expenditure was calculated using the formula of Weir (37).

Carbohydrate oxidation $(\mathrm{CHO})(\mathrm{g} / \mathrm{min})=\left(4.55 * \mathrm{VCO}_{2}\right)-\left(3.21 * \mathrm{VO}_{2}\right)-(2.87 * \mathrm{~N})$

FAT oxidation $(\mathrm{g} / \mathrm{min})=\left(1.67 * \mathrm{VO}_{2}\right)-\left(1.67 * \mathrm{VCO}_{2}\right)-(1.92 * \mathrm{~N})$

$\mathrm{N}(\mathrm{g} / \mathrm{min})=\left(\left(0.15^{*} \mathrm{EE}\right) / 17\right) / 6.25$

Statistics

All data are expressed as means \pm SEM. The total response of parameters after ingestion EGCG or placebo was expressed as the total area under the curve (AUC) and calculated by the trapezoid method. Differences between placebo and EGCG were analyzed by means of student's paired t-test. Normal distribution was tested by the Kolmogorov-Smirnov test. If parameters were not normally distributed they were In transformed. Plasma lactate, TAG, glycerol and the genes CPT-1, ACC-1, HSL and leptin data were In transformed. SPSS 15 for Windows was used to perform all calculation. The level of statistical significance was set at $P \leq 0.05$.

\section{Results}

Circulating metabolites

EGCG supplementation showed no differences in plasma glucose and insulin concentration compared to placebo (Figure 1A-B). Plasma free fatty acids (FFA) concentrations tended to be reduced after EGCG supplementation (AUC, $P=0.07$ ) (Figure 1D). Also, plasma glycerol concentrations were reduced after EGCG supplementation as compared with placebo ( $A \cup C, P=0.02$ ) which was most pronounced in the late postprandial period (240-360 $\mathrm{min}$ ) (Figure 1E). EGCG supplementation did not induce differences in plasma lactate and triglyceride concentrations (TAG), although fasting TAG concentration tended to be reduced after EGCG $(P=0.07)$ (Figure $1 C, 1 F)$. 


\section{Energy expenditure and substrate oxidation}

Supplementation of $300 \mathrm{mg} /$ day EGCG did not change fat and $\mathrm{CHO}$ oxidation (Figure 2AB). Similarly, there were no differences in energy expenditure between conditions (Figure 2C).
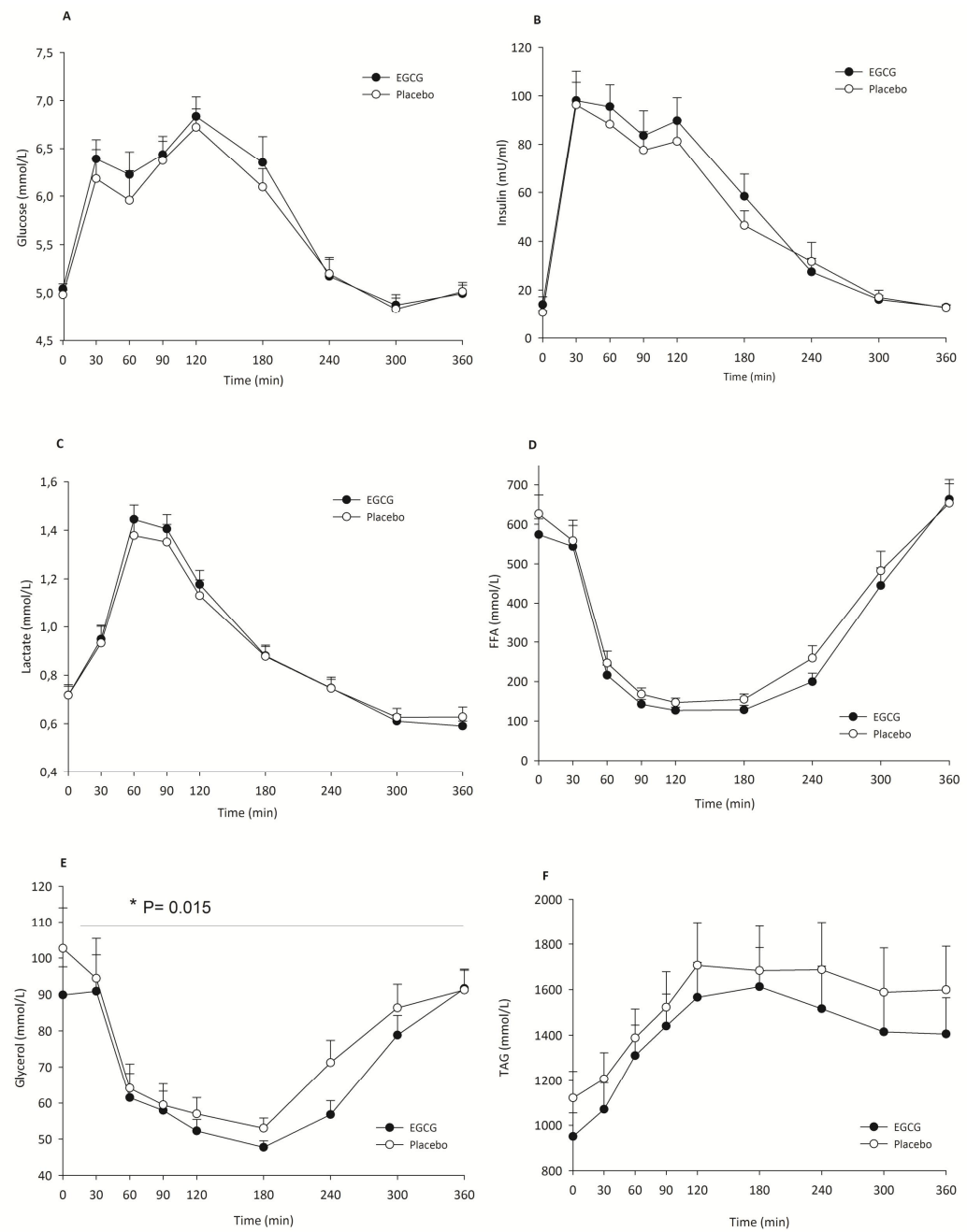

Figure 1. A Time-course of systemic glycemic response after intake of $300 \mathrm{mg} /$ day EGCG or placebo. B Timecourse of systemic insulinemic response after intake $300 \mathrm{mg} /$ day EGCG or placebo. C Time-course of systemic lactate concentrations after intake of $300 \mathrm{mg} /$ day EGCG or placebo. D Time-course of systemic FFA concentrations after intake of $300 \mathrm{mg} /$ day EGCG or placebo. E Time-course of systemic glycerol concentrations after intake of $300 \mathrm{mg} /$ day EGCG or placebo. $\mathbf{F}$ Time-course of systemic TAG concentrations after intake of $300 \mathrm{mg} /$ day EGCG or placebo. Results represent mean values \pm SEM; $n=24 ; *: P \leq 0.05$ 


\section{Chapter 4}

A
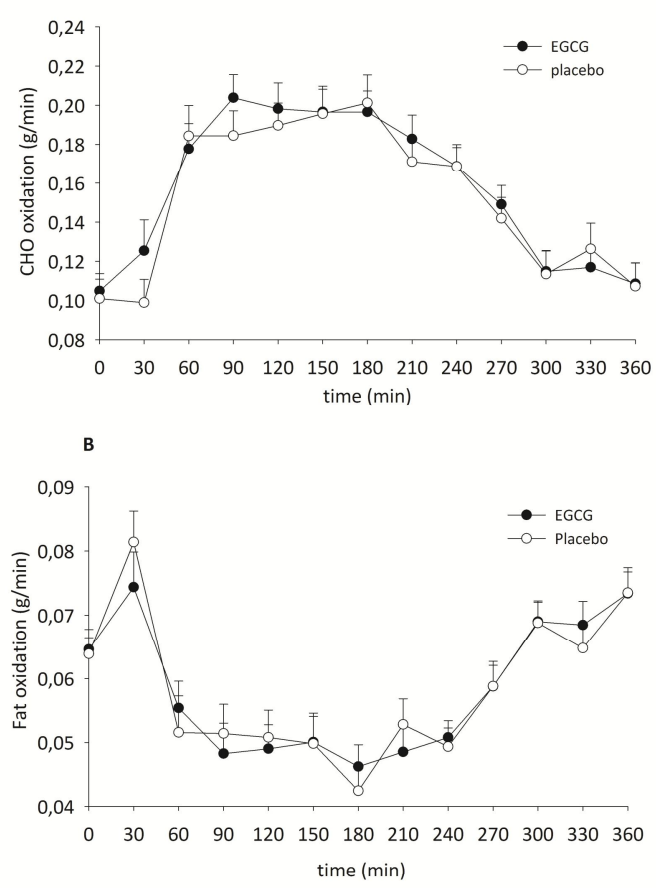

C

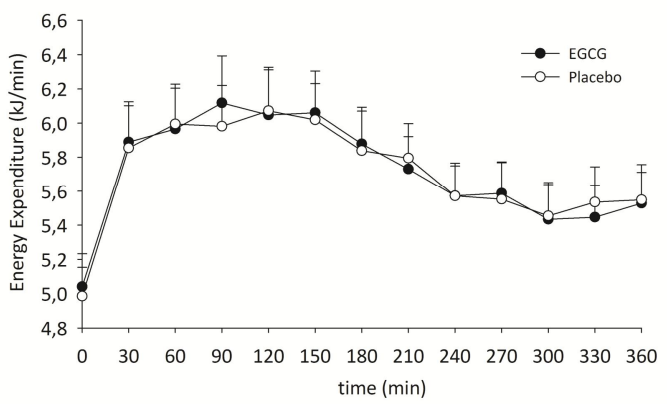

Figure 2. A Time-course of $\mathrm{CHO}$ oxidation rate after intake of $300 \mathrm{mg} /$ day EGCG or placebo. B Time-course of fat oxidation rate after intake $300 \mathrm{mg} /$ day EGCG or placebo. C Time-course of energy expenditure after intake of $300 \mathrm{mg} /$ day EGCG or placebo. Results represent mean values $\pm \mathrm{SEM} ; \mathrm{n}=24 ; *: \mathrm{P} \leq 0.05$ 

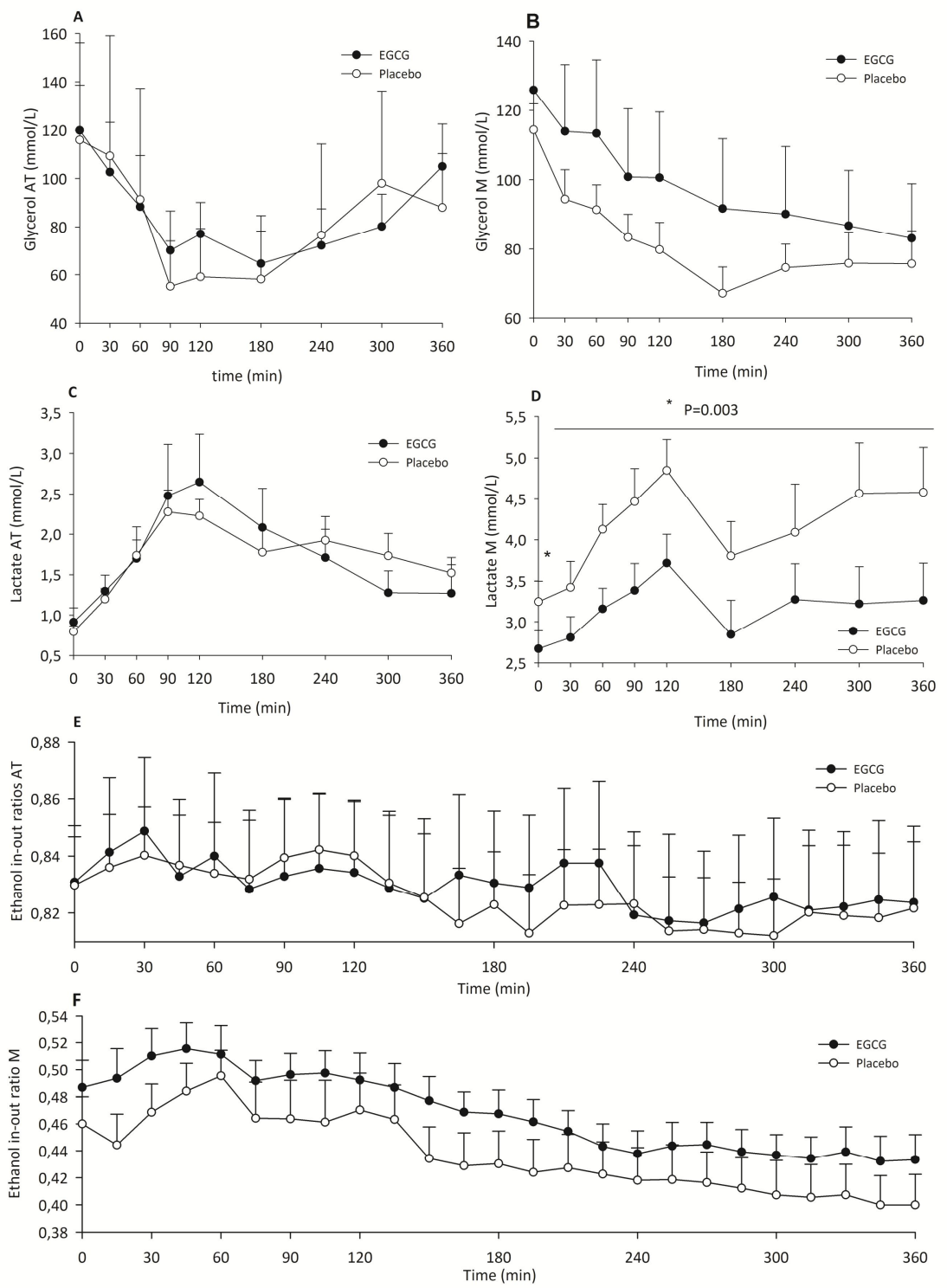

Figure 3. A-B Time-course of interstitial glycerol concentrations in adipose tissue (AT) and skeletal muscle (M) after intake of $300 \mathrm{mg} /$ day EGCG or placebo. C-D Time-course of interstitial lactate concentrations in adipose tissue and skeletal muscle after intake of $300 \mathrm{mg} /$ day EGCG or placebo. E-F Time-course of ethanol in-out ratio in adipose tissue and skeletal muscle after intake of $300 \mathrm{mg} /$ day EGCG or placebo. Results represent mean \pm SEM ; $\mathrm{n}=12 . *$ : $\mathrm{P} \leq 0.05$ 


\section{Chapter 4}

Adipose tissue and skeletal muscle lipolysis

Due to a problem with the microdialysis probes in the adipose tissue, the data of only 6 of the 12 subjects could be analysed. Adipose tissue glycerol, glucose and lactate concentrations, as well as ethanol in-out ratio, were comparable after EGCG supplementation compared to placebo (Figure 3A,C,E, data for glucose not shown).

Skeletal muscle interstitial glycerol, glucose concentrations, as well as ethanol in-out ratio were not different between EGCG supplementation and placebo (Figure 3B,F, glucose data not shown). In skeletal muscle, interstitial lactate was reduced with EGCG both for baseline levels ( $P \varangle 0.001$ ) as well during the postprandial period ( $P=0.003$ ) (Figure 3D).

Adipose tissue gene and protein expression

The mRNA expression of CPT-1, ACC-1, ATGL and HSL were similar after consuming EGCG or placebo capsules. EGCG increased leptin $(P=0.05)$ and $F A T / C D 36(P=0.08)$ mRNA expression compared to placebo (Table 3).

Table 2. Overview of primers and probes for RT-PCR of adipose tissue biopsies.

\begin{tabular}{|c|c|c|c|}
\hline & forward & reverse & Probes \\
\hline $18 \mathrm{~S}$ & CGGCTACCACATCCAAGGAA & GCTGGAATTACCGCGGCT & $\begin{array}{l}\text { 5'-VIC- } \\
\text { TGCTGGCACCAGACTTGCCCTC- } \\
\text { TAM RA-3 }\end{array}$ \\
\hline HSL & $\begin{array}{l}\text { CTGCATAAGGGATGCTTCTATG } \\
\text { G }\end{array}$ & CCTGTCTCGTTGCGTTGTAGT & $\begin{array}{l}\text { 5'-FAM- } \\
\text { CTGCCTGGGCTTCCAGTTCACGC- } \\
\text { TAM RA-3 }\end{array}$ \\
\hline ATGL & $\begin{array}{l}\text { TAGAGTGGCAGGTTGTCTGAAA } \\
\text { TG }\end{array}$ & CCCGTGTACTGTGGGCTCAT & $\begin{array}{l}\text { 5'-FAM- } \\
\text { CACCATCCACGTAGCGCACCCC - } \\
\text { TAM RA-3 }\end{array}$ \\
\hline $\begin{array}{l}\text { CPT } \\
-1\end{array}$ & CCATGTTGTACAGCTTCCAGACA & $\begin{array}{l}\text { CACCGACTGTAGATACCTGTTCA } \\
\text { CA }\end{array}$ & $\begin{array}{l}\text { 5'-FAM - CTGCCTCGCCTGCCGGTCC- } \\
\text { TAM RA-3 }\end{array}$ \\
\hline ACC-1 & CAGCAGGCTGAACTTCACACA & CTGGAAGGCAGTATCCATTCATT & $\begin{array}{l}\text { 5'-FAM- } \\
\text { CACGGATCCAGAGCACGGCACTC- } \\
\text { TAM RA-3 }\end{array}$ \\
\hline $\begin{array}{l}\text { Lepti } \\
n\end{array}$ & CCAAAACCCTCATCAAGACAATT & GAATGAAGTCCAAACCGGTGA & $\begin{array}{l}\text { 5'-FAM- } \\
\text { CACGCAGTCAGTCTCCTCCAAACAGA } \\
\text { AA-TAM RA-3 }\end{array}$ \\
\hline
\end{tabular}


Table 3. Normalized mRNA expression determined by real-time quantitative TaqMan RT-PCR in adipose tissue after EGCG or placebo.

\begin{tabular}{llll}
\hline & EGCG & Placebo & P-value \\
\hline CPT-1 mRNA & $1,06 \cdot 10^{-5} \pm 1,0 \cdot 10^{-6}$ & $9,3 \cdot 10^{-6} \pm 7,4 \cdot 10^{-1}$ & 0.31 \\
ATGL mRNA & $3,51 \cdot 10^{-4} \pm 3,7 \cdot 10^{-5}$ & $3,7 \cdot 10^{-4} \pm 3,0 \cdot 10^{-5}$ & 0.12 \\
HSL mRNA & $5,38 \cdot 10^{-4} \pm 4,7 \cdot 10^{-5}$ & $5,19 \cdot 10^{-4} \pm 4,1 \cdot 10^{-5}$ & 0.73 \\
FAT/CD36 mRNA & $1,73 \cdot 10^{-3} \pm 1,2 \cdot 10^{-4}$ & $1,52 \cdot 10^{-3} \pm 9,1 \cdot 10^{-5}$ & 0.08 \\
ACC-1 mRNA & $2,16 \cdot 10^{-4} \pm 2,1 \cdot 10^{-5}$ & $2,18 \cdot 10^{-4} \pm 2,6 \cdot 10^{-5}$ & 0.81 \\
Leptin mRNA & $5,2 \cdot 10^{-4} \pm 5,9 \cdot 10^{-5 *}$ & $4,3 \cdot 10^{-4} \pm 5,9 \cdot 10^{-5}$ & 0.05
\end{tabular}

M ean value was significantly different from that for placebo: * $\mathrm{P} \leq 0.05$

\section{Discussion}

This study was designed to study the acute effects of EGCG supplementation (300mg/day), the main catechin of green tea, on postprandial lipolysis and fat oxidation in overweight subjects. Supplementation of $300 \mathrm{mg} /$ day EGCG for 3 days did not alter postprandial lipolysis, fat oxidation and/or energy expenditure compared to placebo. Skeletal muscle lactate concentrations, as measured by microdialysis were significantly reduced by EGCG compared to placebo, whilst skeletal muscle glucose concentrations were comparable. These data suggest EGCG may reduce skeletal muscle glycolytic flux, and/or induce a shift towards a more oxidative muscle phenotype.

Studies in rodents indicate that EGCG may acutely stimulate fat oxidation by augmenting sympathic nervous stimulation (38). However, human studies have shown mixed results. Our data of no effect on postprandial fat oxidation and energy expenditure, are consistent with findings of Lonac et al. (39) after EGCG supplementation (945 mg in 48h) in healthy adults and Gregersen et al. (40) (494-684 mg/day catechins and $150 \mathrm{mg}$ caffeine). In contrast, Thielecke et. al did show an increased fat oxidation in the first $2 \mathrm{~h}$ of the postprandial period after 3 day supplementation of EGCG (12), which is in contrast to our findings. This may possibly be related to the fact that in that study an extra dosis of 150 mg EGCG was ingested $1 \mathrm{~h}$ before the meal. In addition, Dulloo et al. showed an increase in 


\section{Chapter 4}

fat oxidation and energy expenditure following a single dose of catechins (375 mg catechins, $270 \mathrm{mg}$ EGCG) $+150 \mathrm{mg}$ caffeine in healthy young men (9). Thus, the synergistic effect of EGCG and caffeine in the study of Dulloo et al. could possibly explain the discrepancy with our present findings. In fact, caffeine has been shown to independently stimulate energy expenditure in a dose-dependent manner, with doses as low as $100 \mathrm{mg}$ showing effects (41). Nevertheless, a synergistic effect of caffeine and catechin could not be confirmed by the study of Gregersen et al. where no acute effect on fat oxidation and energy expenditure was shown with 494-684 mg/day catechins and $150 \mathrm{mg}$ caffeine. This may possibly be explained by the fact that in the latter study the capsules were supplemented in 5 small doses over $11 \mathrm{~h}$, and that the separate doses were too low to elicit an acute response on energy expenditure and fat oxidation (40).

Although there were no significant effects on postprandial fat oxidation in the present study, skeletal muscle lactate concentrations were reduced after EGCG supplementation both in the fasted state as well as during the postprandial period. These data indicate a shift towards a less glycolytic and/or more oxidative muscle phenotype after EGCG. This is in line with previous reports on stimulatory effects on oxidative capacity after green tea ingestion (either 6 portions of 1 gram green tea solids for 2 days or 1 cup of green tea containing 12 gram green tea solid), as indicated by an increased urinary excretion of several citric acid cycle intermediates in healthy humans $(42,43)$. Our data on reduced lactate concentrations are consistent with the study of Murase et al. who reported decreased plasma lactate concentrations during endurance activity (swimming) in mice (24). Since we found no differences in adipose tissue and muscle lipolysis and systemic FFA concentrations, the shift towards a more oxidative phenotype in skeletal muscle was not related to differences in the supply of fatty acids. The shift in muscle phenotype towards more oxidation may possibly be due to a direct effect on mitochondrial function which has been reported for other polyphenols (44). Thus, even though the acute effects of EGCG on fat oxidation were not significantly different from placebo treatment, this does not rule out the possibility that green tea can have beneficial effects on fat oxidation and insulin sensitivity over longer time periods (45). Long-term studies have shown that $12 \mathrm{wk}$ consumption of green tea extracts (375-690 mg catechins) can decrease body weight, waist circumference, and body fat in healthy humans $(10,46)$. Period of supplementation, duration of supplementation, addition of caffeine or other polyphenols and combination with exercise are factors that have to be taken into account for future studies.

Interestingly, systemic glycerol concentrations were decreased in the postprandial period with EGCG. This may be explained by a slightly increased insulin sensitivity of lipolysis after EGCG treatment in other adipose tissue depots, such as the visceral adipose tissue depot, 
but further mechanistic studies are necessary to examine this. Additionally, EGCG supplementation resulted in an upregulation of leptin mRNA expression in adipose tissue, whilst mRNA expression of the fatty acid transporter FAT/CD36 tended to be higher after EGCG supplementation compared to placebo. Josic et al. suggested that green tea may increase satiety although the data should be confirmed in a large clinical trial with overweight and obese subjects (47). Altogether, these data indicate slight effects on adipose tissue metabolism and function, but more pronounced effects may require a longer period of supplementation and/or higher dosage of EGCG.

In conclusion, the 3-day ingestion of $300 \mathrm{mg} /$ day of EGCG had no stimulatory effects on postprandial fat oxidation and energy expenditure in overweight subjects. EGCG reduced lactate concentrations in skeletal muscle, suggesting a reduced glycolytic flux and/or a shift in substrate utilization towards a more oxidative phenotype in skeletal muscle. It can be speculated that the shift towards a more oxidative phenotype may be beneficial in the prevention of obesity and related complications through a reduction of fat accumulation within skeletal muscle, which is a risk marker of insulin resistance and type 2 diabetes (48). 


\section{References}

1. Seidell JC. Prevalence and time trends of obesity in Europe. J Endocrinol Invest 2002;25:816-22.

2. Serrano Rios M. Relationship between obesity and the increased risk of major complications in non-insulin-dependent diabetes mellitus. Eur J Clin Invest 1998;28 Suppl 2:14-7, discussion 17-8.

3. Sano $M$, Tabata $M$, Suzuki $M$, Degawa $M$, Miyase $T$, Maeda-Yamamoto $M$. Simultaneous determination of twelve tea catechins by high-performance liquid chromatography with electrochemical detection. Analyst 2001;126:816-20.

4. Jung YD, Ellis LM. Inhibition of tumour invasion and angiogenesis by epigallocatechin gallate (EGCG), a major component of green tea. Int J Exp Pathol 2001;82:309-16.

5. Sartippour MR, Shao ZM, Heber D, et al. Green tea inhibits vascular endothelial growth factor (VEGF) induction in human breast cancer cells. J Nutr 2002;132:2307-11.

6. Kavanagh KT, Hafer LJ, Kim DW, et al. Green tea extracts decrease carcinogeninduced mammary tumor burden in rats and rate of breast cancer cell proliferation in culture. J Cell Biochem 2001;82:387-98.

7. Osada K, Takahashi M, Hoshina S, Nakamura M, Nakamura S, Sugano M. Tea catechins inhibit cholesterol oxidation accompanying oxidation of low density lipoprotein in vitro. Comp Biochem Physiol C Toxicol Pharmacol 2001;128:153-64.

8. Berube-Parent S, Pelletier C, Dore J, Tremblay A. Effects of encapsulated green tea and Guarana extracts containing a mixture of epigallocatechin-3-gallate and caffeine on $24 \mathrm{~h}$ energy expenditure and fat oxidation in men. $\mathrm{Br} J$ Nutr 2005;94:432-6.

9. Dulloo AG, Duret C, Rohrer D, et al. Efficacy of a green tea extract rich in catechin polyphenols and caffeine in increasing 24-h energy expenditure and fat oxidation in humans. Am J Clin Nutr 1999;70:1040-5.

10. Nagao $T$, Komine $Y$, Soga $S$, et al. Ingestion of a tea rich in catechins leads to a reduction in body fat and malondialdehyde-modified LDL in men. Am J Clin Nutr 2005;81:122-9.

11. Tsuchida T, Itakura H, Nakamura H. Reduction of body fat in humans by long-term ingestion of catechins. Prog M ed 2002;22:2189-2203.

12. Thielecke F, Rahn G, Bohnke J, et al. Epigallocatechin-3-gallate and postprandial fat oxidation in overweight/obese male volunteers: a pilot study. Eur J Clin Nutr 2010;64:704-13.

13. Venables M C, Hulston CJ, Cox HR, Jeukendrup AE. Green tea extract ingestion, fat oxidation, and glucose tolerance in healthy humans. Am J Clin Nutr 2008;87:77884.

14. Maruyama K, Iso H, Sasaki S, Fukino Y. The Association between Concentrations of Green Tea and Blood Glucose Levels. J Clin Biochem Nutr 2009;44:41-5. 
15. Wu LY, Juan CC, Ho LT, Hsu YP, Hwang LS. Effect of green tea supplementation on insulin sensitivity in Sprague-Dawley rats. J Agric Food Chem 2004;52:643-8.

16. Tsuneki H, Ishizuka M, Terasawa M, Wu JB, Sasaoka T, Kimura I. Effect of green tea on blood glucose levels and serum proteomic patterns in diabetic $(\mathrm{db} / \mathrm{db})$ mice and on glucose metabolism in healthy humans. BM C Pharmacol 2004;4:18.

17. Brown AL, Lane J, Coverly J, et al. Effects of dietary supplementation with the green tea polyphenol epigallocatechin-3-gallate on insulin resistance and associated metabolic risk factors: randomized controlled trial. $\mathrm{Br} J \mathrm{Nutr}$ 2009;101:886-94.

18. Borchardt RT, Huber JA. Catechol 0-methyltransferase. 5. Structure-activity relationships for inhibition by flavonoids. J M ed Chem 1975;18:120-2.

19. Baur JA, Pearson KJ, Price NL, et al. Resveratrol improves health and survival of mice on a high-calorie diet. Nature 2006;444:337-42.

20. de Boer VC, de Goffau MC, Arts IC, Hollman PC, Keijer J. SIRT1 stimulation by polyphenols is affected by their stability and metabolism. Mech Ageing Dev 2006;127:618-27.

21. Feng $Y, W u J$, Chen $L$, et al. A fluorometric assay of SIRT1 deacetylation activity through quantification of nicotinamide adenine dinucleotide. Anal Biochem 2009;395:205-10.

22. Chung S, Yao H, Caito S, Hwang JW, Arunachalam G, Rahman I. Regulation of SIRT1 in cellular functions: role of polyphenols. Arch Biochem Biophys;501:79-90.

23. Watanabe J, Kawabata J, Niki R. Isolation and identification of acetyl-CoA carboxylase inhibitors from green tea (Camellia sinensis). Biosci Biotechnol Biochem 1998;62:532-4.

24. Murase T, Haramizu S, Shimotoyodome A, Nagasawa A, Tokimitsu I. Green tea extract improves endurance capacity and increases muscle lipid oxidation in mice. Am J Physiol Regul Integr Comp Physiol 2005;288:R708-15.

25. Sae-Tan S, Grove KA, Kennett MJ, Lambert JD. (-)-Epigallocatechin-3-gallate increases the expression of genes related to fat oxidation in the skeletal muscle of high fat-fed mice. Food Funct 2011;2:111-6.

26. Murase T, Haramizu S, Shimotoyodome A, Tokimitsu I, Hase T. Green tea extract improves running endurance in mice by stimulating lipid utilization during exercise. Am J Physiol Regul Integr Comp Physiol 2006;290:R1550-6.

27. Ullmann U, Haller J, Decourt JD, Girault J, Spitzer V, Weber P. Plasma-kinetic characteristics of purified and isolated green tea catechin epigallocatechin gallate (EGCG) after 10 days repeated dosing in healthy volunteers. Int J Vitam Nutr Res 2004;74:269-78.

28. Ullmann U, Haller J, Bakker GC, Brink EJ, Weber P. Epigallocatechin gallate (EGCG) (TEAVIGO) does not impair nonhaem-iron absorption in man. Phytomedicine 2005;12:410-5.

29. Adriaens MP, Schoffelen PF, Westerterp KR. Intra-individual variation of basal metabolic rate and the influence of daily habitual physical activity before testing. Br J Nutr 2003;90:419-23. 
30. Schoffelen PF, Westerterp KR, Saris WH, Ten Hoor F. A dual-respiration chamber system with automated calibration. J Appl Physiol 1997;83:2064-72.

31. Harris JA, Benedict FG. A Biometric Study of Human Basal M etabolism. Proc Natl Acad Sci U SA 1918;4:370-3.

32. Heim M, Frank O, Kampmann $G$, et al. The phytoestrogen genistein enhances osteogenesis and represses adipogenic differentiation of human primary bone marrow stromal cells. Endocrinology 2004;145:848-59.

33. Arner $\mathrm{P}$, Bulow J. Assessment of adipose tissue metabolism in man: comparison of Fick and microdialysis techniques. Clin Sci (Lond) 1993;85:247-56.

34. Hickner RC, Rosdahl H, Borg I, Ungerstedt U, Jorfeldt L, Henriksson J. Ethanol may be used with the microdialysis technique to monitor blood flow changes in skeletal muscle: dialysate glucose concentration is blood-flow-dependent. Acta Physiol Scand 1991;143:355-6.

35. Arner P. Techniques for the measurement of white adipose tissue metabolism: a practical guide. Int J Obes Relat M etab Disord 1995;19:435-42.

36. Frayn KN. Calculation of substrate oxidation rates in vivo from gaseous exchange. J Appl Physiol 1983;55:628-34.

37. Weir JB. New methods for calculating metabolic rate with special reference to protein metabolism. J Physiol 1949;109:1-9.

38. Klaus S, Pultz S, Thone-Reineke C, Wolfram S. Epigallocatechin gallate attenuates diet-induced obesity in mice by decreasing energy absorption and increasing fat oxidation. Int J Obes (Lond) 2005;29:615-23.

39. Lonac MC, Richards JC, Schweder MM, Johnson TK, Bell C. Influence of ShortTerm Consumption of the Caffeine-Free, Epigallocatechin-3-Gallate Supplement, Teavigo, on Resting M etabolism and the Thermic Effect of Feeding. Obesity (Silver Spring) 2011;19:298-304.

40. Gregersen NT, Bitz C, Krog-Mikkelsen I, et al. Effect of moderate intakes of different tea catechins and caffeine on acute measures of energy metabolism under sedentary conditions. Br J Nutr 2009;102:1187-94.

41. Astrup A, Toubro S, Cannon S, Hein P, Breum L, Madsen J. Caffeine: a doubleblind, placebo-controlled study of its thermogenic, metabolic, and cardiovascular effects in healthy volunteers. Am J Clin Nutr 1990;51:759-67.

42. Van Dorsten FA, Daykin CA, Mulder TP, Van Duynhoven JP. Metabonomics approach to determine metabolic differences between green tea and black tea consumption. J Agric Food Chem 2006;54:6929-38.

43. Law WS, Huang PY, Ong ES, et al. Metabonomics investigation of human urine after ingestion of green tea with gas chromatography/mass spectrometry, liquid chromatography/mass spectrometry and (1)H NM R spectroscopy. Rapid Commun M ass Spectrom 2008;22:2436-46.

44. Fan E, Zhang K. Targeting resveratrol to mitochondria for cardiovascular diseases. Recent Pat Cardiovasc Drug Discov;5:97-102.

45. Maki KC, Reeves MS, Farmer M, et al. Green tea catechin consumption enhances exercise-induced abdominal fat loss in overweight and obese adults. J Nutr 2009;139:264-70. 
46. Chantre P, Lairon D. Recent findings of green tea extract AR25 (Exolise) and its activity for the treatment of obesity. Phytomedicine 2002;9:3-8.

47. Josic J, Olsson AT, Wickeberg J, Lindstedt S, Hlebowicz J. Does green tea affect postprandial glucose, insulin and satiety in healthy subjects: a randomized controlled trial. Nutr J 2010;9:63.

48. Corpeleijn E, Saris WH, Blaak EE. Metabolic flexibility in the development of insulin resistance and type 2 diabetes: effects of lifestyle. Obes Rev 2009;10:17893. 
Chapter 4 


\section{Chapter 5}

\section{Effects of liraglutide on gastric emptying, appetite, 24-hour energy expenditure and glucose metabolism in obese, non-diabetic adults: A randomized placebo-controlled incomplete crossover trial}

Judith GP van Can, Birgitte Sloth, Christine B Jensen, Tu D Le Thi, Anne Flint, Ellen E Blaak and Wim HM Saris (Submitted). 


\section{Chapter 5}

\section{Abstract}

Introduction: M echanisms for liraglutide-induced weight loss are poorly understood.

Aim: We investigated liraglutide's effects on gastric emptying, glycemic parameters, appetite, and energy metabolism in obese non-diabetic individuals.

Design: Participants ( $\mathrm{N}=49,18-75$ years, $\mathrm{BMI}: 30-40 \mathrm{~kg} / \mathrm{m}^{2}$ ) were randomized to $2 / 3$ treatments: liraglutide $1.8 \mathrm{mg}, 3.0 \mathrm{mg}$, or placebo in a double-blind, incomplete crossover trial. After 5 weeks, 24-hour energy expenditure was measured. Gastric emptying, glycemic parameters, and appetite were measured during a 5-hour meal test. Ad libitum energy intake during a subsequent lunch was assessed.

Results: Equivalence in gastric emptying ( $\mathrm{AUC}_{0-300 \mathrm{~min}}$ ) was observed for liraglutide 1.8 versus $3.0 \mathrm{mg}$ (primary endpoint), and liraglutide versus placebo $(90 \% \mathrm{Cls}$ contained within [0.80-1.25]). However, 1-hour gastric emptying decreased by $23 \%$ with liraglutide $3.0 \mathrm{mg}(\mathrm{P}=0.007)$ and $13 \%$ with $1.8 \mathrm{mg}(\mathrm{P}=0.14)$ versus placebo. Both liraglutide doses similarly reduced fasting glucose $(0.5-0.6 \mathrm{mmol} / \mathrm{L}$ versus placebo, $\mathrm{P} \varangle 0.0001)$ and postprandial glucose $C_{\text {maxi }}$ only liraglutide $3.0 \mathrm{mg}$ reduced $\mathrm{AAUC}_{0-300 \mathrm{~min}}$. Glucagon $\mathrm{IAUC}_{0}$. $300 \mathrm{~min}$ decreased by $\sim 30 \%$, and $\mathrm{IAUC}_{0.60 \mathrm{~min}}$ for insulin and C-peptide was $\sim 20 \%$ lower with liraglutide than placebo. Liraglutide doses similarly increased mean postprandial satiety ratings, reduced hunger, and decreased ad libitum energy intake by $\sim 16 \%$ versus placebo. Liraglutide-associated reductions in energy expenditure versus placebo were largely explained by weight and physical activity decreases.

www.clinicaltrials.gov ID:NCT00978393. Funding: Novo Nordisk.

Conclusion: Gastric emptying $\mathrm{AUC}_{0-300 \mathrm{~min}}$ was equivalent for liraglutide 1.8 and $3.0 \mathrm{mg}$. Liraglutide-induced weight loss appears to be mediated by reduced appetite and energy intake, not increased energy expenditure. Liraglutide improved fasting and postprandial glycemia. 


\section{Introduction}

Obesity is associated with multiple metabolic abnormalities, including hyperinsulinemia, impaired glucose metabolism, atherosclerosis and hypertension, which contribute to the development of type 2 diabetes mellitus (T2DM ) and cardiovascular disease (1,2). Diet and life-style modification represent the first-line treatment in obesity management, but as these often fail to provide major and sustainable weight loss, pharmaceutical intervention may be necessary for the achievement of long-term, clinically-relevant weight loss (3).

Glucagon-like peptide-1 (GLP-1) is a neuroendocrine hormone released predominantly from the small intestine in response to food intake. In addition to reducing fasting and postprandial glycemia and enhancing glucose-dependent insulin secretion (4), GLP-1 has been shown to inhibit glucagon secretion and slow gastric emptying $(5,6)$. Furthermore, non-clinical and clinical studies have demonstrated increased satiety, reduced food intake, and subsequent reductions in body weight following administration of GLP-1 $(7 ; 8)$, leading to its investigation for the treatment of obesity.

Liraglutide is a GLP-1 analog with $97 \%$ amino acid sequence homology to native GLP-1. Administered by once-daily subcutaneous injection at doses up to $1.8 \mathrm{mg}$, liraglutide is approved for the treatment of T2DM . Liraglutide $3.0 \mathrm{mg}$ is currently under development for weight management. Results from a phase 2 randomized, placebo-controlled trial of liraglutide (1.2-3.0 mg) in 564 obese non-diabetic adults demonstrated that liraglutide 3.0 mg was more effective than orlistat, or diet and exercise alone, at reducing weight over 20 and 52 weeks, and weight-loss was dose-dependent $(9,10)$. In the 52-week open-label extension, completers on liraglutide 2.4 or $3.0 \mathrm{mg}$ for 2 years sustained an estimated mean weight loss of $7.8 \mathrm{~kg}$ from screening (10).

Slowing of gastric emptying, primarily within the first hour post-meal, has been demonstrated with short-term treatment with liraglutide $1.8 \mathrm{mg}$ in T2DM $(11,12)$, but gastric emptying has not previously been investigated with liraglutide $3.0 \mathrm{mg}$. The primary aim of the present trial was to investigate the effect of liraglutide on gastric emptying in obese subjects without diabetes, with focus on demonstrating equivalence between liraglutide $1.8 \mathrm{mg}$ and liraglutide $3.0 \mathrm{mg}$, since gastric emptying delay may influence absorption of concomitant oral medications. Secondary aims were to investigate the effects of liraglutide on glucose metabolism, appetite, energy intake, energy expenditure (EE), and substrate oxidation rates, and to explore the potential mechanisms for liraglutide-induced weight loss. 


\section{Chapter 5}

\section{Subjects and Methods}

Subjects

Men and women aged 18-75 years with body-mass index (BMI) $30-40 \mathrm{~kg} / \mathrm{m}^{2}$, stable body weight ( $<\mathrm{kg}$ weight change during past 3 months), and fasting blood glucose $<7.0$ $\mathrm{mmol} / \mathrm{L}$ were recruited between September 2009 and April 2011. Key exclusion criteria included: diagnosis of type 1 or type 2 diabetes, use of approved weight-lowering pharmacotherapy within the previous 3 months, previous anti-obesity surgery, cardiovascular diseases, and thyroid stimulating hormone outside reference range. The trial protocol was reviewed and approved by the Medical Ethical Committee of the $M$ aastricht University M edical Centre, and all participants gave written informed consent. The trial was performed in accordance with the Declaration of Helsinki (13) and ICH Good Clinical Practice (14).

Trial design

This was a single-center, randomized, placebo-controlled, double-blind, 2-period incomplete crossover trial. The trial design is shown in Fig. 1. Prior to randomization, fasting blood glucose concentration was measured (EML 105 analyzer, Radiometer M edical A/S, Copenhagen, Denmark) and eligible individuals were randomized to receive 2 of 3 possible treatments (liraglutide $1.8 \mathrm{mg}, 3.0 \mathrm{mg}$, or placebo). At randomization, a dualemission X-ray absorptiometry (DEXA) scan (Lunar Prodigy Model DEXA, General Electric, Wisconsin, USA) was performed to determine body composition. There were 2 treatment periods, each consisting of 5 weeks at home plus a subsequent 2-day in-house stay. A wash-out period of 6-8 weeks between treatment periods was included. 
Figure 1. Trial design

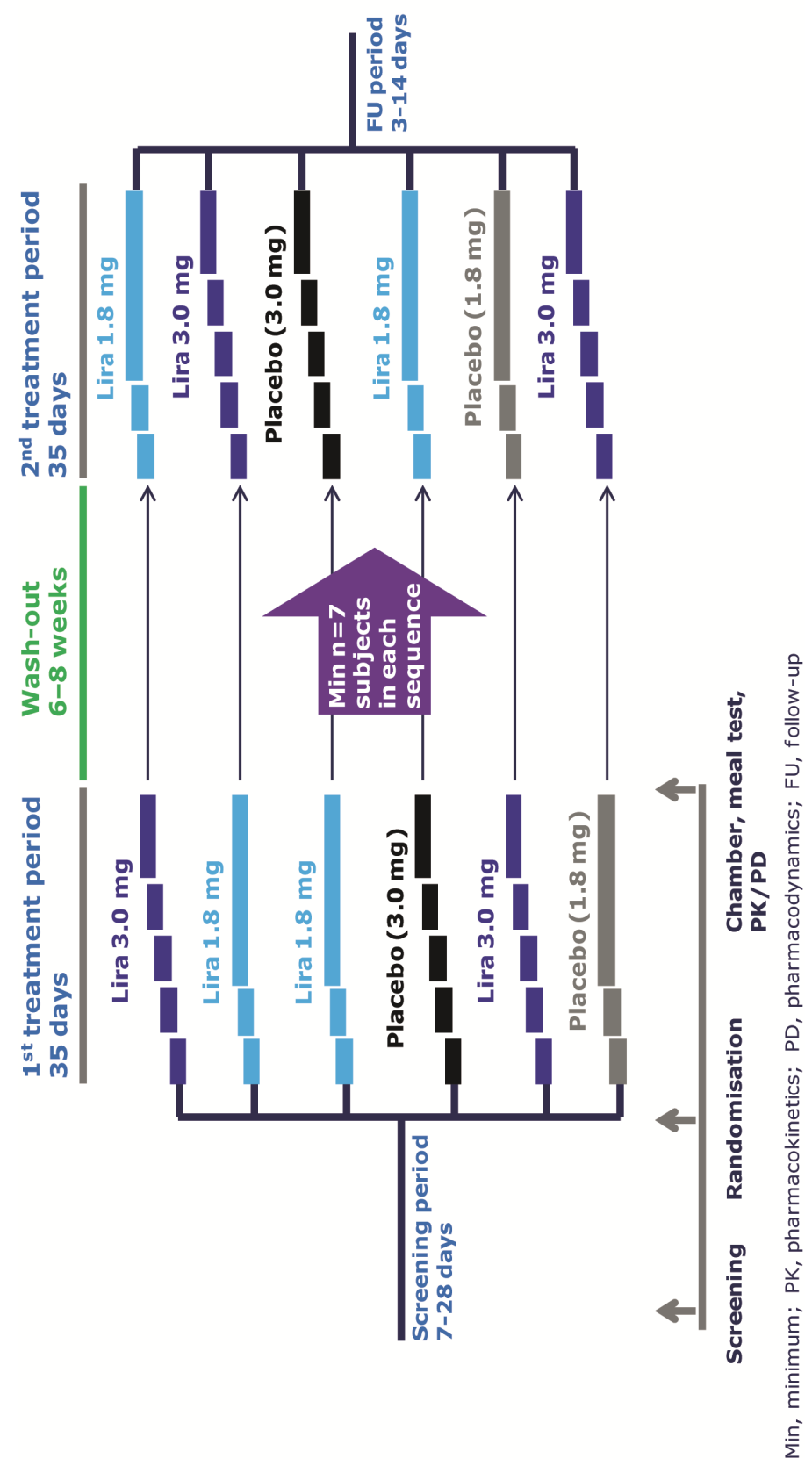




\section{Chapter 5}

\section{Treatment}

Liraglutide $1.8 \mathrm{mg}, 3.0 \mathrm{mg}$, and placebo were administered once daily by evening subcutaneous injections, using a pre-filled injection pen, FlexPen ${ }^{\circledR}$, with $3 \mathrm{~mL}$ cartridges and NovoFine ${ }^{\circledR}$ needles $8 \mathrm{~mm} \times 30 \mathrm{G}$ (Novo Nordisk A/S, Bagsværd, Denmark). Dosing started at $0.6 \mathrm{mg} /$ day and increased by weekly $0.6 \mathrm{mg}$ increments to mitigate gastrointestinal side effects. Steady-state liraglutide concentrations are known to be reached after 3-5 days of treatment (15). To maintain blinding, placebo treatment was subdivided into 2 groups with different injection volumes, corresponding to the 2 liraglutide doses. Liraglutide $(6.0 \mathrm{mg} / \mathrm{mL})$ and vehicle were provided in identical pens. Participants and investigators were thus blinded with respect to treatment (liraglutide or placebo), but not dose volume.

Meal test

After each 5-week period, a 5-hour standardized breakfast meal test was performed to measure gastric emptying, postprandial glycemic parameters, and subjective appetite ratings. Approximately 5 hours after the breakfast, an ad libitum lunch meal was provided for assessment of energy intake.

After baseline blood sampling, a standardized breakfast was served, consisting of 2 wholegrain Wasa ${ }^{\circledR}$ crackers (Wasa AB, Stockholm, Sweden) with $10 \mathrm{~g}$ margarine and $40 \mathrm{~g}$ of full-fat Gouda cheese (totaling 250 kcal). A Resource ${ }^{\circledR} 2.0$ energy drink (43 E\% carbohydrate, $40 \mathrm{E} \%$ fat, $17 \mathrm{E} \%$ protein, Nestle S.A., Vevey, Switzerland) and $200 \mathrm{ml}$ water were also provided. The drink volume was adjusted individually so that the meal's total energy content corresponded to $40 \%$ of the participant's sleeping energy expenditure (SEE), calculated during the first chamber visit. The participants started the meal with the drink, in which $1.5 \mathrm{~g}$ acetaminophen (Paracetamol 500 PCH, Pharmachemie BV, Haarlem, The Netherlands) was dissolved to measure gastric emptying $(16,17)$. Thereafter, the 2 crackers and water were consumed, all within 15 minutes. Blood samples were taken for assessment of plasma glucose, C-peptide, glucagon, acetaminophen, and serum insulin concentrations. In addition, ratings for appetite (satiety, fullness, hunger, and prospective food consumption), thirst, well-being, and nausea were recorded by visual analog scales (VAS) (18). Overall appetite score (OAS) was calculated as the average of the four individual scores (satiety + fullness + [100-prospective food consumption] $+[100$ hunger])/4. The subsequent ad libitum lunch consisted of lasagna (549 kJ/100g; $41 \mathrm{E} \%$ carbohydrate, $41 \mathrm{E} \%$ fat and $18 \mathrm{E} \%$ protein) served with $200 \mathrm{~mL}$ water, completed within 30 minutes. Participants were instructed to eat until pleasantly satiated. 
Respiratory chamber

Total EE (TEE) and 24-hour substrate oxidation rates were assessed during a 24-hour stay in an open-circuit respiratory chamber (19) during the 2-day in-house stay after each treatment period. Participants arrived in the evening and stayed overnight to get accustomed to the chamber and to enable measurement of SEE (used to calculate energy requirements for the 24-hour stay).

Gas exchange was calculated from oxygen consumption and carbon dioxide production in the respiratory chamber. The room was ventilated with fresh air at a rate of 70-80 L/min and was measured with a dry gas meter (Schlumberger, type G6, Delft, The Netherlands). Oxygen and carbon dioxide concentrations were measured using paramagnetic oxygen analyzers (M agnos G6 and Uras 3G, Hartmann \& Braun, Frankfurt, Germany). During each 15-min period, six samples of outgoing air for each chamber, and one sample each of fresh air, zero gas and calibration gas were selected and recorded by computer. TEE, 24-hour carbohydrate, fat and protein oxidation rates and 24-hour respiratory quotient (RQ) were calculated from oxygen consumption and carbon dioxide production $(20,21)$. Energy balance was calculated as 24-hour energy intake minus TEE. During both chamber stays, 24-hour urinary nitrogen, adrenalin, and noradrenalin concentrations were measured. The nitrogen excreted in the urine was used in the protein oxidation calculation.

During daytime, participants had 3 exercise periods of bench stepping for $3 \times 5 \mathrm{~min}$. Physical activity was monitored with a radar system using the Doppler principle. For calculation of activity-induced EE (AIEE), EE was plotted against radar output and averaged over 30-min periods. The intercept of the regression line at lowest radar output represented resting energy expenditure (REE). AIEE was calculated by subtracting resting metabolic rate (RM R) from TEE (22). Physical activity level (PAL) was calculated by dividing TEE by SEE with the lowest radar output.

Safety assessments

Safety assessments included adverse events (AEs), medical history, vital signs, ECG, physical examination, standard safety laboratory assessments, and lipase, amylase and calcitonin measurements. 24-hour heart rate (HR) was measured in the respiratory chamber using a HR monitoring system (Polar Electro, Oy, Finland) with 1-min intervals. 


\section{Chapter 5}

Statistical analysis

The primary endpoint of the trial was gastric emptying, measured as $A U C_{0-300 m i n}$ of acetaminophen postprandial concentration profiles during the standardized meal test. The liraglutide $3.0 \mathrm{mg}$ and $1.8 \mathrm{mg}$ groups were to be declared equivalent with respect to gastric emptying if the 2 -sided $90 \%$ confidence interval $(\mathrm{Cl})$ for the estimated ratio of acetaminophen $\mathrm{AUC}_{0-300 \mathrm{~min}}$ between the 2 groups was fully contained within the interval 0.80-1.25.

Sample size estimation was based on a previous clinical trial (11), in which the withinsubject variance of $\log \left(\mathrm{AUC}_{0-300 \mathrm{~min}}\right)$ for acetaminophen was estimated to be approximately 0.03 and the between-subject variance, 0.04 . Based on this, 10,000 simulations were run based on different true ratios (1.00 to 1.15) and on 48 and 42 subjects in total. Assuming the true ratio to be no more than $1.10,48$ individuals were planned to be randomized and at least 7 participants had to complete each sequence.

The full analysis set of all randomized individuals and the safety analysis set (all individuals receiving at least one dose of trial product) were the same and therefore used for all

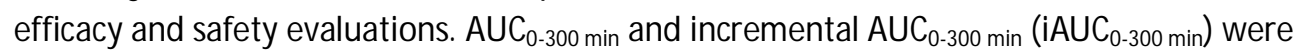
calculated using the trapezoidal method. For log-transformed meal test endpoints (all except iAUC), the estimated treatment differences and the corresponding $\mathrm{Cl}$ were backtransformed to the original scale and presented as the ratio between liraglutide and placebo, with corresponding $95 \% \mathrm{Cl}$. Mean differences or ratios between treatment groups were estimated using a parametric linear mixed-effect model that included period and treatment group as fixed effects, and subject as a random effect. Statistical analysis of all secondary endpoints was two-sided and on a $5 \%$ significance level.

For TEE and substrate oxidation rates, exploratory post-hoc analyses were performed to investigate which factors might have contributed to the results.

\section{Results}

$\underline{\text { Trial population }}$

Of 62 screened individuals, 49 ( 29 males and 20 females) were randomized and exposed to trial drug. Of these, 44 completed the trial and 5 withdrew; 2 because of AEs (toe thrombosis and tooth infection) and 3 due to other reasons (spouse health problems [2] and discomfort in respiratory chamber). All 49 individuals exposed to trial product were included in the analysis set. It should be noted that 2 participants missed a single dose 3 


\section{Effects of liraglutide on gastric emptying and energy expenditure in obese subjects}

and 4 days, respectively, prior to the assessment visit (but were included in the analyses). Participants were of mean $( \pm S D)$ age $48.3 \pm 13.2$ years, height $1.72 \pm 0.09 \mathrm{~m}$, weight $102.0 \pm 13.9 \mathrm{~kg}, \mathrm{BMI} 34.2 \pm 2.7 \mathrm{~kg} / \mathrm{m}^{2}$, and fat mass $33.1 \pm 7.1 \%$; mean fasting plasma glucose (FPG) was $5.4 \pm 0.55 \mathrm{mmol} / \mathrm{L}$. Estimated mean 5-week weight losses of $2.1 \mathrm{~kg}(95 \% \mathrm{Cl}-3.2$; $1.1)$ and $2.5 \mathrm{~kg}(-3.5 ;-1.4)$ were observed from randomization with liraglutide $1.8 \mathrm{mg}$ and $3.0 \mathrm{mg}$, respectively, compared with placebo ( $\mathrm{\prec} \odot .001$ ) (Table 2, Supplemental Appendix).

\section{Gastric emptying}

Equivalence in gastric emptying $\left(\mathrm{AUC}_{0-300 \mathrm{~min}}\right)$ at the end of the 5-week treatment periods was observed for liraglutide $1.8 \mathrm{mg}$ versus $3.0 \mathrm{mg}$, and liraglutide versus placebo, as $90 \%$ Cls for the estimated ratios were fully contained within the interval [0.80-1.25] (Fig. 2A, Table 1). However, mean $A \cup C_{0.60 m i n}$ was reduced by $23 \%(P=0.007)$ with liraglutide $3.0 \mathrm{mg}$ compared to placebo (Fig. $2 \mathrm{~B})$. The maximum concentration $\left(\mathrm{C}_{\max }\right)$ was lower with liraglutide $1.8 \mathrm{mg}$ versus placebo $(\mathrm{P}=0.04)$ (Table 1$)$.

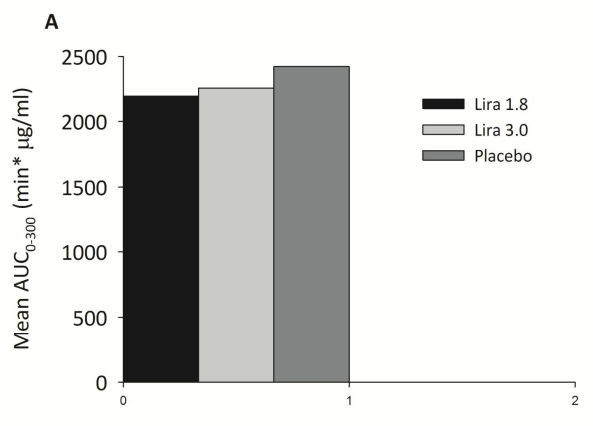

ER Lira 1.8-Lira 3.0 (90\% Cl): $1.03(0.92-1.15)$ ER Lira 1.8-Placebo (90\% Cl): $0.9(0.81-1.01)$ ER Lira 3.0-Placebo $(90 \% \mathrm{Cl}): 0.93(0.83-1.04)$

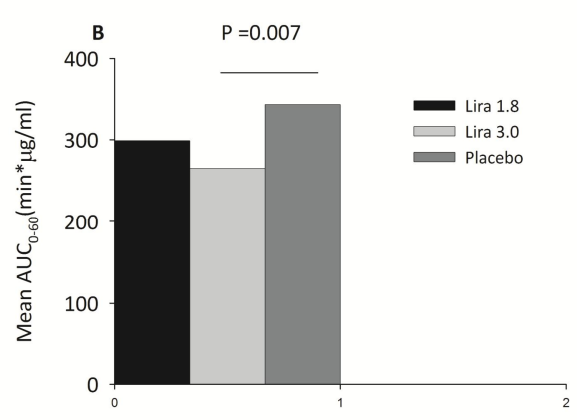

ER Lira 1.8-Lira 3.0 (95\% Cl): 0.89 (0.74-1.06) ER Lira 1.8-Placebo $(95 \% \mathrm{Cl})$ : $0.87(0.73-1.05)$ ER LIRA 3.0-Placebo (95\% Cl): 0.77 (0.64-0.92)

Figure 2. Gastric emptying over 5 hours (primary endpoint, A) and in the first hour (B) after standard breakfast meal, as assessed by the acetaminophen absorption technique. Data are estimated means. Treatment ratios are calculated using the parametric linear mixed effect model using log transformed values, together with $90 \% \mathrm{Cls}$ (primary endpoint $A \cup C_{0-300 m i n}$ ) or $95 \% \mathrm{Cls}\left(\mathrm{AUC}_{0-60 \mathrm{~min}}\right.$ ). The model included effects of subject, period, and treatment group and the subject effect was included as a random effect. AUC, area under the curve; ER, estimated rate. 


\section{Chapter 5}

\section{$\underline{\text { Glycemic parameters }}$}

M ean FPG concentrations decreased by $0.5-0.6 \mathrm{mmol} / \mathrm{L}$ with liraglutide $1.8 \mathrm{mg}$ and $3.0 \mathrm{mg}$ compared to placebo ( $\mathrm{P} \varangle .0001$ ) (Table 1 ). There were no significant differences in mean fasting glucagon, insulin or C-peptide concentrations between treatments. Postprandial 5hour profiles are shown in Fig. 3. The mean incremental postprandial glucose response (iAUC $0.300 \mathrm{~min}$ ) was attenuated by $\sim 26 \%$ with liraglutide $3.0 \mathrm{mg}$ compared to both placebo and liraglutide $1.8 \mathrm{mg}(P=0.02)$. No significant differences were observed in the initial 1-

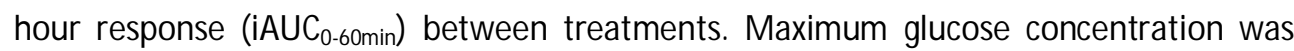
reached after approximately 30 minutes and was significantly reduced with both liraglutide doses versus placebo (Table 1). For glucagon, mean $\mathrm{iAUC}_{0-300 \mathrm{~min}}$ was reduced by $\sim 30 \%$ with both liraglutide doses compared with placebo (Fig. 3, Table 1). For insulin and C-peptide, no significant differences were observed in mean iAUC $_{0-300 m i n}$ between liraglutide doses and placebo. However the initial response ( ${\mathrm{i} A U \mathrm{C}_{0.60 \mathrm{~min}}}$ ) was reduced with liraglutide (both doses) compared with placebo for both insulin (22-26\% reduction) and Cpeptide (18-21\%).
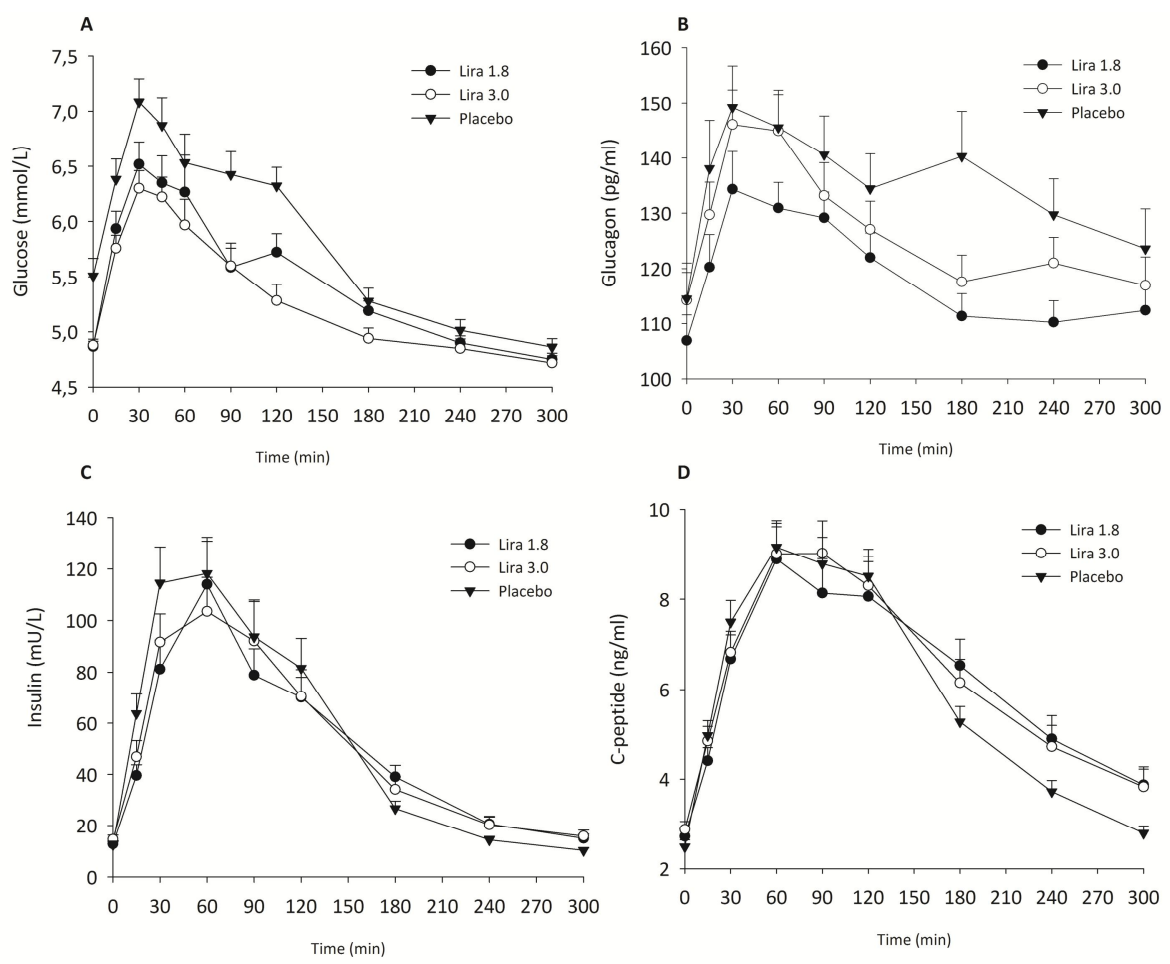

Figure 3. Effect of liraglutide and placebo on postprandial glucose (A), glucagon (B), insulin (C) and C-peptide concentration. Data are presented as mean \pm SEM . 
Subjective VAS ratings of appetite, thirst, well-being, and nausea

Appetite ratings during the 5-hour meal test are shown in Fig. 4. M ean fasting ratings for OAS and individual appetite components were comparable in all treatment groups (Table 1, Supplemental Appendix). Mean ratings $\left(\mathrm{AUC}_{15-300 \mathrm{~min} / 285 \mathrm{~min}}\right)$, maximum ratings and $15-$ min postprandial ratings were significantly and similarly increased with liraglutide $1.8 \mathrm{mg}$ and $3.0 \mathrm{mg}$ compared to placebo for OAS (indicating reduced appetite), satiety, fullness and '100-prospective food consumption' (indicating reduced prospective consumption). For '100-hunger', only the mean rating was significantly increased with liraglutide $1.8 \mathrm{mg}$ and $3.0 \mathrm{mg}$ versus placebo (indicating reduced hunger). For nausea, only the fasting rating was significantly greater with liraglutide $3.0 \mathrm{mg}$ compared to both placebo and liraglutide $1.8 \mathrm{mg}$. The mean thirst rating was similarly decreased with liraglutide $1.8 \mathrm{mg}$ and $3.0 \mathrm{mg}$ compared to placebo; no significant treatment differences were observed for other thirst ratings or well-being ratings (data not shown). 


\section{Chapter 5}
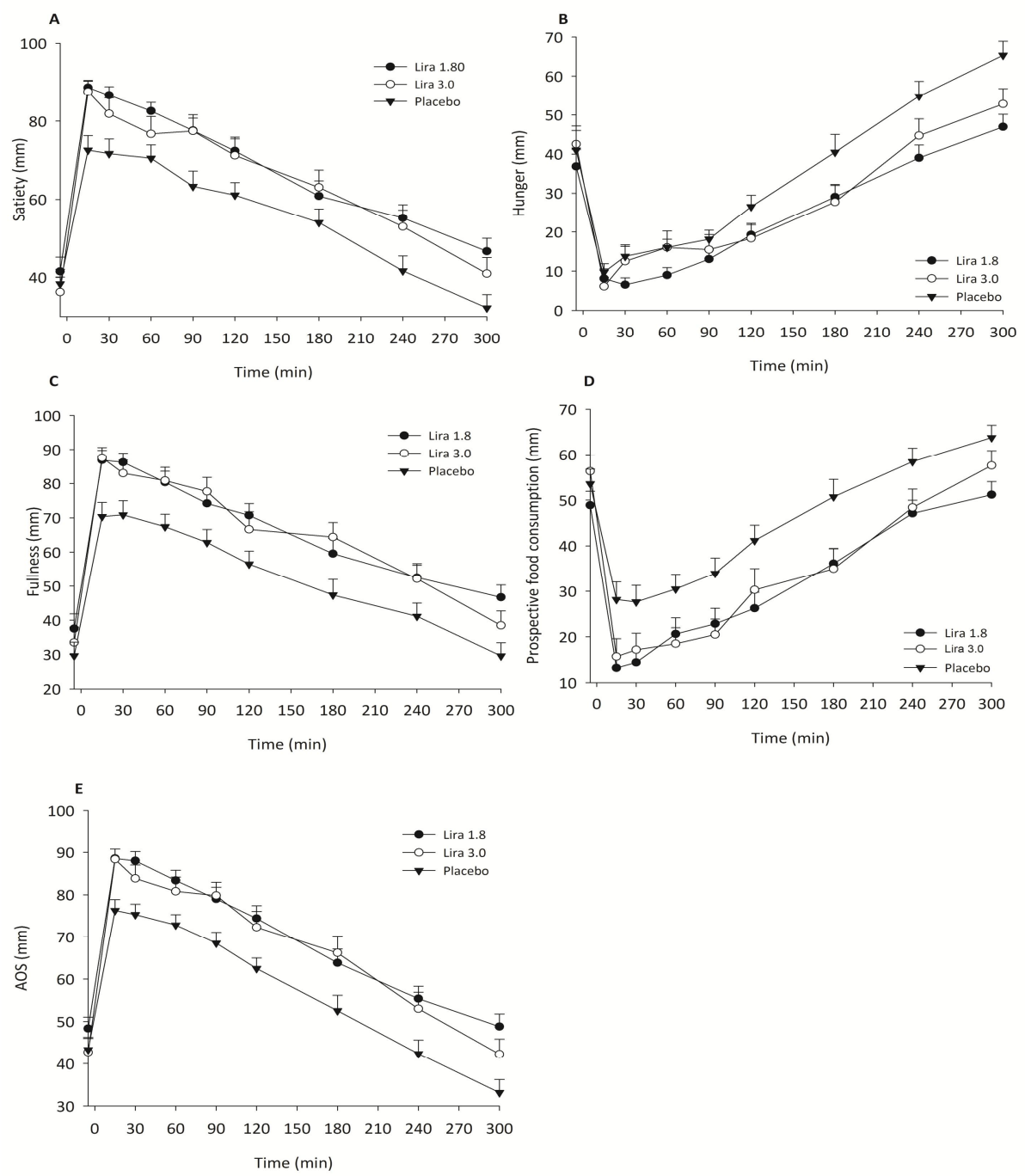

Figure 4. Appetite ratings (assessed by VAS) following the breakfast meal, and energy intake during ad libitum lunch meal, served 5 hours after breakfast. Data for energy intake are estimated means, appetite ratings are presented as mean $\pm \mathrm{SE}$, and treatment differences are calculated using the parametric linear mixed effect model on the original outcome values. The model included effects of subject, period, and treatment group and the subject effect was included as a random effect. ETD, estimated treatment difference; OAS, overall appetite score. OAS $=($ satiety + fullness $+[100$-hunger $]+[100$-prospective food consumption $]) / 4$. 


\section{Energy intake}

M ean estimated energy intake during the ad libitum lunch was significantly reduced by $588 \mathrm{~kJ}$ and $568 \mathrm{~kJ} \mathrm{(} \mathrm{16 \% )} \mathrm{with} \mathrm{liraglutide} 1.8 \mathrm{mg}$ and $3.0 \mathrm{mg}$, respectively, compared to placebo (Fig. 5).

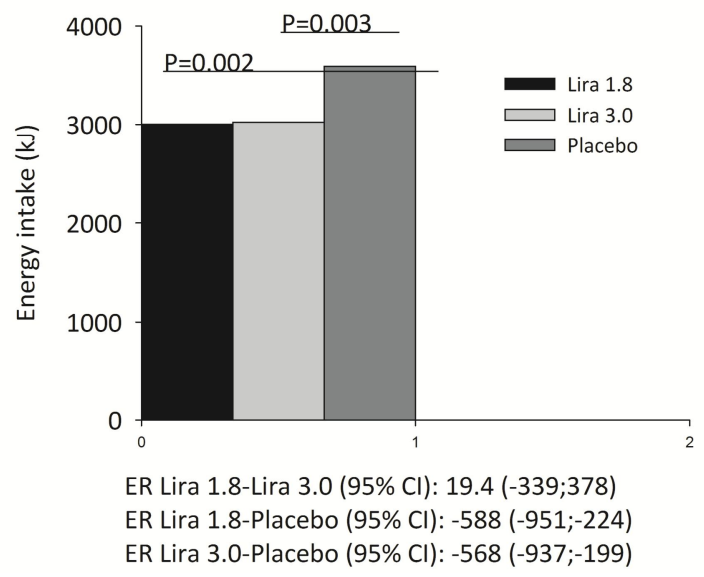

Figure 5. Energy intake during ad libitum lunch meal, served 5 hours after breakfast. Data for energy intake are estimated means, presented as mean \pm SEM , and treatment differences are calculated using the parametric linear mixed effect model on the original outcome values. The model included effects of subject, period, and treatment group and the subject effect was included as a random effect.

\section{Energy expenditure and substrate oxidation rates}

In the respiratory chamber, all treatment groups had a slightly negative 24-hour energy balance (mean -4.6 to $-2.8 \%$ ), which was significantly greater with liraglutide 1.8 mg versus placebo (Table 2, Supplemental Appendix), though energy balance for all participants was within an acceptable $10 \%$ limit (range -10.0 to $6.2 \%$ ) (23). Mean TEE was significantly lower with both liraglutide doses compared to placebo, $350 \mathrm{~kJ} / 24$ hours and $581 \mathrm{~kJ} / 24$ hours for liraglutide $1.8 \mathrm{mg}$ and $3.0 \mathrm{mg}$, respectively. Similarly, 3-hour EE during the period with lowest spontaneous physical activity (a surrogate marker of REE) was significantly lower in both liraglutide treatment groups versus placebo. The activity-related endpoints PAL and AIEE decreased with liraglutide $3.0 \mathrm{mg}$ compared to placebo, but only the difference in mean AIEE was significant $(P=0.03)$. By adding baseline fat-free mass and 


\section{Chapter 5}

weight and PAL after 5 weeks as covariates to the TEE model post hoc, the observed treatment differences were no longer statistically significant (Fig. 6, Table 2, Supplemental Appendix).
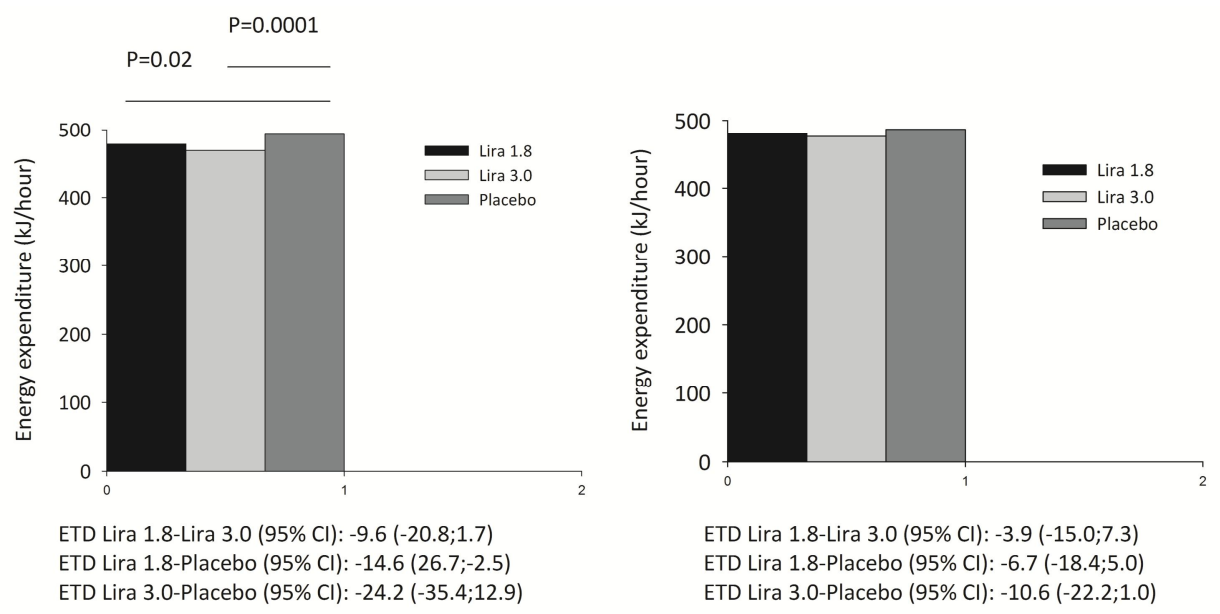

Figure 6. Total 24-hour energy expenditure (TEE). Data are estimated means for the original analysis (top panel) and post-hoc adjusted analysis (bottom panel). Treatment differences for TEE were calculated using the parametric linear mixed-effect model including effects of period and treatment group. Subject was included as a random effect. For the adjusted analysis, gender and fat-free mass (assessed at baseline); body weight and energy balance (assessed prior to chamber entry after each 5-week period); and urinary noradrenalin excretion and PAL (assessed in the chamber) were added as covariates to the original model. Noradrenalin, energy balance, and gender were found to be non-significant and thus excluded from the final model. ETD, estimated treatment difference.

RQ was significantly reduced with liraglutide $1.8 \mathrm{mg}$ compared to placebo and a similar (non-significant) trend was observed for liraglutide $3.0 \mathrm{mg}$ (Table 2, Supplemental Appendix). The lower RQ with liraglutide translated into significantly increased fat oxidation with liraglutide $1.8 \mathrm{mg}$ at the expense of significantly lower mean carbohydrate and protein oxidation with both liraglutide doses versus placebo. Post-hoc substrate oxidation analyses, which adjusted for gender and energy balance, confirmed the relative shift in 24-hour substrate oxidation towards fat oxidation with liraglutide treatment. The treatment-related decreases in protein oxidation were, however, no longer statistically significant.

Urinary 24-hour noradrenalin excretion was reduced with both liraglutide $1.8 \mathrm{mg}$ (estimated ratio 0.9 [95\% Cl 0.8; 1.0], $\mathrm{P}=0.02$ ) and $3.0 \mathrm{mg}$ (ratio 0.9 [0.8; 1.0$], \mathrm{P}=0.03$ ) compared with placebo; no differences were observed for adrenalin (data not shown). 


\section{Safety}

Overall, liraglutide was well tolerated and no safety concerns were identified. The proportion of individuals reporting AEs, which were all of mild or moderate severity, was similar for liraglutide $1.8 \mathrm{mg}(90 \%)$ and $3.0 \mathrm{mg}(94 \%)$, and lower (75\%) for placebo. Decreased appetite and gastrointestinal disorders (most commonly nausea) were reported more frequently with liraglutide (Table 3, Supplemental Appendix). One serious $\mathrm{AE}$ (toe thrombosis) was reported in the liraglutide $3.0 \mathrm{mg}$ group, and led to withdrawal. There appeared to be a treatment-related asymptomatic increase in median serum lipase activity with liraglutide compared to placebo, otherwise no clinically-relevant treatmentrelated changes in safety laboratory measures were apparent. Mean systolic blood pressure decreased by approximately $6-9 \mathrm{mmHg}$ from baseline to end of treatment in all groups. No noticeable changes were observed for mean diastolic blood pressure. Liraglutide treatment was associated with increased mean pulse at end-of-treatment compared to baseline ( $2-3$ beats/min), and estimated mean 24-hour HR during the chamber stay was significantly greater with both liraglutide doses compared to placebo (6-7 beats/min; $P \varangle 0.0001$ ).

Table1. Comparison of estimated means and treatment differences for gastric emptying, glucose, glucagon, insulin, and C-peptide after 5 weeks of treatment.

\begin{tabular}{|c|c|c|c|c|c|}
\hline Parameter & $\begin{array}{l}\text { Liraglutide } \\
\qquad 1.8 \mathrm{mg}\end{array}$ & $\begin{array}{l}\text { Liraglutide } \\
\quad 3.0 \mathrm{mg}\end{array}$ & Placebo & $\begin{array}{l}\text { Treatment ratio (R) or difference } \\
\text { (D) for } \\
{ }^{1} \text { lira } 1.8 \mathrm{mg} \text { vs. placebo } \\
{ }^{2} \text { lira } 3.0 \mathrm{mg} \text { vs. placebo } \\
{ }^{3} \text { lira } 3.0 \mathrm{mg} \text { vs. lira } 1.8 \mathrm{mg} \\
\end{array}$ & $P$ value \\
\hline Gastric emptying & $n=30$ & $n=30$ & $n=30$ & & \\
\hline $\begin{array}{l}\mathrm{AUC} \mathrm{C}_{0-300 \mathrm{~min}} \\
\text { (min* } \mu \mathrm{g} / \mathrm{mL}) \\
\text { (Primary endpoint) }\end{array}$ & 2193 & 2252 & 2424 & $\begin{array}{l}{ }^{1} \mathrm{R}: 0.90(0.81 ; 1.01) \\
{ }^{2} \mathrm{R}: 0.93(0.83 ; 1.04) \\
\text { 3 } \mathrm{S}: 1.03(0.92 ; 1.15)\end{array}$ & $\begin{array}{l}0.15 \\
0.28 \\
0.69\end{array}$ \\
\hline$A \cup C_{0-60 \min }(\min * \mu \mathrm{g} / \mathrm{mL})$ & 299.4 & 265.2 & 343.1 & $\begin{array}{l}{ }^{1} R: 0.87(0.73 ; 1.05) \\
{ }^{2} R: 0.77(0.64 ; 0.93) \\
{ }^{3} R: 0.89(0.74 ; 1.06)\end{array}$ & $\begin{array}{c}0.14 \\
0.007 \\
0.18\end{array}$ \\
\hline$C_{\max }(\mu \mathrm{g} / \mathrm{m} / \mathrm{L})$ & 10.54 & 11.37 & 11.76 & $\begin{array}{l}{ }^{1} R: 0.90(0.81 ; 0.99) \\
{ }^{2} R: 0.97(0.87 ; 1.07) \\
{ }^{3} R: 1.08(0.97 ; 1.20)\end{array}$ & $\begin{array}{l}0.04 \\
0.52 \\
0.14\end{array}$ \\
\hline Glucose & $n=30$ & $n=30$ & $n=30$ & & \\
\hline $\begin{array}{l}\text { Fasting plasma } \\
\text { (mmol/L) } \\
\text { glucose }\end{array}$ & 4.85 & 4.89 & 5.43 & $\begin{array}{l}{ }^{1} \mathrm{R}: 0.89(0.86 ; 0.93) \\
{ }^{2} \mathrm{R}: 0.90(0.87 ; 0.94) \\
{ }^{3} \mathrm{R}: 1.01(0.97 ; 1.05)\end{array}$ & $\begin{array}{c}\varangle 0.0001 \\
\varangle 0.0001 \\
0.70\end{array}$ \\
\hline
\end{tabular}




\section{Chapter 5}

\section{Postprandial values}

$\begin{array}{llll}\text { IAUC }_{0-300 \mathrm{~min}} & 191.8 & 143.0 & 192.2\end{array}$

(min* $\mathrm{mmol} / \mathrm{L})$

${ }^{1} \mathrm{D}:-0.37(-40.8 ; 40.09) \quad 0.99$

LD: $-49.1(-89.6 ;-8.68) \quad 0.02$

${ }^{3} \mathrm{D}:-48.8(-88.7 ;-8.85) \quad 0.02$

\begin{tabular}{|c|c|c|c|c|c|}
\hline $\begin{array}{l}\text { iAUC } \mathrm{C}_{0-60 \mathrm{~min}} \\
\text { (min*mmol/L) }\end{array}$ & 76.25 & 66.97 & 76.65 & $\begin{array}{l}{ }^{1} \mathrm{D}:-0.40(-16.0 ; 15.2) \\
\text { 'D: -9.68 (-25.2; 5.88) } \\
{ }^{3} \mathrm{D}:-9.27(-24.6 ; 6.07)\end{array}$ & $\begin{array}{l}0.96 \\
0.22 \\
0.23\end{array}$ \\
\hline $\mathrm{C}_{\max }(\mathrm{mmol} / \mathrm{L})$ & 6.97 & 6.75 & 7.45 & $\begin{array}{l}{ }^{1} R: 0.94(0.88 ; 1.00) \\
\text { LR: } 0.91(0.85 ; 0.96) \\
{ }^{3} R: 0.97(0.91 ; 1.03)\end{array}$ & $\begin{array}{c}0.04 \\
0.003 \\
0.30\end{array}$ \\
\hline Glucagon & $n=30$ & $n=30$ & $n=30$ & & \\
\hline $\begin{array}{l}\text { Fasting plasma } \\
\text { (pg/mL) } \\
\text { glucagon }\end{array}$ & 106.5 & 109.5 & 108.5 & $\begin{array}{l}{ }^{1} \mathrm{R}: 0.98(0.90 ; 1.07) \\
{ }^{2} \mathrm{R}: 1.01(0.93 ; 1.10) \\
{ }^{3} \mathrm{R}: 1.03(0.95 ; 1.12)\end{array}$ & $\begin{array}{l}0.66 \\
0.83 \\
0.51\end{array}$ \\
\hline $\begin{array}{l}\text { Postprandial values } \\
\text { iAUC } \mathrm{C}_{0-300 \mathrm{~min}} \\
\text { (min*pg/mL) }\end{array}$ & 4781 & 4866 & 6957 & $\begin{array}{l}{ }^{1} D:-2176(-4277 ;-74.6) \\
\text { ¿D: } 2091(-4191 ; 10.08) \\
\text { '3: 85.31(-2000; 2171) }\end{array}$ & $\begin{array}{c}0.04 \\
0.051 \\
0.94\end{array}$ \\
\hline $\begin{array}{l}\mathrm{iAUC}_{0-60 \mathrm{~min}} \\
\text { (min*pg/mL) }\end{array}$ & 1294 & 1460 & 1688 & $\begin{array}{l}{ }^{1} D:-394(-891 ; 102.6) \\
{ }^{2} D:-227(-724 ; 269.3) \\
{ }^{3} D: 166.8(-328 ; 661.5)\end{array}$ & $\begin{array}{l}0.12 \\
0.36 \\
0.50\end{array}$ \\
\hline $\mathrm{C}_{\max }(\mathrm{pg} / \mathrm{mL})$ & 145.5 & 147.0 & 156.9 & $\begin{array}{l}{ }^{1} \mathrm{R}: 0.93(0.87 ; 0.99) \\
{ }^{2} \mathrm{R}: 0.94(0.88 ; 1.00) \\
{ }^{3} \mathrm{R}: 1.01(0.95 ; 1.08)\end{array}$ & $\begin{array}{l}0.03 \\
0.06 \\
0.75\end{array}$ \\
\hline Insulin & $n=30$ & $n=30$ & $n=30$ & & \\
\hline $\begin{array}{l}\text { Fasting serum (mU/L) } \\
\text { insulin }\end{array}$ & 11.36 & 12.68 & 10.77 & $\begin{array}{l}{ }^{1} R: 1.05(0.87 ; 1.28) \\
{ }^{2} R: 1.18(0.97 ; 1.43) \\
{ }^{3} R: 1.12(0.92 ; 1.35)\end{array}$ & $\begin{array}{l}0.58 \\
0.10 \\
0.25\end{array}$ \\
\hline $\begin{array}{l}\text { Postprandial values } \\
\text { iAUC } C_{0-300 \mathrm{~min}} \\
\text { (min*mU/L) }\end{array}$ & 12075 & 11009 & 13131 & $\begin{array}{l}{ }^{1} D:-1056(-3517 ; 1405) \\
{ }^{2} D:-2122(-4583 ; 338.7) \\
{ }^{3} D:-1066 \text { (-3490; 1358) }\end{array}$ & $\begin{array}{l}0.39 \\
0.09 \\
0.38\end{array}$ \\
\hline $\mathrm{iAUC} \mathrm{C}_{0-60 \mathrm{~min}}(\mathrm{~min} * \mathrm{mU} / \mathrm{L})$ & 3735 & 3532 & 4778 & $\begin{array}{l}{ }^{1} D:-1043(-1847 ;-238) \\
{ }^{2} D:-1246(-2050 ;-441) \\
{ }^{3} D:-203(-996 ; 589.1)\end{array}$ & $\begin{array}{c}0.01 \\
0.003 \\
0.61\end{array}$ \\
\hline $\mathrm{C}_{\max }(\mathrm{mU} / \mathrm{L})$ & 111.6 & 121.6 & 119.4 & $\begin{array}{l}{ }^{1} \mathrm{R}: 0.93(0.77 ; 1.14) \\
{ }^{2} \mathrm{R}: 1.02(0.83 ; 1.24)\end{array}$ & $\begin{array}{l}0.50 \\
0.86\end{array}$ \\
\hline
\end{tabular}


${ }^{3} \mathrm{R}: 1.09(0.89 ; 1.33)$

\begin{tabular}{|c|c|c|c|c|c|}
\hline C-peptide & $n=30$ & $n=30$ & $n=30$ & & \\
\hline $\begin{array}{l}\text { Fasting plasma } \\
\text { (ng/mL) }\end{array}$ & 2.58 & 2.67 & 2.41 & & \\
\hline C-peptide & & & & $\begin{array}{l}{ }^{1} \mathrm{R}: 1.07(0.96 ; 1.19) \\
{ }^{2} \mathrm{R}: 1.11(1.00 ; 1.24) \\
{ }^{3} \mathrm{R}: 1.04(0.93 ; 1.15)\end{array}$ & $\begin{array}{l}0.20 \\
0.06 \\
0.52\end{array}$ \\
\hline $\begin{array}{l}\text { Postprandial values } \\
\text { iAUC } C_{0-300 \mathrm{~min}} \\
\text { (min*ng/mL) }\end{array}$ & 1088 & 1030 & 1122 & & \\
\hline & & & & $\begin{array}{l}{ }^{1} \mathrm{D}:-33.5(-215 ;-148.0) \\
\text { 'D: -92.2 (-274; 89.27) } \\
{ }^{3} \mathrm{D}:-58.7(-238 ; 120.1)\end{array}$ & $\begin{array}{l}0.71 \\
0.31 \\
0.51\end{array}$ \\
\hline $\begin{array}{c}\mathrm{iAUC}_{0.60 \mathrm{~min}} \\
\text { (min*ng/mL) }\end{array}$ & 216.6 & 207.7 & 263.2 & & \\
\hline & & & & $\begin{array}{l}{ }^{1} D:-46.7(-84.0 ; 9.31) \\
\text { 'D: }-55.5(-92.8 ;-18.1) \\
{ }^{3} D:-8.83(-45.7 ; 28.00)\end{array}$ & $\begin{array}{c}0.02 \\
0.004 \\
0.63\end{array}$ \\
\hline $\mathrm{C}_{\max }(\mathrm{ng} / \mathrm{mL})$ & 9.39 & 10.20 & 9.55 & $\begin{array}{l}{ }^{1} \mathrm{R}: 0.98(0.88 ; 1.10) \\
{ }^{2} \mathrm{R}: 1.07(0.95 ; 1.19) \\
{ }^{3} \mathrm{R}: 1.09(0.97 ; 1.21)\end{array}$ & $\begin{array}{l}0.76 \\
0.24 \\
0.14\end{array}$ \\
\hline
\end{tabular}

Data are estimated means. Treatment ratios/ differences are estimated means ( $95 \% \mathrm{Cls})$, except for primary endpoint $A \cup C_{0-300 m i n}$, where they are estimated means $(90 \% \mathrm{Cls})$. Comparisons between treatment groups were performed using the parametric linear mixed effect model using log transformed values (iAUC was analyzed on the original scale). The model included effects of subject, period and treatment group (subject was included as a random effect).

\section{Discussion}

The results of this study confirmed the hypothesis of gastric emptying equivalence between liraglutide $1.8 \mathrm{mg}$ and $3.0 \mathrm{mg}$ during the 5-hour meal test after 5 weeks of treatment. Some evidence of delayed gastric emptying during the first hour of the meal test was apparent with liraglutide $3.0 \mathrm{mg}$ (a non-significant trend with $1.8 \mathrm{mg}$ was observed), consistent with results from previous trials with liraglutide $1.8 \mathrm{mg}$ in T2DM $(11,12)$. The clinical relevance of this initial delay in gastric emptying is unknown, but is considered unlikely to be important in the context of co-administered oral medications. FPG was reduced to a similar extent with both liraglutide doses versus placebo. Interestingly, however, only liraglutide $3.0 \mathrm{mg}$ significantly reduced both 5-hour postprandial endpoints, $\mathrm{i}_{\mathrm{AUC}} \mathrm{C}_{0-300 \mathrm{~min}}$ and $\mathrm{C}_{\max }$. Both liraglutide doses were associated with decreases in overall appetite during the 5 -hour meal test, and lower energy intake at the subsequent ad libitum lunch, with no statistically significant differences between doses. Post-hoc analyses suggested that the small reductions in EE with liraglutide compared to placebo were predominantly explained by concomitant treatment-related decreases in body weight and PAL. 


\section{Chapter 5}

Both fasting and postprandial glycemic control was improved with liraglutide treatment in this population of obese individuals without T2DM. These findings are consistent with previous trials with liraglutide at doses up to $2.0 \mathrm{mg}$ in T2DM (24-26), and in a phase 2 dose-finding trial in obese individuals without T2DM (9), about 30\% of whom had prediabetes at baseline. In that study, liraglutide reduced the prevalence of prediabetes over 2 years by half (10). As no significant differences in mean fasting glucagon or insulin concentrations between liraglutide and placebo were observed in this trial, reductions in FPG may be ascribed to improved insulin sensitivity due to weight loss (27). Interestingly, 5-hour postprandial glycemia was further improved with liraglutide $3.0 \mathrm{mg}$, compared to $1.8 \mathrm{mg}$, in the face of similar improvements in 5-hour postprandial glucagon and 1-hour postprandial insulin concentrations. Taken together, these results support the efficacy of liraglutide, particularly at the $3.0 \mathrm{mg}$ dose, for improved fasting and postprandial glycemic control in obese individuals without T2DM. Ongoing phase 3 trials will establish the clinical relevance of these findings in delaying the onset of T2DM in individuals with prediabetes, as well as further improving glycemic control in individuals with established T2DM .

Both liraglutide doses similarly suppressed appetite and increased satiety in this trial, as reflected in subjective VAS ratings during the 5-hour meal test. Importantly, subsequent ad libitum energy intake with liraglutide treatment was significantly reduced by more than $500 \mathrm{~kJ}$ compared to placebo, a reduction of $\sim 16 \%$. Energy intake has not previously been assessed with liraglutide $3.0 \mathrm{mg}$, but in a previous trial with liraglutide $1.8 \mathrm{mg}$ in T2DM , a non-significant reduction in energy intake of $-9 \%$ versus placebo was observed after 4 weeks, associated with a significant weight reduction of $1.3 \mathrm{~kg}$ (12). M oreover, a metaanalysis demonstrated reductions in energy intake during a test meal of a mean 12\% (727 kJ) during native GLP-1 infusion in participants with and without T2DM (28). Clinical Practice Guidelines suggest that a daily reduction in energy intake of $2.6 \mathrm{MJ}$ will predict a weight loss of about $0.5 \mathrm{~kg}$ weekly (assuming no change in energy expenditure) (29).

This study is the first to investigate the effects of liraglutide on EE in obese non-diabetic individuals. TEE was slightly but statistically significantly reduced with liraglutide treatment (both $1.8 \mathrm{mg}$ and $3.0 \mathrm{mg}$ ), largely explained by a treatment-related reduction in body weight over the 5-week period and reduced PAL, assessed during the chamber stay. A previous study showed no acute effects of liraglutide $0.6 \mathrm{mg}$ on 24-hour EE, as assessed by indirect calorimetry, after 3 days of treatment in T2DM (30). Likewise, subsequent studies have revealed no treatment-related changes in REE or TEE in obese individuals without T2DM after at least 14 weeks of treatment with the GLP-1 analog exenatide (31,32), or in REE in T2DM after 4 weeks of liraglutide treatment (2 weeks on $1.8 \mathrm{mg}$ ) (12). In the current study, EE during the period with the lowest spontaneous physical activity (representative of REE) was significantly lower with liraglutide versus placebo. However, differences between the studies, mainly in methodology and treatment duration, make 
comparisons difficult. While significant weight loss is usually associated with a decrease in REE favoring weight regain (33), it is interesting that liraglutide treatment at doses of 1.8 $\mathrm{mg}$ and above promotes satiety and reduces hunger, despite reductions in EE and a relative shift in substrate oxidation, both of which indicate a negative energy balance. The durability of this response and its relevance for long-term weight maintenance remain to be determined. However, sustained 2-year weight loss with liraglutide treatment together with diet and exercise has previously been demonstrated in obese individuals without T2DM (10).

Liraglutide was generally well tolerated. As seen previously with liraglutide, the most frequently reported side-effects were gastrointestinal, but dose-escalation helps to mitigate these (34). Consistent with previous trials with liraglutide and other GLP-1 receptor agonists, slight increases in pulse and lipase activity were observed (35-37), the clinical relevance of which remains to be determined. The decrease in urinary 24-hour noradrenaline excretion was likely due to weight loss (38).

Limitations of the study include the fact that it was powered for the primary endpoint only, hence caution must be exercised when interpreting the results, as no correction for multiplicity was done. Moreover, the crossover design of the trial was incomplete; hence participants were not exposed to all treatments. Assessments were made with liraglutide concentrations at steady-state. However, as the maintenance dose is achieved by dose escalation to mitigate gastrointestinal side-effects, some weight loss was observed with liraglutide during the 5-week period. An impact of this weight loss on some of the study endpoints cannot be ruled out.

This study confirmed equivalence between liraglutide 1.8 and $3.0 \mathrm{mg}$ with respect to gastric emptying. Results suggest that liraglutide-induced weight loss is mediated via effects on appetite sensations and subsequent reduced energy intake, rather than increased EE. Moreover, postprandial glucose concentrations were improved with liraglutide, particularly at the higher dose. Ongoing clinical trials will determine the clinical implications of this finding in delaying onset of diabetes in obese individuals with prediabetes and improving glycemic control in T2DM.

\section{Acknowledgments}

This study would not have been possible without the research team at Maastricht University (sub-investigator Guy Vijgen, clinical dieticians Sandy Monsheimer and Karin Wings, and respiratory chamber technician Paul Schoffelen), and most importantly the commitment of the study participants. We also thank Johanna Welch, PhD, and Angela Harper, PhD, who provided medical writing services on behalf of Novo Nordisk A/S. 


\section{References}

1. Kopelman PG. Obesity as a medical problem. Nature 2000; 404(6778):635-643.

2. Mokdad AH, Ford ES, Bowman BA et al. Prevalence of obesity, diabetes, and obesity-related health risk factors, 2001. JAMA : the journal of the American Medical Association 2003; 289(1):76-79.

3. Bays HE. Current and investigational antiobesity agents and obesity therapeutic treatment targets. Obes Res 2004; 12(8):1197-1211.

4. Meier JJ, Gethmann A, Gotze 0 et al. Glucagon-like peptide 1 abolishes the postprandial rise in triglyceride concentrations and lowers levels of non-esterified fatty acids in humans. Diabetologia 2006; 49(3):452-458.

5. Wettergren A, Schjoldager B, Mortensen PE, Myhre J, Christiansen J, Holst JJ. Truncated GLP-1 (proglucagon 78-107-amide) inhibits gastric and pancreatic functions in man. Dig Dis Sci 1993; 38(4):665-673.

6. Flint A, Raben A, Ersboll AK, Holst JJ, Astrup A. The effect of physiological levels of glucagon-like peptide-1 on appetite, gastric emptying, energy and substrate metabolism in obesity. Int J Obes 2001; 25(6):781-792.

7. Flint A, Raben A, Astrup A, Holst JJ. Glucagon-like peptide 1 promotes satiety and suppresses energy intake in humans. J Clin Invest 1998; 101(3):515-520.

8. Meeran K, O'Shea D, Edwards CM et al. Repeated intracerebroventricular administration of glucagon-like peptide-1-(7-36) amide or exendin-(9-39) alters body weight in the rat. Endocrinology 1999; 140(1):244-250.

9. Astrup A, Rossner S, Van Gaal L et al. Effects of liraglutide in the treatment of obesity: a randomised, double-blind, placebo-controlled study. Lancet 2009; 374:1606-1616.

10. Astrup A, Carraro R, Finer N et al. Safety, tolerability and sustained weight loss over 2 years with the once-daily human GLP-1 analog, liraglutide. Int J Obes (Lond) 2012;36(6):843-54. doi: 10.1038/ijo.2011.158.

11. Kapitza C, Zdravkovic M, Hindsberger C, Flint A. The effect of the once-daily human glucagon-like peptide 1 analog liraglutide on the pharmacokinetics of acetaminophen. Adv Ther 2011; 28(8):650-660.

12. Horowitz $M$, Flint $A$, Jones $K L$ et al. Effect of the once-daily human GLP-1 analogue liraglutide on appetite, energy intake, energy expenditure and gastric emptying in type 2 diabetes. Diabetes Res Clin Pract 2012.

13. World Medical Association. Declaration of Helsinki. Ethical Principles for M edical Research Involving Human Subjects. Last amended by the 59th WMA Assembly, Seoul. http://www.wma.net/en/30publications/10policies/b3/ . 2008.

14. ICH Harmonised Tripartite Guideline. International Conference on Harmonisation. Good Clinical Practice . 1996. 17-12-2009.

15. Agerso H, Jensen LB, Elbrond B, Rolan P, Zdravkovic M. The pharmacokinetics, pharmacodynamics, safety and tolerability of NN2211, a new long-acting GLP-1 derivative, in healthy men. Diabetologia 2002; 45(2):195-202. 
16. Willems M, Quartero AO, Numans M E. How useful is paracetamol absorption as a marker of gastric emptying? A systematic literature study. Dig Dis Sci 2001; 46(10):2256-2262.

17. Sanaka M, Kuyama Y, Yamanaka M. Guide for judicious use of the paracetamol absorption technique in a study of gastric emptying rate of liquids. J Gastroenterol 1998; 33(6):785-791.

18. Flint A, Raben A, Blundell JE, Astrup A. Reproducibility, power and validity of visual analogue scales in assesment of appetite sensations in single test meal studies. Int J Obes Relat Metab Disord 2000; 24:38-48.

19. Schoffelen PF, Westerterp KR, Saris WH, Ten HF. A dual-respiration chamber system with automated calibration. J Appl Physiol 1997; 83(6):2064-2072.

20. Weir J.B. New methods for calculating metabolic rate with special reference to protein metabolism. J Physiol 1949; 109:1-9.

21. Frayn KN. Calculation of substrate oxidation rates in-vivo from gaseous exchange. Journal of Applied Physiology Respiratory Environmental and Exercise Physiology 1983; 55(2):628-634.

22. Westerterp K.r, Wilson S.A, Rolland V. Diet induced thermogenesis measured over $24 \mathrm{~h}$ in a respiration chamber: effect of diet composition. Int J Obes Relat Metab Disord 1999; 23(3):287-292.

23. Schrauwen $P$, van Marken Lichtenbelt WD, Westerterp KR. Energy balance in a respiration chamber: individual adjustment of energy intake to energy expenditure. Int J Obes Relat M etab Disord 1997; 21(9):769-774.

24. Vilsboll T, Zdravkovic M, Le-Thi T et al. Liraglutide, a long-acting human glucagonlike peptide-1 analog, given as monotherapy significantly improves glycemic control and lowers body weight without risk of hypoglycemia in patients with type 2 diabetes. Diabetes Care 2007; 30(6):1608-1610.

25. Flint A, Kapitza C, Hindsberger C, Zdravkovic M. The once-daily human glucagonlike peptide-1 (GLP-1) analog liraglutide improves postprandial glucose levels in type 2 diabetes patients. Adv Ther 2011; 28(3):213-226.

26. Blonde L, Russell-Jones D. The safety and efficacy of liraglutide with or without oral antidiabetic drug therapy in type 2 diabetes: an overview of the LEAD 1-5 studies. Diabetes Obes M etab 2009; 11 Suppl 3:26-34.

27. Zander M, Madsbad S, Madsen JL, Holst JJ. Effect of 6-week course of glucagonlike peptide 1 on glycaemic control, insulin sensitivity, and beta-cell function in type 2 diabetes: a parallel-group study. Lancet 2002; 359(9309):824-830.

28. Verdich C, Flint A, Gutzwiller JP et al. A meta-analysis of the effect of glucagonlike peptide-1 (7-36) amide on ad libitum energy intake in humans. J Clin Endocrinol M etab 2001; 86(9):4382-4389.

29. Ayyad C, Andersen T. Long-term efficacy of dietary treatment of obesity: a systematic review of studies published between 1931 and 1999. Obes Rev 2000; 1(2):113-119.

30. Harder H, Nielsen L, Tu DT, Astrup A. The effect of liraglutide, a long-acting glucagon-like peptide 1 derivative, on glycemic control, body composition, and 


\section{Chapter 5}

24-h energy expenditure in patients with type 2 diabetes. Diabetes Care 2004; 27(8):1915-1921.

31. Dushay J, Gao C, Gopalakrishnan GS et al. Short-term exenatide treatment leads to significant weight loss in a subset of obese women without diabetes. Diabetes Care 2012; 35(1):4-11.

32. Bradley DP, Kulstad R, Racine N, Shenker Y, M eredith M, Schoeller DA. Alterations in energy balance following exenatide administration. Appl Physiol Nutr Metab 2012; 10.1139/h2012-068.

33. Rosenbaum M, Leibel RL. Adaptive thermogenesis in humans. Int J Obes (Lond) 2010; 34 Suppl 1:S47-S55.

34. Neumiller JJ, Campbell RK. Liraglutide: a once-daily incretin mimetic for the treatment of type 2 diabetes mellitus. Ann Pharmacother 2009; 43(9):1433-1444.

35. Garber A, Henry R, Ratner R et al. Liraglutide versus glimepiride monotherapy for type 2 diabetes (LEAD-3 Mono): a randomised, 52-week, phase III, double-blind, parallel-treatment trial. Lancet 2009; 373:473-481.

36. Devries JH, Bain SC, Rodbard HW et al. Sequential Intensification of Metformin Treatment in Type 2 Diabetes With Liraglutide Followed by Randomized Addition of Basal Insulin Prompted by A1C Targets. Diabetes Care 2012.

37. Lando HM, Alattar M, Dua AP. Elevated Amylase and Lipase in Patients Using GLP1 Receptor Agonists or DPP-4 Inhibitors in the Outpatient Setting. Endocr Pract 2012;1-16.

38. Rosenbaum M, Hirsch J, M urphy E, Leibel RL. Effects of changes in body weight on carbohydrate metabolism, catecholamine excretion, and thyroid function. Am J Clin Nutr 2000; 71(6):1421-1432. 


\section{Supplemental Data}

Table 1. Comparison of estimated means and treatment differences for appetite and nausea ratings (assessed by visual analog scales following the breakfast meal) after 5 weeks of treatment.

Treatment difference (D) for

\begin{tabular}{|c|c|c|c|c|}
\hline \multirow{3}{*}{ Parameter } & Liraglutide & Liraglutide & \multicolumn{2}{|r|}{${ }^{1}$ lira 1.8 mg vs. placebo } \\
\hline & & & Placebo & \\
\hline & $1.8 \mathrm{mg}$ & $3.0 \mathrm{mg}$ & & ${ }^{2}$ lira 3.0 mg vs. placebo \\
\hline
\end{tabular}

\begin{tabular}{|c|c|c|c|c|}
\hline Appetite & $n=30$ & $n=30$ & $n=30$ & \\
\hline \multicolumn{5}{|l|}{ Overall appetite (mm) } \\
\hline \multirow[t]{4}{*}{ Fasting rating } & 47 & 44 & 43 & \\
\hline & & & ${ }^{1} \mathrm{D}: 4(3 ; 11)$ & 0.23 \\
\hline & & & ${ }^{2} \mathrm{D}: 2(5 ; 8)$ & 0.64 \\
\hline & & & ${ }^{3} \mathrm{D}:-3(-9 ; 4)$ & 0.44 \\
\hline \multirow[t]{4}{*}{ M ean rating $A U C_{15-300 \mathrm{~min} / 285 \mathrm{~min}}$} & 68 & 68 & 56 & \\
\hline & & & ${ }^{1} \mathrm{D}: 12(6 ; 18)$ & 0.0004 \\
\hline & & & ${ }^{2} \mathrm{D}: 12(6 ; 18)$ & 0.0003 \\
\hline & & & ${ }^{3} \mathrm{D}: 0.2(-6 ; 6)$ & 0.94 \\
\hline \multirow[t]{4}{*}{ M aximum rating } & 91 & 92 & 81 & \\
\hline & & & ${ }^{1} \mathrm{D}: 10(4 ; 16)$ & 0.001 \\
\hline & & & ${ }^{2} \mathrm{D}: 11(5 ; 16)$ & 0.0005 \\
\hline & & & ${ }^{3} \mathrm{D}: \quad 1(-5 ; 7)$ & 0.80 \\
\hline \multirow[t]{3}{*}{ 15-min postprandial rating } & 88 & 88 & 77 & \\
\hline & & & ${ }^{1} \mathrm{D}: 11(6 ; 17)$ & 0.0002 \\
\hline & & & ${ }^{2} \mathrm{D}: 11(6 ; 17)$ & 0.0002 \\
\hline
\end{tabular}


Chapter 5

${ }^{3} \mathrm{D}: \quad 0(-6 ; 6)$

0.98

\begin{tabular}{|c|c|c|c|c|c|}
\hline Satiety (mm) & $n=30$ & $n=30$ & $n=30$ & & \\
\hline \multirow[t]{4}{*}{ Fasting rating } & 40 & 38 & 38 & & \\
\hline & & & & ${ }^{1} \mathrm{D}: 2(7 ; 12)$ & 0.61 \\
\hline & & & & ${ }^{2} \mathrm{D}:-0(10 ; 9)$ & 0.92 \\
\hline & & & & ${ }^{3} \mathrm{D}:-3(-12 ; 6)$ & 0.54 \\
\hline \multirow[t]{4}{*}{ M ean rating $A U C_{15-300 \mathrm{~min} / 285 \mathrm{~min}}$} & 66 & 66 & 55 & & \\
\hline & & & & ${ }^{1} \mathrm{D}: 11(4 ; 18)$ & 0.002 \\
\hline & & & & ${ }^{2} \mathrm{D}: 11(4 ; 18)$ & 0.002 \\
\hline & & & & ${ }^{3} \mathrm{D}:-0.3(-7 ; 6)$ & 0.94 \\
\hline \multirow[t]{4}{*}{ Maximum rating } & 90 & 91 & 81 & & \\
\hline & & & & ${ }^{1} \mathrm{D}: 10(4 ; 16)$ & 0.0021 \\
\hline & & & & ${ }^{2} \mathrm{D}: 11(5 ; 17)$ & 0.0009 \\
\hline & & & & ${ }^{3} \mathrm{D}: 1(-5 ; 7)$ & 0.78 \\
\hline \multirow[t]{4}{*}{ 15-min postprandial rating } & 88 & 87 & 73 & & \\
\hline & & & & ${ }^{1} \mathrm{D}: 15(8 ; 22)$ & $\varangle .0001$ \\
\hline & & & & ${ }^{2} \mathrm{D}: 14(7 ; 21)$ & 0.0001 \\
\hline & & & & ${ }^{3} \mathrm{D}:-1(-8 ; 6)$ & 0.84 \\
\hline Fullness (mm) & $n=30$ & $n=30$ & $n=30$ & & \\
\hline \multirow[t]{4}{*}{ Fasting rating } & 35 & 35 & 30 & & \\
\hline & & & & ${ }^{1} \mathrm{D}: 5(-5 ; 15)$ & 0.31 \\
\hline & & & & ${ }^{2} \mathrm{D}: 5(-5 ; 15$ & 0.33 \\
\hline & & & & ${ }^{3}$ D: $-0(-10 ; 10)$ & 0.97 \\
\hline \multirow[t]{2}{*}{ M ean rating $A U C_{15-300 \mathrm{~min} / 285 \mathrm{~min}}$} & 64 & 66 & 52 & & \\
\hline & & & & ${ }^{1} \mathrm{D}: 12(5 ; 19)$ & 0.001 \\
\hline
\end{tabular}


Effects of liraglutide on gastric emptying and energy expenditure in obese subjects

'D: $15(8 ; 22) \quad 0.0001$

${ }^{3} \mathrm{D}: 3(-4 ; 10) \quad 0.42$

\begin{tabular}{|c|c|c|c|c|}
\hline \multirow[t]{4}{*}{ Maximum rating } & 90 & 92 & 79 & \\
\hline & & & ${ }^{1} \mathrm{D}: 12(5 ; 19)$ & 0.0009 \\
\hline & & & ${ }^{2} \mathrm{D}: 13(6 ; 20)$ & 0.0003 \\
\hline & & & ${ }^{3} \mathrm{D}: \quad 1(-6 ; 8)$ & 0.73 \\
\hline \multirow[t]{4}{*}{ 15-min postprandial rating } & 87 & 87 & 71 & \\
\hline & & & ${ }^{1} \mathrm{D}: 16(7 ; 25)$ & 0.0006 \\
\hline & & & ${ }^{2} \mathrm{D}: 16(7 ; 25)$ & 0.0005 \\
\hline & & & ${ }^{3} \mathrm{D}: \quad 0(-9 ; 9)$ & 0.97 \\
\hline
\end{tabular}

\begin{tabular}{|c|c|c|c|c|c|}
\hline (100-hunger) (mm) & $n=30$ & $n=30$ & $n=30$ & & \\
\hline \multirow[t]{4}{*}{ Fasting rating } & 62 & 58 & 59 & & \\
\hline & & & & ${ }^{1} \mathrm{D}: 3(-9 ; 15)$ & 0.57 \\
\hline & & & & ${ }^{2} \mathrm{D}:-1(-13 ; 11)$ & 0.92 \\
\hline & & & & ${ }^{3} \mathrm{D}:-4(-16 ; 8)$ & 0.50 \\
\hline \multirow[t]{4}{*}{ M ean rating $A U C_{15-300 \mathrm{~min} / 285 \mathrm{~min}}$} & 75 & 72 & 63 & & \\
\hline & & & & ${ }^{1} \mathrm{D}: 11(4 ; 18)$ & 0.002 \\
\hline & & & & ${ }^{2} \mathrm{D}: 9(2 ; 16)$ & 0.01 \\
\hline & & & & ${ }^{3} \mathrm{D}:-2(-9 ; 4)$ & 0.51 \\
\hline \multirow[t]{4}{*}{ Maximum rating } & 96 & 96 & 94 & & \\
\hline & & & & ${ }^{1} \mathrm{D}: 2(-2 ; 6)$ & 0.40 \\
\hline & & & & ${ }^{2} \mathrm{D}: 2(-2 ; 6)$ & 0.29 \\
\hline & & & & ${ }^{3} \mathrm{D}: 0(-4 ; 4)$ & 0.83 \\
\hline \multirow[t]{2}{*}{ 15-min postprandial rating } & 91 & 94 & 91 & & \\
\hline & & & & ${ }^{1} \mathrm{D}: 0(-5 ; 6)$ & 0.89 \\
\hline
\end{tabular}


Chapter 5

${ }^{2} \mathrm{D}: 3(-2 ; 9)$

${ }^{3}$ D: $3(-3 ; 8)$

\begin{tabular}{|c|c|c|c|}
\hline $\begin{array}{l}\text { (100-prospective food } \\
\text { consumption) (mm) }\end{array}$ & $n=30$ & $n=30$ & $n=30$ \\
\hline
\end{tabular}

\begin{tabular}{|c|c|c|c|c|c|}
\hline \multirow[t]{4}{*}{ Fasting rating } & 51 & 45 & 45 & & \\
\hline & & & & ${ }^{1} D: 5(-3 ; 14)$ & 0.19 \\
\hline & & & & ${ }^{2} \mathrm{D}: 0(-8 ; 8)$ & 0.97 \\
\hline & & & & ${ }^{3} \mathrm{D}:-5(-13 ; 3)$ & 0.19 \\
\hline \multirow[t]{4}{*}{ M ean rating $A U C_{15-300 \mathrm{~min} / 285 \mathrm{~min}}$} & 66 & 67 & 54 & & \\
\hline & & & & ${ }^{1} \mathrm{D}: 13(6 ; 19)$ & 0.0002 \\
\hline & & & & ${ }^{2} \mathrm{D}: 13(7 ; 20)$ & 0.0001 \\
\hline & & & & ${ }^{3} \mathrm{D}: 0.7(-6 ; 7)$ & 0.82 \\
\hline \multirow[t]{4}{*}{ Maximum rating } & 92 & 90 & 80 & & \\
\hline & & & & ${ }^{1} \mathrm{D}: 12(6 ; 18)$ & 0.0004 \\
\hline & & & & ${ }^{2} \mathrm{D}: 10(4 ; 17)$ & 0.002 \\
\hline & & & & ${ }^{3} \mathrm{D}:-2(-8 ; 5)$ & 0.59 \\
\hline \multirow[t]{4}{*}{ 15-min postprandial rating } & 87 & 84 & 72 & & \\
\hline & & & & ${ }^{1} \mathrm{D}: 15(5 ; 24)$ & 0.003 \\
\hline & & & & ${ }^{2} \mathrm{D}: 12(3 ; 22)$ & 0.01 \\
\hline & & & & ${ }^{3} \mathrm{D}:-2(-12 ; 7)$ & 0.64 \\
\hline Nausea (mm) & $n=30$ & $n=30$ & $n=30$ & & \\
\hline \multirow[t]{4}{*}{ Fasting rating } & 5 & 11 & 4 & & \\
\hline & & & & ${ }^{1} \mathrm{D}: 1(-6 ; 7)$ & 0.81 \\
\hline & & & & ${ }^{2} \mathrm{D}: 7(1 ; 14)$ & 0.02 \\
\hline & & & & ${ }^{3} \mathrm{D}: 7(0 ; 13)$ & 0.04 \\
\hline
\end{tabular}




\section{Effects of liraglutide on gastric emptying and energy expenditure in obese subjects}

$\begin{array}{llll}\text { Mean rating } \mathrm{AUC}_{15-300 \mathrm{~min} / 285 \mathrm{~min}} & 13 & 16 & 12\end{array}$

${ }^{1} \mathrm{D}: 2(-6 ; 9) \quad 0.66$

${ }^{2} \mathrm{D}: 5(-2 ; 12) \quad 0.18$

${ }^{3} \mathrm{D}: 3(-4 ; 10)$

$\begin{array}{llll}\text { Maximum rating } & 28 & 34 & 26\end{array}$

${ }^{1} \mathrm{D}: 2(-12 ; 16)$

${ }^{2} \mathrm{D}: 8(-5 ; 22) \quad 0.23$

${ }^{3} \mathrm{D}: 6(-8 ; 20) \quad 0.39$

15-min postprandial rating $\quad 18 \quad 22 \quad 13$

${ }^{1} \mathrm{D}: 4(-7 ; 16) \quad 0.46$

${ }^{2} \mathrm{D}: 9(-3 ; 21) \quad 0.14$

${ }^{3} \mathrm{D}: 4(-7 ; 16)$

Data are estimated means. Treatment differences are estimated means ( $95 \% \mathrm{Cls})$. Overall appetite score was the average of the 4 scores (satiety +fullness $+[100$-prospective food consumption] $+[100$-hunger $] / 4$. Comparisons between treatment groups were performed using the parametric linear mixed effect model on the original outcome values. The model included effects of subject, period and treatment group (subject was included as a random effect). 


\section{Chapter 5}

Table 2. Comparison of estimated means and treatment differences for energy expenditure, substrate oxidation rates and weight measures after 5 weeks of treatment.

Treatment difference (D)

for

\begin{tabular}{|c|c|c|c|c|}
\hline Parameter & $\begin{array}{l}\text { Liraglutide } \\
\qquad 1.8 \mathrm{mg}\end{array}$ & $\begin{array}{l}\text { Liraglutide } \\
\qquad 3.0 \mathrm{mg}\end{array}$ & Placebo & $\begin{array}{l}{ }^{1} \text { lira } 1.8 \mathrm{mg} \text { vs. placebo } \\
{ }^{2} \text { lira } 3.0 \mathrm{ma} \mathrm{vs,} \mathrm{placebo}\end{array}$ \\
\hline & & & & ${ }^{3}$ lira $3.0 \mathrm{mg}$ vs. lira $1.8 \mathrm{~m}$ \\
\hline
\end{tabular}

\begin{tabular}{|c|c|c|c|c|c|}
\hline Energy expenditure & $n=26$ & $n=30$ & $n=29$ & & \\
\hline \multirow[t]{4}{*}{ Energy balance (\%) } & -4.63 & -3.74 & -2.76 & & \\
\hline & & & & ${ }^{1} \mathrm{D}:-1.87(-3.58 ;-0.17)$ & 0.03 \\
\hline & & & & ${ }^{2} \mathrm{D}:-0.98(-2.59 ; 0.64)$ & 0.23 \\
\hline & & & & ${ }^{3} \mathrm{D}: 0.90(-0.75 ; 2.54)$ & 0.28 \\
\hline \multirow[t]{4}{*}{ TEE $(\mathrm{kJ} / \mathrm{h})$ - original analysis } & 478.3 & 468.8 & 492.9 & & \\
\hline & & & & ${ }^{1} D:-14.6(-26.7 ;-2.45)$ & 0.02 \\
\hline & & & & ${ }^{2} \mathrm{D}:-24.2(-35.4 ;-12.9)$ & 0.0001 \\
\hline & & & & ${ }^{3} \mathrm{D}:-9.59(-20.8 ; 1.66)$ & 0.09 \\
\hline
\end{tabular}

TEE (kJ/h) - post hoc analysis $\quad 480.0 \quad 476.2 \quad 486.8$

$$
\begin{array}{ll}
{ }^{1} \mathrm{D}:-6.71(-18.4 ; 4.96) & 0.25 \\
{ }^{2} \mathrm{D}:-10.6(-22.2 ; 1.02) & 0.07 \\
{ }^{3} \mathrm{D}:-3.89(-15.0 ; 7.25) & 0.48
\end{array}
$$

3-hour EE during lowest SPA $\quad 323.6 \quad 324.3 \quad 333.9$

$(\mathrm{kJ} / \mathrm{h})$

${ }^{1} \mathrm{D}:-10.3(-20.2 ;-0.34) \quad 0.04$

${ }^{2} \mathrm{D}:-9.6(-19.0 ;-0.12) \quad 0.05$

${ }^{3} \mathrm{D}: 0.71(-8.6 ; 10.0)$

$\begin{array}{llll}\text { PAL } & 1.48 & 1.45 & 1.48\end{array}$
${ }^{1}$ D: $-0.00(-0.04 ; 0.03)$
0.79 
Effects of liraglutide on gastric emptying and energy expenditure in obese subjects

\begin{tabular}{|c|c|c|c|c|c|}
\hline & & & & ${ }^{2} \mathrm{D}:-0.03(-0.07 ; 0.00)$ & 0.06 \\
\hline & & & & ${ }^{3}$ D: $-0.03(-0.06 ; 0.01)$ & 0.12 \\
\hline AlEE & 166.9 & 155.1 & 168.6 & & \\
\hline & & & & ${ }^{1} \mathrm{D}:-1.74(-14.7 ; 11.24)$ & 0.79 \\
\hline & & & & ${ }^{2} \mathrm{D}:-13.5(-25.7 ;-1.4)$ & 0.03 \\
\hline & & & & ${ }^{3} \mathrm{D}:-11.8(-24.0 ; 0.42)$ & 0.06 \\
\hline Substrate oxidation rates & & & & & \\
\hline 24-hour RQ & $n=26$ & $n=30$ & $n=29$ & & \\
\hline & 0.86 & 0.88 & 0.88 & & \\
\hline & & & & ${ }^{1} \mathrm{D}:-0.02(-0.03 ;-0.01)$ & $\varangle .0001$ \\
\hline & & & & ${ }^{2} \mathrm{D}:-0.01(-0.02 ; 0.00)$ & 0.09 \\
\hline & & & & ${ }^{3} \mathrm{D}: 0.01(0.00 ; 0.02)$ & 0.006 \\
\hline 24-hour fat oxidation $(\mathrm{kJ} / \mathrm{h})$ & $n=26$ & $n=30$ & $n=29$ & & \\
\hline - original analysis & 172.1 & 151.6 & 143.7 & & \\
\hline & & & & ${ }^{1} \mathrm{D}: 28.36(12.50 ; 44.21)$ & 0.0008 \\
\hline & & & & ${ }^{2} \mathrm{D}: 7.92(-6.95 ; 22.79)$ & 0.29 \\
\hline & & & & ${ }^{3} \mathrm{D}:-20.4(-35.5 ;-5.42)$ & 0.009 \\
\hline 24-hour $\mathrm{CHO}$ oxidation (kJ/h) & $n=26$ & $n=30$ & $n=29$ & & \\
\hline - original analysis & 269.9 & 282.4 & 313.1 & & \\
\hline & & & & ${ }^{1}$ D: -43.2 (-63.3; -23.2) & $\varangle .0001$ \\
\hline & & & & ${ }^{2} \mathrm{D}:-30.7(-49.5 ;-11.9)$ & 0.002 \\
\hline & & & & ${ }^{3} \mathrm{D}: 12.52(-6.45 ; 31.48)$ & 0.19 \\
\hline 24-hour protein oxidation & $n=28$ & $n=30$ & $n=30$ & & \\
\hline
\end{tabular}




\section{Chapter 5}

$(\mathrm{kJ} / \mathrm{h})$

- original analysis

47.67

45.86

51.44

${ }^{1} \mathrm{D}:-3.77(-7.39 ;-0.15) \quad 0.04$

${ }^{2} \mathrm{D}:-5.58(-9.14 ;-2.03) \quad 0.003$

${ }^{3} \mathrm{D}:-1.81(-5.37 ; 1.75) \quad 0.31$

\begin{tabular}{|c|c|c|c|c|c|}
\hline 24-hour fat oxidation (\%) & $n=26$ & $n=30$ & $n=29$ & & \\
\hline \multirow[t]{4}{*}{ - post hoc analysis } & 35.46 & 32.28 & 29.43 & & \\
\hline & & & & ${ }^{1} D: 6.03(2.86 ; 9.19)$ & 0.0003 \\
\hline & & & & ${ }^{2} \mathrm{D}: 2.85(-0.09 ; 5.78)$ & 0.06 \\
\hline & & & & ${ }^{3} \mathrm{D}-3.18(-6.16 ;-0.20)$ & 0.04 \\
\hline 24-hour $\mathrm{CHO}$ oxidation (\%) & $n=26$ & $n=30$ & $n=29$ & & \\
\hline \multirow[t]{4}{*}{ - post hoc analysis } & 56.90 & 60.32 & 63.59 & & \\
\hline & & & & ${ }^{1} \mathrm{D}:-6.69(-10.3 ;-3.04)$ & 0.0005 \\
\hline & & & & ${ }^{2} \mathrm{D}:-3.27(-6.65 ; 0.10)$ & 0.06 \\
\hline & & & & ${ }^{3} \mathrm{D}: 3.42(-0.00 ; 6.84)$ & 0.05 \\
\hline 24-hour protein oxidation (\%) & $n=26$ & $n=30$ & $n=29$ & & \\
\hline \multirow[t]{4}{*}{ - post hoc analysis } & 9.94 & 9.72 & 10.14 & & \\
\hline & & & & ${ }^{1} \mathrm{D}:-0.20(-1.01 ; 0.61)$ & 0.63 \\
\hline & & & & ${ }^{2} \mathrm{D}:-0.42(-1.16 ; 0.32)$ & 0.26 \\
\hline & & & & ${ }^{3} \mathrm{D}:-0.22(-0.97 ; 0.53)$ & 0.55 \\
\hline Weight measures & $n=30$ & $n=32$ & $n=33$ & & \\
\hline \multirow[t]{4}{*}{ Body weight $(\mathrm{kg})$} & 100.3 & 100.0 & 102.5 & & \\
\hline & & & & ${ }^{1} \mathrm{D}:-2.14(-3.21 ;-1.07)$ & 0.0002 \\
\hline & & & & ${ }^{2} \mathrm{D}:-2.46(-3.53 ;-1.38)$ & $\varangle .0001$ \\
\hline & & & & ${ }^{3} \mathrm{D}:-0.32(-1.38 ; 0.74)$ & 0.55 \\
\hline
\end{tabular}




\begin{tabular}{llcc}
\hline BMI $\left(\mathrm{kg} / \mathrm{m}^{2}\right)$ & 33.54 & 33.41 & \\
& ${ }^{1} \mathrm{D}:-0.72(-1.09 ;-0.36)$ & 0.0003 \\
& ${ }^{2} \mathrm{D}:-0.86(-1.22 ;-0.49)$ & $\varangle .0001$ \\
& ${ }^{3} \mathrm{D}:-0.14(-0.49 ; 0.22)$ & 0.45
\end{tabular}

TEE, 24-hour total energy expenditure; SPA, spontaneous physical activity; PAL, physical activity level; AIEE, activity induced energy expenditure; RQ, respiratory quotient; $\mathrm{CHO}$, carbohydrate; $\mathrm{BMI}$, body mass index

Data are estimated means. Treatment differences are estimated means $(95 \% \mathrm{Cls})$. Comparisons between treatment groups were performed using the parametric linear mixed effect model. The model included effects of subject, period and treatment group (subject was included as a random effect).

In the post hoc analysis for TEE, the covariates gender and fat-free mass (assessed at baseline); weight and energy balance (assessed prior to chamber entry after each 5-week period); and urinary noradrenalin and PAL (assessed in the chamber) were added to the original linear mixed-effect model. Effects of noradrenalin, energy balance and gender were found to be not significant and excluded from the model.

In the post hoc analyses for substrate oxidation rates, energy balance and gender were added as fixed effects to the original model. Substrate oxidation rates were expressed as either $\mathrm{kJ} / \mathrm{h}$ or $\%$ of TEE. 


\section{Chapter 5}

Table 3. Adverse events with an incidence of $>5 \%$ in any treatment group

\begin{tabular}{|c|c|c|c|c|c|c|c|c|c|c|c|c|}
\hline & \multicolumn{4}{|c|}{ Liraglutide $1.8 \mathrm{mg}$} & \multicolumn{4}{|c|}{ Liraglutide $3.0 \mathrm{mg}$} & \multicolumn{4}{|c|}{ Placebo } \\
\hline & N & (\%) & $\mathbf{E}$ & $\mathbf{R}$ & $\mathbf{N}$ & (\%) & $\mathbf{E}$ & $\mathbf{R}$ & $\mathbf{N}$ & (\%) & $\mathbf{E}$ & $\mathbf{R}$ \\
\hline Safety analysis set & 30 & & & & 32 & & & & 32 & & & \\
\hline Exposure (years) & 3.2 & & & & 3.4 & & & & 3.5 & & & \\
\hline All adverse events & 27 & $(90.0)$ & 117 & 36.1 & 30 & $(93.8)$ & 86 & 25.1 & 24 & $(75.0)$ & 54 & 15.6 \\
\hline \multicolumn{13}{|l|}{ Gastrointestinal disorders } \\
\hline Nausea & 11 & $(36.7)$ & 18 & 5.6 & 9 & $(28.1)$ & 13 & 3.8 & 3 & (9.4) & 4 & 1.2 \\
\hline Diarrhea & 6 & $(20.0)$ & 6 & 1.9 & 9 & $(28.1)$ & 13 & 3.8 & 3 & (9.4) & 3 & 0.9 \\
\hline Feces hard & 5 & $(16.7)$ & 6 & 1.9 & & & & & 1 & (3.1) & 1 & 0.3 \\
\hline $\begin{array}{l}\text { Gastroesophageal reflux } \\
\text { disease }\end{array}$ & 4 & (13.3) & 12 & 3.7 & 5 & $(15.6)$ & 6 & 1.8 & 4 & $(12.5)$ & 4 & 1.2 \\
\hline Abdominal pain upper & 2 & (6.7) & 4 & 1.2 & 1 & (3.1) & 1 & 0.3 & 1 & (3.1) & 1 & 0.3 \\
\hline Constipation & 2 & (6.7) & 2 & 0.6 & 3 & (9.4) & 3 & 0.9 & 1 & (3.1) & 1 & 0.3 \\
\hline Eructation & 2 & (6.7) & 2 & 0.6 & & & & & 1 & (3.1) & 1 & 0.3 \\
\hline $\begin{array}{l}\text { Infrequent bowel } \\
\text { movements }\end{array}$ & 2 & (6.7) & 2 & 0.6 & & & & & & & & \\
\hline Vomiting & 2 & (6.7) & 2 & 0.6 & 4 & $(12.5)$ & 4 & 1.2 & & & & \\
\hline \multicolumn{13}{|l|}{ Nervous system disorders } \\
\hline Headache & 15 & $(50.0)$ & 19 & 5.9 & 9 & $(28.1)$ & 11 & 3.2 & 10 & (31.3) & 11 & 3.2 \\
\hline Dizziness & 3 & $(10.0)$ & 4 & 1.2 & 2 & (6.3) & 3 & 0.9 & 3 & (9.4) & 3 & 0.9 \\
\hline \multicolumn{13}{|l|}{ Metabolism and nutrition } \\
\hline Decreased appetite & 9 & $(30.0)$ & 10 & 3.1 & 8 & $(25.0)$ & 8 & 2.3 & 1 & (3.1) & 1 & 0.3 \\
\hline \multicolumn{13}{|l|}{$\begin{array}{l}\text { Infections and } \\
\text { infestations }\end{array}$} \\
\hline Influenza & 5 & (16.7) & 5 & 1.5 & 5 & $(15.6)$ & 5 & 1.5 & 5 & (15.6) & 5 & 1.4 \\
\hline Nasopharyngitis & 2 & (6.7) & 2 & 0.6 & 1 & (3.1) & 1 & 0.3 & & & & \\
\hline
\end{tabular}


Effects of liraglutide on gastric emptying and energy expenditure in obese subjects

General disorders and

administration site

conditions

Influenza-like illness

2

(6.7)

2

$0.6 \quad 2$

(6.3)

20.6

1

(3.1) $\quad 1$

0.3

Musculoskeletal and

connective tissues

disorders
Bursitis
2
(6.7)
2
0.6

$\mathrm{N}$, number of subjects with adverse event; \%, proportion in analysis set having adverse events; $\mathrm{E}$, Number of adverse events; $\mathrm{R}$, event rate, exposure years. 
Chapter 5 


\section{Supplement to chapter 5:}

\section{Transcriptional regulation of adipose tissue metabolism after 5 week treatment with liraglutide in obese subjects}

Judith GP van Can, Johan Jocken, Wim HM Saris and Ellen E Blaak. 


\section{Supplement to chapter 5}

\section{Abstract}

Introduction: Effect of GLP -1 analog liraglutide on adipose tissue metabolism is poorly understood.

Aim: We aimed to investigate the effects of liraglutide on mRNA expression in adipose tissue in obese individuals.

Design: Participants $\left(\mathrm{N}=49,18-75\right.$ years, $\mathrm{BM} / 30-40 \mathrm{~kg} / \mathrm{m}^{2}$ ) were randomized to 2 of 3 treatments: once-daily liraglutide $1.8 \mathrm{mg}, 3.0 \mathrm{mg}$, or placebo in a double-blind, incomplete cross-over trial. After 5 weeks, a fat biopsy was collected in the fasted state to determine mRNA expression by RT-PCR.

Results and conclusion: mRNA expression in adipose tissue of genes involved in insulin signalling (IRS-1 and GLUT-4) adipocyte differentiation (PPARY), adipokine secretion (adiponectin, leptin and DPP-4) and lipolysis (ATGL and HSL) did not change after treatment with 1.8 and $3.0 \mathrm{mg}$ liraglutide compared with placebo. Based on the present data liraglutide does not seem to exert major effects on adipose tissue metabolism. Nevertheless, several of these pathways may be regulated at posttranscriptional and/or posttranslational level, which implicates that we cannot exclude a role of adipose tissue based on transcriptional data only. 


\section{Introduction}

Obesity is characterized by an excessive accumulation of adipose tissue and is associated with the development of type 2 diabetes mellitus and hyperlipidemia (1). The growth of adipose tissue involved cellular hypertrophy and hyperplasia (2). Adipocytes play an important role in energy homeostasis by storing energy in lipid droplets $(3,4)$. Furthermore, adipose tissue functions as an endocrine organ, secreting adipokines that regulate energy metabolism in fat and other tissues $(5,6)$. Hypertrophy is the result of excess lipid accumulation in adipocytes due to high energy intake. Obesity is characterized by adipocyte hyperthrophy, an upregulation of pro-inflammatory adipokines and cytokines, linked to an increase in pro-inflammatory cytokines and a downregulation of adiponectin secretion, thereby leading to insulin resistance $(7,8)$. Glucagon-like peptide-1 (GLP-1) is a neuroendocrine hormone released predominantly from the small intestine in response to food intake (9). Furthermore, preclinical and clinical studies have demonstrated increased satiety, reduced food intake, and subsequent reductions in body weight following administration of GLP-1, leading to its investigation for the treatment of obesity $(10,11)$. Given the rapid inactivation of endogenous GLP-1 by the enzyme dipeptidyl-peptidase-4 (DPP-4), alternative therapeutic approaches have been developed, such as GLP-1 receptor agonists (GLP-1R) which are resistant to DPP4 mediated degradation (12). One of the approved GLP-1R agonists is liraglutide, which is used to treat type 2 diabetes mellitus (13). The increase in GLP-1 activity has emerged as a useful therapeutic tool for the treatment of type 2 diabetes mellitus and obesity. GLP-1R is expressed in many tissues, including pancreas, lung, heart, kidney, intestine, stomach, muscle, as well as the central and peripheral nervous systems $(9,14)$. The actions of GLP-1 on $\beta$-cells and the nervous and digestive system are well known. The effect of GLP- 1 on adipose tissue metabolism is still poorly defined. Studies in isolated rat and human adipocytes have demonstrated that GLP-1 has the ability to induce both lipogenic as lipolytic mechanisms (15-17). Although the function of GLP-1R has been more extensively studies in 3T3-L1 adipocytes, the exact function in human adipose tissue remains unclear (18). Boschmann showed that vildagliptin, a DPP4 inhibitor, resulted in an increase in postprandial adipose tissue lipolysis and augmented postprandial systemic fat oxidation rate in overweight/obese subjects (19). In the study reported in chapter 5 we showed that liragultide has pronounced effects on weight loss, glycemic control, insulin sensitivity and results in an increased fat oxidation. The hypothesis of the present study is that these effects may be related to an improved adipose tissue function and an increased lipolysis. 


\section{Supplement to chapter 5}

The aim of this study is to investigate the effects of a 5 week treatment with $1.8 \mathrm{mg}$ and $3.0 \mathrm{mg}$ liraglutide on expression of genes involved in lipolysis and adipose tissue function in obese subjects.

\section{Methods}

The complete design of the study is described in chapter 5 of this thesis. Briefly, we studied the effects of a 5 week treatment with $1.8 \mathrm{mg}$ and $3.0 \mathrm{mg}$ liraglutide on gastric emptying, substrate oxidation, glucose metabolism and food intake in obese subjects.

A small amount (about $1 \mathrm{~g}$ ) of abdominal subcutaneous adipose tissue was collected after 5 weeks of treatment with liraglutide or placebo, when subjects were fasted, under local anesthesia using a needle biopsy technique and snap frozen in liquid nitrogen. The adipose tissue was homogenized in $1 \mathrm{ml}$ trizol for RNA stabilization. RNA was isolated and quantified and checked for purity on the NanoDrop 1000 (NanoDrop Technologies, Wilmington, DE,USA). RNA integrity was evaluated using the BioAnalyser (Agilent, Palo Alto, CA, USA). To minimize methodological errors due to variation in CDNA-synthesis, CDNA-synthesis was performed simultaneously for all subjects included in the analysis (iScript CDNA synthesis kit, Bio-rad Laboratories Inc., Hercules CA, USA). The Quantitative real-time PCR was performed in a volume of $25 \mu$ l containing $12.5 \mathrm{ng}$ CDNA, $1 \times$ IQ SYBR Green Supermix and $400 \mathrm{nM}$ of gene-specific forward and reverse primers. CDNA was amplified using a two-step program $\left(40\right.$ cycles of $10 \mathrm{sec}$ at $95^{\circ} \mathrm{C}$ and $45 \mathrm{sec}$ at $60^{\circ} \mathrm{C}$ ) with $\mathrm{MylQ}^{\mathrm{TM}}$ system (Bio-rad Laboratories Inc., Veenendaal, The Netherlandss). Gene expression levels were expressed relative to geometric mean of two internal references, i.e ribosomal protein L 13a (RPL13a) and $\beta$-2-microglobulin ( $\beta 2 M)$. RPL13a and $\beta 2 M$ were used as reference genes as they were identified as most stable as established by Genorm (20).

\section{Statistics}

Gene expression was expressed as normalized values relative to RPL13a and $32 \mathrm{M}$. Mean differences between treatment groups were determined by a linear model that included treatment group as fixed effects and subject as a random effect. All data are expressed as mean with \pm SEM . The level of statistical significance was set at $P \leq 0.05$. 


\section{Results}

Treatment with $1.8 \mathrm{mg}$ or $3.0 \mathrm{mg}$ liraglutide did not result in differences in changes in gene expression in pathways of adipokine production (adipencetin, leptin and DPP-4, figure 1 and 2), adipogenesis (PPARY, figure 2), lipolysis (ATGL and HSL, figure 2) and insulin signaling (IRS-1 and GLUT-4, figure 1) .
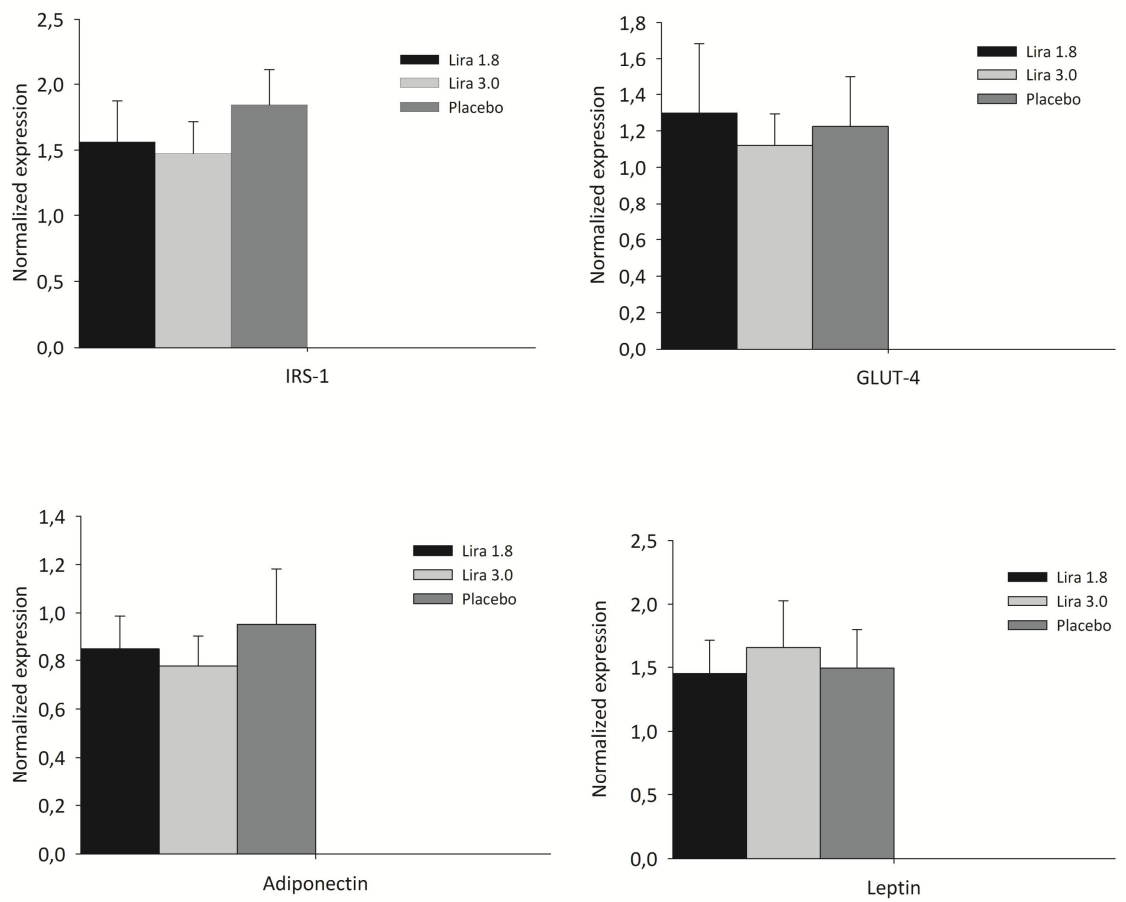

Figure 1. Normalized gene expression in adipose tissue of IRS-1, GLUT-4, Adiponectin and Leptin in 26-29 subjects after 5 week treatment of $1.8 \mathrm{mg}, 3.0 \mathrm{mg}$ liraglutide and placebo. 

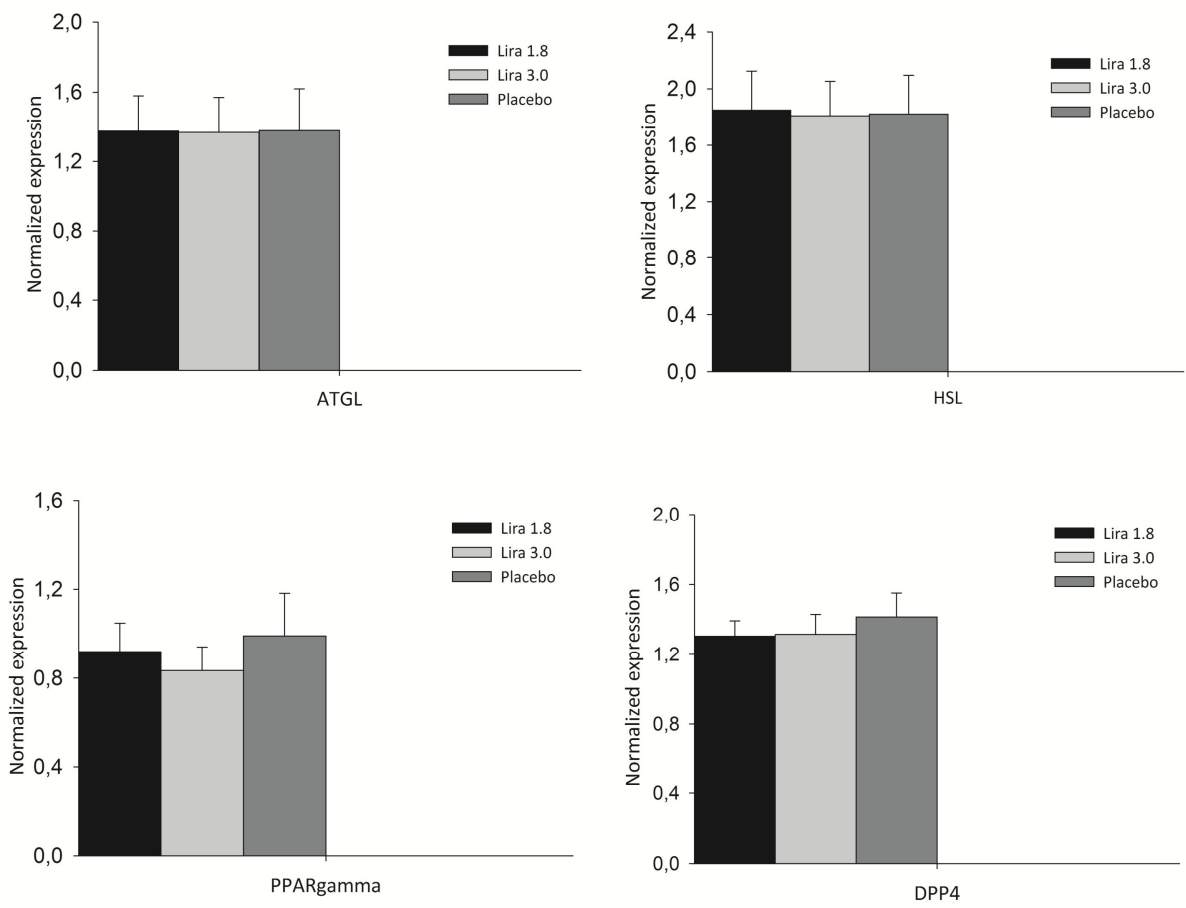

Figure 2. Normalized gene expression in adipose tissue of ATGL, HSL, PPARy and DDP4 in 26-29 subjects after 5 week treatment of $1.8 \mathrm{mg}, 3.0 \mathrm{mg}$ liraglutide and placebo.

\section{Discussion}

In the present study, no differences in adipose tissue gene expression of pathways related to isulin signalling (IRS-1, GLUT-4), adipokine production (adiponectin, leptin, DPP-4), lipolysis (HSL, ATGL) adiposgenesis (PPARY), was observed after 5 weeks of treatment with liraglutide.

Liraglutide improved glycemic control, by reducing fasting and postprandial glucose concentrations and increased insulin sensitivity, weight loss and fat oxidation as described in chapter 5. However, the mechanisms by which the GLP-1R in adipose tissue may contribute in the improvement remain to be defined. Expression of GLUT-4 and IRS-1 in adipose tissue did not differ between treatment groups and placebo in obese subjects. This is not consistent with studies in 3T3-L1 cells showed an upregulation of glucose transporters and insulin signalling molecules $(21,22)$. As most of the glucose is taken up by skeletal muscle, more pronounced effects on glucose transport and insulin signalling 
may be found in skeletal muscle. In addition, adiponectin and leptin secretion were unaltered after treatment with liraglutide compared with placebo. Recently, a novel adipokine, DPP-4, released from differentiated human adipocytes was identified. Lamers et. al demonstrate that DPP4 impaired insulin signalling in 3 different primary cell types, namely, adipocytes, skeletal muscle and smooth muscle cells (26). In the present study, DPP4 mRNA expression in adipose tissue did not alter after treatment of liraglutide compared with placebo. DPP4 release can be reversed to normal levels by surgery-induced weight loss (26). The weight loss induced by liraglutide in the present study may be not enough to induce changes in mRNA expression of DPP-4. Future work will be needed to address the mechanism and the functional role of DPP-4 in the pathogenesis of insulin resistance and obesity-associated complications.

Liragutide resulted in an increase of fat oxidation at the expense of $\mathrm{CHO}$ oxidation. This may be due to an increase in lipolysis, which was observed by Bosschman after a 7 day treatment with vildagliptin (19). In addition, Vendrell et al. showed that GLP-1 stimulates lipolysis, by glycerol release, in adipocytes in a receptor-dependent manner (23). These effects on lipolysis could not be confirmed in the present study, where no changes were observed in mRNA expression of the lipolytic genes HSL and ATGL after treatment with liraglutide. This may indicate no pronounced effects on lipolysis, but we cannot exclude effects on adipose tissue lipolysis since we know that lipolysis is importantly regulated at post-trancriptional and post-translational level.

Suppressed adipogenesis, accompanied by an increase in adipocyte size, is linked to increased insulin resistance (24). It has been suggested that GLP-1 increases the differentiation of adipocyte precursors into mature adipocytes, which may further contribute to enhanced insulin sensitivity by preventing ectopic lipid accumulation $(1,25)$. PPARy mRNA expression, a marker of adipocyte differentiation, was unaffected by liraglutide treatment. The effect of liraglutide on adipogenesis may involve other genes which are not measured in this study. The underlying signalling pathway may involve activation of protein kinase C (PKC), extracellular signal-regulated kinases (ERK) and AKT, which leads to altered proliferation, apoptosis and differentiation (25).

In conclusion, treatment of 1.8 and $3.0 \mathrm{mg}$ liraglutide did not result in differences in expression of genes in adipose tissue involved on pathways of adipokine production, adipogenesis, lipolysis and insulin signaling. This does not rule out the possibility that liraglutide has an effect of adipose tissue function but perhaps more pronounced effects are observed at post-trancriptional and post-translational level. Furthermore, the treatment period of 5 weeks may be not long enough to induce structural changes in adipose tissue function. Future studies are needed to investigate the long-term effects of 


\section{Supplement to chapter 5}

liraglutide on adipose tissue function. In addition, it would be of interest to determine circulating GLP-1 and adipokine and lipid concentrations in future studies.

\section{References}

1. Kahn BB, Flier JS. Obesity and insulin resistance. J Clin Invest 2000;106:473-81.

2. Jo J, Gavrilova O, Pack S, et al. Hypertrophy and/or Hyperplasia: Dynamics of Adipose Tissue Growth. PLoS Comput Biol 2009;5:e1000324.

3. Cornelius P, MacDougald OA, Lane MD. Regulation of adipocyte development. Annu Rev Nutr 1994;14:99-129.

4. Hwang CS, Loftus TM, Mandrup S, Lane MD. Adipocyte differentiation and leptin expression. Annu Rev Cell Dev Biol 1997;13:231-59.

5. Koerner A, Kratzsch J, Kiess W. Adipocytokines: leptin--the classical, resistin--the controversical, adiponectin--the promising, and more to come. Best Pract Res Clin Endocrinol M etab 2005;19:525-46.

6. Takeda S, Elefteriou $F$, Levasseur $R$, et al. Leptin regulates bone formation via the sympathetic nervous system. Cell 2002;111:305-17.

7. Hausman DB, DiGirolamo M, Bartness TJ, Hausman GJ, Martin RJ. The biology of white adipocyte proliferation. Obes Rev 2001;2:239-54.

8. Kadowaki T, Yamauchi T. Adiponectin and adiponectin receptors. Endocr Rev 2005;26:439-51.

9. Drucker DJ. The biology of incretin hormones. Cell M etab 2006;3:153-65.

10. Flint A, Raben A, Astrup A, Holst JJ. Glucagon-like peptide 1 promotes satiety and suppresses energy intake in humans. J Clin Invest 1998;101:515-20.

11. Meeran K, O'Shea D, Edwards CM, et al. Repeated intracerebroventricular administration of glucagon-like peptide-1-(7-36) amide or exendin-(9-39) alters body weight in the rat. Endocrinology 1999;140:244-50.

12. Holst JJ. The physiology of glucagon-like peptide 1. Physiol Rev 2007;87:1409-39.

13. Drucker DJ, Dritselis A, Kirkpatrick P. Liraglutide. Nat Rev Drug Discov 2010;9:2678.

14. Li Y, Tweedie D, Mattson MP, Holloway HW, Greig NH. Enhancing the GLP-1 receptor signaling pathway leads to proliferation and neuroprotection in human neuroblastoma cells. J Neurochem 2010;113:1621-31.

15. Majumdar ID, Weber HC. Gastrointestinal regulatory peptides and their effects on fat tissue. Curr Opin Endocrinol Diabetes Obes 2010;17:51-6.

16. Ruiz-Grande C, Alarcon C, Merida E, Valverde I. Lipolytic action of glucagon-like peptides in isolated rat adipocytes. Peptides 1992;13:13-6.

17. Villanueva-Penacarrillo ML, Marquez L, Gonzalez N, Diaz-Miguel M, Valverde I. Effect of GLP-1 on lipid metabolism in human adipocytes. Horm Metab Res 2001;33:73-7.

18. Montrose-Rafizadeh $\mathrm{C}$, Yang $\mathrm{H}$, Wang $\mathrm{Y}$, Roth J, Montrose M H, Adams LG. Novel signal transduction and peptide specificity of glucagon-like peptide receptor in 3T3-L1 adipocytes. J Cell Physiol 1997;172:275-83. 
19. Boschmann M, Engeli S, Dobberstein K, et al. Dipeptidyl-peptidase-IV inhibition augments postprandial lipid mobilization and oxidation in type 2 diabetic patients. J Clin Endocrinol Metab 2009;94:846-52.

20. Vandesompele J, De Preter K, Pattyn F, et al. Accurate normalization of real-time quantitative RT-PCR data by geometric averaging of multiple internal control genes. Genome Biol 2002;3:RESEARCH0034.

21. Wang Y, Kole HK, Montrose-Rafizadeh C, Perfetti R, Bernier M, Egan JM. Regulation of glucose transporters and hexose uptake in 3T3-L1 adipocytes: glucagon-like peptide-1 and insulin interactions. J M ol Endocrinol 1997;19:241-8.

22. Gao H, Wang X, Zhang Z, et al. GLP-1 amplifies insulin signaling by up-regulation of IRbeta, IRS-1 and Glut4 in 3T3-L1 adipocytes. Endocrine 2007;32:90-5.

23. Vendrell J, El Bekay R, Peral B, et al. Study of the potential association of adipose tissue GLP-1 receptor with obesity and insulin resistance. Endocrinology 2011;152:4072-9.

24. Meissburger B, Stachorski L, Roder E, Rudofsky G, Wolfrum C. Tissue inhibitor of matrix metalloproteinase 1 (TIM P1) controls adipogenesis in obesity in mice and in humans. Diabetologia 2011;54:1468-79.

25. Challa TD, Beaton N, Arnold M, Rudofsky G, Langhans W, Wolfrum C. Regulation of adipocyte formation by GLP-1/GLP-1R signaling. J Biol Chem 2012;287:6421-30.

26. Lamers D, Famulla S, Wronkowitz N, et al. Dipeptidyl peptidase 4 is a novel adipokine potentially linking obesity to the metabolic syndrome. Diabetes 2011;60:1917-25. 
Supplement to chapter 5 


\section{Chapter 6}

\section{General Discussion}

Judith GP van Can 
The prevalence of type 2 diabetes mellitus is increasing rapidly. In susceptible people, mostly overweight or obese, blood glucose levels may rise and induce a pre-diabetic state, resulting in impaired fasting glucose (IFG) and/or impaired glucose tolerance (IGT) (1). These states of impaired glucose metabolism increase the risk for developing type 2 diabetes mellitus and cardiovascular disease (2). Besides genetic factors, lifestyle factors such as, an increased intake of energy-dense high fat foods and reduced levels of physical activity play an important role in the increased prevalence of type 2 diabetes mellitus. Lifestyle intervention programs directed towards a healthy diet, increased physical activity and moderate weight reduction have been shown to be effective in the prevention of type 2 diabetes mellitus $(3,4)$. However, $30 \%$ of the high-risk subjects do not respond to lifestyle interventions indicating the need for additional preventive strategies. Metabolic inflexibility ie. an impaired capacity to regulate fat oxidation, may be one of the contributing mechanisms to body weight gain and insulin sensitivity. Reversal of metabolic inflexibility by means of dietary or pharmacological strategies may, therefore, be a plausible option to increase the success of lifestyle intervention. In this thesis, nutritional intervention, by means of structurally manipulated carbohydrates and by polyphenols and by pharmacological intervention by a GLP-1 analog have been studied in their capacity to modulate fat oxidation and their related positive effects on metabolic profile. Results will be discussed in the following paragraphs, followed by recommendations for future research.

\section{Slowly digestible carbohydrates}

Carbohydrates provide the major nutrient source of the Western diet (55-60\%) and preferably come from whole grain foods rich in fiber and low in added sugar. Debate is still ongoing for several years about glycaemic index and its relevance to type 2 diabetes mellitus and weight management (5-8). However, it is difficult to review and interpret the published results because of the large variety in design between studies (differences in energy and fibre content) and subject characteristics (lean, obese, type 2 diabetes mellitus). Postprandial glycemia and insulinemia have been implicated in the etiology of metabolic chronic diseases like obesity and type 2 diabetes mellitus. The underlying mechanisms relating reduced postprandial glucose to the prevention of these diseases are less clear (9). One of the putative mechanisms is that reduction of postprandial glucose and insulin responses may affect body weight control and insulin sensitivity by promoting fat oxidation at the expense of carbohydrate oxidation $(8,10)$. In Chapter 2A-B we hypothesized that the ingestion of two structurally manipulated $\mathrm{CHO}$, trehalose (TRE) and isomaltulose (IMU) may reduce postprandial glycaemic and insulinemic responses, thereby increasing lipolysis and fat oxidation. Trehalose is a disaccharide of glucose with 
an a-1,1 glycoside linkage and isomaltulose is disaccharide produced by an enzymic conversion of sucrose, whereby the 1,2-glycosidic linkage between glucose and fructose is rearranged to a 1,6-glycosidic linkage. Indeed, ingestion of trehalose as well isomaltulose resulted in a dampened glycemic and insulinemic response compared with glucose and sucrose, respectively, in overweight subjects. In addition, a different pattern of fat oxidation was observed, resulting in an attenuated inhibition of postprandial fat oxidation after ingestion of IMU in combination with a mixed meal. The attenuated inhibition of postprandial fat oxidation could be attributed to greater supply of FFA to the fat-oxidizing tissue, secondary to a reduced insulin mediated suppression of lipolysis (11). Indeed, circulating FFA concentrations were also less inhibited with IMU as compared to SUC when combined with mixed meal ingestion. Our data are consistent with animal studies that show that a reduced GI can shift postprandial substrate use in favour of fat oxidation, independent of diet-induced changes in body composition or energy intake $(12,13)$. Similar findings were observed in humans during exercise conditions and in healthy men, where ingestion of IMU resulted in a higher fat oxidation $(14,15)$. Taken together, the IMU induced dampened insulinemic response may reduce the insulin-mediated reduction in lipolysis, thereby increasing fatty acid availability and reducing the inhibition of postprandial fat oxidation. Additionally, the IMU-induced reduced glycemic response may directly affect skeletal muscle fat oxidation, since increased glucose concentrations may inhibit fatty acid oxidation via increased malonyl-CoA concentrations and subsequent inhibition of CPT-1 (16). This illustrates that the regulation of glucose and fatty acid oxidation is a coordinated process and the exact mechanisms for the IMU mediated increase in postprandial fat oxidation have to be studied in more detail in future studies.

The ingestion of IMU together with a mixed meal may favour fat oxidation above storage in adipose and non-adipose tissues and may thereby have a favourable effect on body weight control and insulin sensitivity. A lower rate of adaptation to a high fat diet has been shown to lead to weight gain over time, in particular with modern lifestyle conditions with a low level of physical activity (17). Flatt proposed that subjects who have a reduced postprandial fat oxidation, continue to oxidize carbohydrate in the postabsorptive state thereby depleting their endogenous glycogen stores; which stimulates food intake (18). This leads to increased food intake to replace these diminished carbohydrate stores which will simultaneously increase fat storage. There are also indications that the more energy efficient handling of fat as compared to other macronutrients and a reduced capacity to adjust fat oxidation to an increased dietary fat intake as well may contribute to a positive energy balance and body weight gain and in particular to the development of insulin resistance and type 2 diabetes mellitus $(19,20)$. The dynamic process of adjusting fat oxidation to fatty acid uptake and IM TG turnover may prevent the muscle from excess lipid storage, whereas an impaired flexibility may 
lead to lipid accumulation and thereby impairing insulin sensitivity. Additionally, it has been hypothesized an altered pattern of glycemia like a chronic high early glycemic response followed by late below baseline glycemia and late increased FFA concentrations are associated with development of insulin resistance. Increasaed FFA concentrations may induce insulin resistance, whilst the chronically increased glucose concentrations may exhaust $B$-cell function in the long term (21). In this respect, it can be speculated that the altered pattern of glycemia and circulating FFA concentrations with IMU as compared to SUC may have positive long term effects with respect to insulin sensitivity and insulin secretion.

Finally, it has been suggested that a reduced glycemic and/or insulinemic response may have direct effects on satiety and appetite, but evidence is not consistent $(22,23)$. Chapter 2B showed a decreased peak in ghrelin concentration when IMU was ingested as a drink, possibly indicating less inhibition of hunger. However, no significant effects on ghrelin were observed when IMU was ingested with a mixed meal, indicating that these putative appetite-reducing effects of IMU disappear under more physiological conditions. Our data are consistent with Peters et al. who tested 3 carbohydrates differing in digestibility of rapidly, slowly to non-digestible. Despite differing effects on plasma glucose concentrations, appetite responses to these carbohydrates were not different (24). Furthermore, we observed no effect on circulating GLP1 during ingestion of IMU as a drink as well as combined with a mixed meal. Taken together, our data do not support a hormonal response in favour of increasing satiety.

There are indications that individuals with IGT and insulin resistant obese individuals have abnormalities in postprandial FFA metabolism and consequently adapt more slowly to a higher dietary fat intake as compared to lean subjects $(19,25)$. Subjects with impairments in fat oxidation are less responsive to FFA availability and to adjust their fat oxidation, thereby potentially less responsive to interventions to modulate fat oxidation. Abnormalities in postprandial FFA metabolism have already been documented in individuals with IGT and insulin resistant obese individuals and it is uncertain whether the beneficial effects of IMU and TRE also extend to this group $(25,26)$. Therefore, we examined the metabolic effects of trehalose and isomaltulose in a similar design as described in chapter 2A-B in IGT subjects to investigate whether the IMU-induced positive effects on fat oxidation also extended to this group of prediabetic subjects. The results were consistent with the findings in overweight subjects, showing beneficial effects on fat oxidation when IMU was ingested with a mixed meal, indicating that also in this group IMU might be an useful addition to the diet.

In summary, the studies described in chapter 2A-B and $\mathbf{3}$ show improved glycaemic control and reduced insulinemia, which induced a shift in substrate use towards fat 150 
oxidation when IMU was consumed with a mixed meal. Long-term studies are required to investigate the effects on body weight regulation and insulin sensitivity to obtain more information on whether exchanging rapidly available carbohydrates with IMU is an effective strategy in preventing obesity and concomitant metabolic disturbances. Additionally, the beneficial effects have been observed when IMU was ingested as a drink and it is uncertain of the effects will last when IMU is used in a different matrix.

\section{Green tea and polyphenols}

In recent years there has been an increased interest in the health benefits of polyphenols in the prevention of obesity and type 2 diabetes mellitus. Green tea extracts (GTE), particularly the catechin EGCG, have been suggested to affect body weight control and insulin sensitivity, possibly mediated through effects on fat oxidation $(27,28)$. The number of human studies on the effects of EGCG on fat oxidation is sparse and data are not consistent. In chapter 4, we hypothesized that a 3 day supplementation of $300 \mathrm{mg} /$ day EGCG would increase postprandial fat oxidation through a stimulation of lipolysis in overweight subjects. Short-term EGCG supplementation did not result in changes in circulating FFA and had no effect on postprandial fat oxidation. These data are in line with the results of the study of Lonac et al. who showed no effect of 3 day EGCG supplementation on fat oxidation in lean subjects, whilst others did observe an effect on fat oxidation after short-term EGCG supplementation $(29,30)$. The discrepancies between these findings are discussed below in more detail. In a subgroup we investigated the effects of EGCG on local adipose tissue and skeletal muscle metabolism, by measuring glycerol, glucose and lactate using microdialysis. Consistent with the lack of effect on fat oxidation, we observed no effects on local adipose tissue and skeletal muscle blood flow and interstitial glycerol concentrations, indicating no effects on local lipolysis. Nevertheless, lactate concentrations were strongly reduced (25\%) with EGCG as compared to placebo both during fasting as well as postprandial conditions, whilst local blood flow and glucose concentration were comparable. This may indicate a shift towards a more oxidative phenotype after EGCG supplementation. This is in line with previous reports on stimulatory effects of green tea ingestion on oxidative capacity in healthy humans, (either 6 portions of 1 gram green tea solids for 2 days or 1 cup of green tea containing 12 gram green tea solid), as indicated by an increased urinary excretion of several citric acid cycle intermediates $(31,32)$. Also, an increase in oxidative capacity is supported by findings of an increased $\mathrm{VO}_{2}$ max during exercise while on short-term EGCG supplementation (405 $\mathrm{mg} /$ day) in healthy men (33). In that study, the capsules ( 7 in total) were ingested 48 hours prior to data collection, consuming one capsule with each meal. The final capsule was consumed 2-hours before exercise testing. Finally, our data on reduced lactate 
concentrations are consistent with the study of Murase et al. who reported decreased plasma lactate concentrations during endurance activity (swimming) in mice (34).

One of the putative mechanisms for the effect of EGCG on fat oxidation is through inhibiting catechol-o-methyltransferase (COMT), inhibiting norepinephrine reuptake (at neuronal ends or in circulation). As a consequence there is a prolonged stimulation of the adrenergic receptors, thereby increasing lipolysis and fat oxidation. It has been suggested that the COMT mechanism is not powerful enough to cause the full effect of EGCG (35). As indicated above, we have found no increase in local or systemic lipolysis, indicating no effects on COMT. This also indicates that the pronounced shift in skeletal muscle glycolytic capacity, as evidenced by the reduced interstitial lactate concentrations, may be rather due to a direct effect on skeletal muscle handling than due to differences in fuel supply. The shift in muscle phenotype towards more oxidation can be speculated to be due to direct effects on the transcriptional coactivator Peroxisome proliferator-activated receptor- $\nu$ coactivator 1 alpha (PGC- $1 \alpha$ ), the activation of sirtuins (in particular sirtuin 1 ), and subsequent effects on mitochondrial function which has been reported for other polyphenols (36-40). Taken together, a 3 day supplementation of $300 \mathrm{mg} /$ day EGCG does not seem sufficient to induce changes in postprandial fat oxidation. Despite this, the reduced muscle lactate concentration indicate a switch to a more oxidative phenotype in skeletal muscle. More pronounced effects on fat oxidation with EGCG may be obtained with a longer duration of supplementation or a higher dose, combining EGCG with other components that may increase fat oxidation to obtain synergistic effects or combining EGCG with other lifestyle intervention like exercise. These options are discussed below.

\section{Longer supplementation period or higher dose}

A longer period of supplementation than the 3 day period of the present study could be necessary to elicit an effect on whole-body fat oxidation. The bioavailability of EGCG is rather low, making it questionable if circulating EGCG concentrations are high enough levels to exert direct effects on adipose tissue and metabolism, as suggested from in vitro studies (41-43). Thielecke et. al did show an increased fat oxidation in the first $2 \mathrm{~h}$ of the postprandial period after 3 day supplementation of EGCG, which is in contrast to our findings (30). This may possibly be related to the fact that in that study an extra dose of $150 \mathrm{mg}$ EGCG was ingested $1 \mathrm{~h}$ before the meal. In addition, it has been suggested that the effects of EGCG on fat oxidation are cumulative over time, a hypothesis that is supported by evidence from animal studies $(44,45)$. 


\section{Combination with other components like caffeine and other polyophenols}

The reported favourable effects of EGCG on fat oxidation are often reported when caffeine is simultaneously given. Caffeine is known to independently increase energy expenditure (46). It is plausible that when EGCG and caffeine are consumed together, they act synergistically. Dulloo et al. showed an acute effect of GTE (375 mg, $270 \mathrm{mg}$ EGCG) and caffeine ( $150 \mathrm{mg}$ ) on fat oxidation and energy expenditure in lean subjects (47). The shortterm effects on energy expenditure have been further supported by the use of GTE at higher doses ( $540 \mathrm{mg} / \mathrm{d}$ and $300 \mathrm{mg}$ caffeine) (48). A long-term study (12 weeks) suggests that the effect of the combination of EGCG and caffeine on energy expenditure persists over time (49). Other dietary polyphenols may also have the potential to improve fat oxidation and mitochondrial function. Resveratrol, an activator of SIRT-1 and PGC- $1 \alpha$, showed an improved mitochondrial function, protection from diet-induced obesity and insulin resistance in animals $(39,50)$. Human studies with resveratrol are scarce, Timmers et al. found some opposite effects as compared with animal studies. Supplementation with $150 \mathrm{mg}$ resveratrol for 30 days resulted in a reduction in energy expenditure and fat oxidation in obese subjects. Nevertheless skeletal muscle mitochondrial respiration was increased, liver fat accumulation was decreased, HOM A-index decreased and postprandial adipose tissue lipolysis tended to be reduced, indicating positive effects on overall metabolic profile (51). It still remains to be elucidated if resveratrol is as effective as supplement to stimulate fat oxidation in humans, in particular when used in combination with EGCG. Furthermore, soy isoflavones, in particular genistein, may have anti-obesity activities via effects on lipid metabolism, skeletal muscle TAG and PPARa expression (5255). Animal studies showed that genistein prevented fat accumulation possibly by increasing PGC-1 mRNA and UCP-2 mRNA (56). These polyphenols may have differential and possibly partly overlapping mechanisms of actions and combined together they could have additive or synergistic effects on postprandial fat oxidation as EGCG alone has no effects on postprandial fat oxidation. At this moment, no human data are available on the combined effects of these polyphenols on fat oxidation.

\section{Exercise}

Rains et al. hypothesized that the effects of EGCG may be the greatest under conditions of elevated norepinephrine release, such as exercise (57). Animal studies showed that EGCG increased endurance capacity based upon a greater reliance on fat oxidation $(34,58)$. This observation is consistent with a study in young men where short-term $(890 \mathrm{mg}$ polyphenols + 366 mg EGCG) supplementation increased fat oxidation during moderate intensity exercise (59). Ota et al. showed similar results in Japanese men consuming a 
green tea beverage ( $570 \mathrm{mg}+40 \mathrm{mg}$ caffeine) as part of an exercise program for 8 weeks. Fat oxidation was increased in the latter study under both exercising and sedentary conditions in the green tea group as compared to placebo (60). Furthermore, the combined effects of EGCG, caffeine and a 10 week exercise program resulted in changes in body composition in overweight and obese women (61). However, Dean et al. reported no additional effects of EGCG on fat oxidation in male cyclists (62). Based on the studies described above, it can be speculated that EGCG may have more pronounced effects in sedentary subjects instead of well trained athletes.

Overall, the utilisation of green tea and/or EGCG would be a useful addition to a diet. However, the hardest part is to find consensus how and under what conditions EGCG might have beneficial effects on fat oxidation and body weight regulation, as discussed above. There are several ways to supplement EGCG, in a pill form or a beverage. It is estimated that the content EGCG is a cup of green tea is approximately $90 \mathrm{mg}$, implying that to reach the same dosage one would have to drink about 7 cups of tea per day, which makes it difficult to incorporate it in a healthy diet in form of normal daily products. Further research is necessary to determine the effectiveness of EGCG in relation to dose and period of supplementation, the combination with other bioactive components and lifestyle components.

\section{Pharmacological agents}

Pharmacotherapy can enhance the weight-reducing effect of lifestyle changes and can facilitate long-term weight maintenance (63). As a result of adverse effects, contraindications, drug interactions and costs, many subjects who may benefit from pharmacotherapy for obesity do not receive this treatment. A relatively new class of agents, the GLP-1 receptor agonist family, has gained intense interest as a potential therapeutic agent for obesity management. Liraglutide has been shown to reduce body weight in subjects with type 2 diabetes mellitus. In a randomized trial lasting up to 52 weeks, treatment with $1.2 \mathrm{mg}$ and $1.8 \mathrm{mg}$ of liraglutide reduced body weight up to $3.2 \mathrm{~kg}$ $(64,65)$. The underlying mechanisms relating to weight loss are unknown yet. As the GLP1 receptor is localized on different tissues, its hypothesized that the underlying mechanism is a combination from signals from the CNS and effects on peripheral tissues like skeletal muscle and adipose tissue. Chapter 5 describes the effects of 5 weeks of treatment with $1.8 \mathrm{mg}$ and $3.0 \mathrm{mg}$ liraglutide on substrate oxidation, glucose metabolism, appetite and food intake in obese subjects. Liraglutide showed a reduction of body weight $(-2.14$ and $-2.46 \mathrm{~kg})$ and $\mathrm{BMI}\left(-0.72\right.$ and $\left.-0.86 \mathrm{~kg} / \mathrm{m}^{2}\right)$ in both liraglutide groups as compared with placebo in obese subjects after 5 weeks of treatment. Weight loss 
occurred with liraglutide while no counselling regarding diet, physical activity and weight management was given. These results are in line with a phase 3 study in obese subjects where 20 weeks of treatment with liraglutide resulted in mean weight loss of 5.5 and 7.2 $\mathrm{kg}$ in obese subjects as compared with placebo (66). In some trials, weight loss appeared to have reached a plateau by $12-20$ weeks of treatment, whereas in another study weight loss was progressive for up to 26 weeks $(67,68)$.

Effects on energy expenditure and fat oxidation

The role of GLP-1 in the control of energy expenditure and substrate oxidation rates is not clearly understood. Animal and human studies have provided contradictory evidence as whether GLP-1 has a stimulatory or an inhibitory effect on thermogenesis. Both central and peripheral GLP-1 administration increased oxygen consumption in rats $(69,70)$. Conversely, GLP-1 infusion reduced diet-induced thermogenesis and postprandial CHO oxidation in lean and obese humans $(71,72)$. These human studies used supraphysiological doses that may have amplified the effect on energy expenditure by slowing down gastric emptying. Chapter 5 showed that the use of liraglutide reduces $24 \mathrm{~h}$ energy expenditure and increases fat oxidation in favour of $\mathrm{CHO}$ oxidation after 5 weeks of treatment compared with placebo. The reduction in EE was largely explained by weight loss and reduced physical activity. The underlying mechanism of the switch in substrate utilization is unknown yet. The increased fat oxidation is independent of weight loss, energy balance and physical activity, this may indicate that liraglutide has a direct effect on fat oxidation. One of the putative mechanisms for the increased fat oxidation is that liraglutide stimulates lipolysis and thereby fat oxidation. Support for this hypothesis comes from an in vitro study in adipocytes of obese subjects, which showed an increased lipolytic effect and a reduction in lipogenic action by GLP-1 (73). In addition, Boschmann et al. showed that the use of vildagliptin, a DPP-4 inhibitor, increased adipose tissue lipolysis and postprandial fat oxidation as indicated by raised dialysate glycerol concentrations (74). As reported in chapter 5, we studied adipose insulin signalling, adipogenesis and lipolysis in more detail at the transcriptional level. We did not observe a difference in the expression of the lipolytic genes, HSL and ATGL. This may indicate no pronounced effects on lipolysis, but we cannot exclude effects on adipose tissue lipolysis since we know that lipolysis is importantly regulated at postprancriptional and posttranslational level. Unfortunately, we have from this study no available data on circulating FFA and glycerol concentrations. The shift in substrate oxidation in favour of fat oxidation may have longterm implications for body weight regulation and fat storage in non-adipose tissue, thereby improving insulin sensitivity (9). Interestingly, Inoue et al showed that liraglutide reduced visceral fat in subjects with type 2 diabetes mellitus (75). Both fasting as well as 
postprandial glucose concentrations were attenuated after treatment with liraglutide compared with placebo. These results are in line with studies in subjects with type 2 diabetes. Clinical trials have shown that liraglutide significantly reduced fasting plasma glucose with concomitant weight loss in type 2 diabetes subjects $(65,76)$. Flint et al. showed that postprandial glucose concentrations were attenuated after liraglutide treatment in type 2 diabetics (77). Despite a reduction in glucose concentrations, fasting and postprandial insulin concentrations were not different between liraglutide and placebo. Insulin and C-peptide concentrations were markedly reduced in the first 60 minutes after the test meal. The reduced glucose concentrations in combination with the unchanged insulin concentrations suggests an improved insulin sensitivity with liraglutide It is tempting to speculate that the insulin sensitizing effects of liraglutide may be related to the improved capacity to oxidize fat by reducing the amount of lipid accumulation in non-adipose tissue like skeletal muscle. Finally, the reduction of glucagon secretion lessens hepatic glucose output and contributes to the improved glycaemic control (78). Interestingly, DPP4, involved in the breakdown of incretins was recently identified as a new adipokine released from differentiated human adipocytes. Lamers et al. demonstrated that DDP-4 impairs insulin signalling in primary cells of adipocytes, skeletal muscle and smooth muscle cells. Obese subjects are characterized by increased circulating DDP-4 concentrations and it may be speculated that DPP-4 may interfere with insulin sensitivity not only in adipose tissue but also in other insulin sensitive tissues (79). These findings stress the putative importance of GLP analogues in the prevention of obesity related complications. Future studies are needed to define the pathways that link adipose GLP-1 to insulin sensitivity and type 2 diabetes mellitus.

\section{Concluding remarks and future research}

The major findings of the present thesis are summarized below:

1 Ingestion of IMU combined with a mixed meal induced a shift in substrate use in favour of fat oxidation in overweight and IGT subjects. The exact mechanisms for the IMU mediated increase in postprandial fat oxidation have to be studied in more detail in future studies. Furthermore, it has to be determined whether IMU will translate into long term metabolic effects when rapidly available carbohydrates are replaced with IMU in food products.

2 Short-term supplementation of $300 \mathrm{mg} /$ day EGCG has no effect on postprandial fat oxidation in overweight subjects. Nevertheless a pronounced shift towards a more oxidative phenotype was observed in a subgroup. Future research should focus under what conditions EGCG will have the optimal effect, such as dosage of EGCG, the duration 
of supplementation and the combination with other supplements or lifestyle components like exercise. To define the most optimal strategy more studies are needed to further elucidate the underlying mechanisms of the effects of EGCG on fat oxidation and the role of specific tissues like adipose tissue and skeletal muscle.

3 The use of the GLP-1 analog liraglutide for 5 weeks resulted in body weight loss and an improved glycemic control in obese subjects. Future studies should explore the long-term effects on weight maintenance and improved insulin sensitivity which would make liraglutide a suitable agent in the treatment of obesity.

4 Our study was one of the first to demonstrate significant effect of a GLP1 analog on energy expenditure and fat oxidation. Liraglutide induced a shift in substrate use towards a higher fat oxidation, although the underlying mechanism remains to be elucidated. Future experiments are needed to address the effects of liraglutide on fatty acid handling in adipose tissue as well as skeletal muscle. This is of particular interest since recent studies show that DPP-4, responsible for the degradation of GLP1, was identified as a novel adipokine and that obese subjects are characterized by increased concentrations of DPP4 (84). Lamers et al.(84) demonstrated that DDP-4 impairs insulin signalling in primary cells of adipocytes, skeletal muscle and smooth muscle cells. DPP-4 may interfere with insulin sensitivity not only in adipose tissue but also in other insulin sensitive tissues (79). Future studies are needed to define the pathways that link GLP-1 to insulin sensitivity and type 2 diabetes mellitus.

Taken together, in this thesis we demonstrated the effectiveness of two dietary strategies and a GLP-1 analog to modulate fat oxidation. Although lifestyle intervention should be the first step in body weight management and diabetes prevention, not all subjects effectively respond to intervention. To improve the metabolic flexibility to respond to lifestyle intervention dietary supplements or pharmacological intervention may be a useful tool to increase the lifestyle intervention success. But before that, the duration, dose and synergy with other bioactive compounds and lifestyle components like diet and exercise remains to be defined in more detail.

In particular, the glucagon-like peptide-1 receptor agonists, such as liraglutide and exenatide may be promising new drugs for the treatment of obesity as it not only induces weight loss but also improves fat oxidation and the metabolic profile. However, the durability of the weight loss and the improved metabolic profile induced by GLP-1 receptor agonists needs to be established. Finally, it has to be emphasized that body weight maintenance and type 2 diabetes mellitus prevention can only be successful when 
a behavioural change is made and individuals are committed to lose weight and maintain a healthy lifestyle.

\section{References}

1. Genuth $S$, Alberti KG, Bennett $P$, et al. Follow-up report on the diagnosis of diabetes mellitus. Diabetes Care 2003;26:3160-7.

2. Must A, Spadano J, Coakley EH, Field AE, Colditz G, Dietz WH. The disease burden associated with overweight and obesity. JAM A 1999;282:1523-9.

3. Tuomilehto J, Lindstrom J, Eriksson JG, et al. Prevention of type 2 diabetes mellitus by changes in lifestyle among subjects with impaired glucose tolerance. $\mathrm{N}$ Engl J Med 2001;344:1343-50.

4. Corpeleijn E, Feskens EJ, Jansen EH, et al. Improvements in glucose tolerance and insulin sensitivity after lifestyle intervention are related to changes in serum fatty acid profile and desaturase activities: the SLIM study. Diabetologia 2006;49:2392401.

5. Bornet FR, Jardy-Gennetier AE, Jacquet N, Stowell J. Glycaemic response to foods: impact on satiety and long-term weight regulation. Appetite 2007;49:535-53.

6. Brand-M iller J, M cM illan-Price J, Steinbeck K, Caterson I. Dietary glycemic index: health mplications. J Am Coll Nutr 2009;28 Suppl:446S-449S.

7. Raben A. Should obese patients be counselled to follow a low-glycaemic index diet? No. Obes Rev 2002;3:245-56.

8. Ludwig DS. The glycemic index: physiological mechanisms relating to obesity, diabetes, and cardiovascular disease. JAM A 2002;287:2414-23.

9. Brand-M iller JC, Holt SH, Pawlak DB, M cM illan J. Glycemic index and obesity. Am J Clin Nutr 2002;76:281S-5S.

10. Roberts SB. High-glycemic index foods, hunger, and obesity: is there a connection? Nutr Rev 2000;58:163-9.

11. Wolever TM, Mehling C. Long-term effect of varying the source or amount of dietary carbohydrate on postprandial plasma glucose, insulin, triacylglycerol, and free fatty acid concentrations in subjects with impaired glucose tolerance. Am J Clin Nutr 2003;77:612-21.

12. Scribner KB, Pawlak DB, Aubin CM, Majzoub JA, Ludwig DS. Long-term effects of dietary glycemic index on adiposity, energy metabolism, and physical activity in mice. Am J Physiol Endocrinol M etab 2008;295:E1126-31.

13. Pawlak DB, Kushner JA, Ludwig DS. Effects of dietary glycaemic index on adiposity, glucose homoeostasis, and plasma lipids in animals. Lancet 2004;364:778-85.

14. Arai $H$, Mizuno A, Sakuma $M$, et al. Effects of a palatinose-based liquid diet (Inslow) on glycemic control and the second-meal effect in healthy men. Metabolism 2007; 56:115-21. 
15. Achten J, Jentjens RL, Brouns F, Jeukendrup AE. Exogenous oxidation of isomaltulose is lower than that of sucrose during exercise in men. J Nutr 2007;137:1143-8.

16. McGarry JD. Glucose-fatty acid interactions in health and disease. Am J Clin Nutr 1998;67:500S-504S.

17. Astrup A. The relevance of increased fat oxidation for body-weight management: metabolic inflexibility in the predisposition to weight gain. Obes Rev 2011;12:85965.

18. Flatt JP. The difference in the storage capacities for carbohydrate and for fat, and its mplications in the regulation of body weight. Ann N Y Acad Sci 1987;499:10423.

19. Corpeleijn E, Saris WH, Blaak EE. Metabolic flexibility in the development of insulin resistance and type 2 diabetes: effects of lifestyle. Obes Rev 2009;10:17893.

20. Galgani J, Ravussin E. Energy metabolism, fuel selection and body weight regulation. Int J Obes (Lond) 2008;32 Suppl 7:S109-19.

21. Willett W, Manson J, Liu S. Glycemic index, glycemic load, and risk of type 2 diabetes. Am J Clin Nutr 2002;76:274S-80S.

22. Ludwig DS, Majzoub JA, Al-Zahrani A, Dallal GE, Blanco I, Roberts SB. High glycemic index foods, overeating, and obesity. Pediatrics 1999;103:E26.

23. Warren JM, Henry CJ, Simonite V. Low glycemic index breakfasts and reduced food intake in preadolescent children. Pediatrics 2003;112:e414.

24. Peters HP, Ravestein P, van der Hijden HT, Boers HM, Mela DJ. Effect of carbohydrate digestibility on appetite and its relationship to postprandial blood glucose and insulin levels. Eur J Clin Nutr 2010;65:47-54.

25. M ensink M, Blaak EE, van Baak M A, Wagenmakers AJ, Saris WH. Plasma free Fatty Acid uptake and oxidation are already diminished in subjects at high risk for developing type 2 diabetes. Diabetes 2001;50:2548-54.

26. Reaven GM. The fourth musketeer--from Alexandre Dumas to Claude Bernard. Diabetologia 1995;38:3-13.

27. Wolfram S, Wang $Y$, Thielecke F. Anti-obesity effects of green tea: from bedside to bench. Mol Nutr Food Res 2006;50:176-87.

28. Grove KA, Lambert JD. Laboratory, epidemiological, and human intervention studies show that tea (Camellia sinensis) may be useful in the prevention of obesity. J Nutr 2010;140:446-53.

29. Lonac MC, Richards JC, Schweder MM, Johnson TK, Bell C. Influence of ShortTerm Consumption of the Caffeine-Free, Epigallocatechin-3-Gallate Supplement, Teavigo, on Resting Metabolism and the Thermic Effect of Feeding. Obesity (Silver Spring) 2011;19:298-304.

30. Thielecke F, Rahn G, Bohnke J, et al. Epigallocatechin-3-gallate and postprandial fat oxidation in overweight/obese male volunteers: a pilot study. Eur J Clin Nutr 2010;64:704-13. 
31. Van Dorsten FA, Daykin CA, Mulder TP, Van Duynhoven JP. Metabonomics approach to determine metabolic differences between green tea and black tea consumption. J Agric Food Chem 2006;54:6929-38.

32. Law WS, Huang PY, Ong ES, et al. Metabonomics investigation of human urine after ingestion of green tea with gas chromatography/mass spectrometry, liquid chromatography/mass spectrometry and (1)H NM R spectroscopy. Rapid Commun Mass Spectrom 2008;22:2436-46.

33. Richards JC, Lonac MC, Johnson TK, Schweder MM, Bell C. Epigallocatechin-3gallate increases maximal oxygen uptake in adult humans. Med Sci Sports Exerc 2010;42:739-44.

34. Murase T, Haramizu S, Shimotoyodome A, Nagasawa A, Tokimitsu I. Green tea extract improves endurance capacity and increases muscle lipid oxidation in mice. Am J Physiol Regul Integr Comp Physiol 2005;288:R708-15.

35. Borchardt RT, Huber JA. Catechol 0-methyltransferase. 5. Structure-activity relationships for inhibition by flavonoids. J M ed Chem 1975;18:120-2.

36. Chung S, Yao H, Caito S, Hwang JW, Arunachalam G, Rahman I. Regulation of SIRT1 in cellular functions: role of polyphenols. Arch Biochem Biophys;501:79-90.

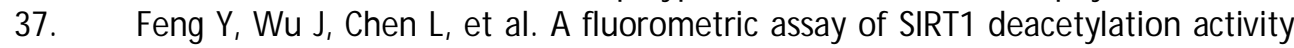
through quantification of nicotinamide adenine dinucleotide. Anal Biochem 2009;395:205-10.

38. de Boer VC, de Goffau MC, Arts IC, Hollman PC, Keijer J. SIRT1 stimulation by polyphenols is affected by their stability and metabolism. Mech Ageing Dev 2006;127:618-27.

39. Baur JA, Pearson KJ, Price NL, et al. Resveratrol improves health and survival of mice on a high-calorie diet. Nature 2006;444:337-42.

40. Fan E, Zhang K. Targeting resveratrol to mitochondria for cardiovascular diseases. Recent Pat Cardiovasc Drug Discov;5:97-102.

41. Donovan JL, Crespy V, M anach C, et al. Catechin is metabolized by both the small intestine and liver of rats. J Nutr 2001;131:1753-7.

42. Moon HS, Chung CS, Lee HG, Kim TG, Choi YJ, Cho CS. Inhibitory effect of (-)epigallocatechin-3-gallate on lipid accumulation of 3T3-L1 cells. Obesity (Silver Spring) 2007;15:2571-82.

43. Sakurai N, M ochizuki K, Kameji H, Shimada M, Goda T. (-)-Epigallocatechin gallate enhances the expression of genes related to insulin sensitivity and adipocyte differentiation in 3T3-L1 adipocytes at an early stage of differentiation. Nutrition 2009;25:1047-56.

44. Wu CH, Lu FH, Chang CS, Chang TC, Wang RH, Chang C). Relationship among habitual tea consumption, percent body fat, and body fat distribution. Obes Res 2003;11:1088-95.

45. Murase T, Nagasawa A, Suzuki J, Hase T, Tokimitsu I. Beneficial effects of tea catechins on diet-induced obesity: stimulation of lipid catabolism in the liver. Int J Obes Relat M etab Disord 2002;26:1459-64. 
46. Astrup A, Toubro S, Cannon S, Hein P, Breum L, Madsen J. Caffeine: a doubleblind, placebo-controlled study of its thermogenic, metabolic, and cardiovascular effects in healthy volunteers. Am J Clin Nutr 1990;51:759-67.

47. Dulloo AG, Duret $C$, Rohrer $D$, et al. Efficacy of a green tea extract rich in catechin polyphenols and caffeine in increasing 24-h energy expenditure and fat oxidation in humans. Am J Clin Nutr 1999;70:1040-5.

48. Rudelle S, Ferruzzi MG, Cristiani I, et al. Effect of a thermogenic beverage on 24hour energy metabolism in humans. Obesity (Silver Spring) 2007;15:349-55.

49. Auvichayapat $P$, Prapochanung $M$, Tunkamnerdthai $O$, et al. Effectiveness of green tea on weight reduction in obese Thais: A randomized, controlled trial. Physiol Behav 2008;93:486-91.

50. Lagouge M, Argmann C, Gerhart-Hines Z, et al. Resveratrol improves mitochondrial function and protects against metabolic disease by activating SIRT1 and PGC-1alpha. Cell 2006;127:1109-22.

51. Timmers $\mathrm{S}$, Konings $\mathrm{E}$, Bilet $\mathrm{L}$, et al. Calorie restriction-like effects of 30 days of resveratrol supplementation on energy metabolism and metabolic profile in obese humans. Cell M etab 2011;14:612-22.

52. Park HJ, Yang JY, Ambati S, et al. Combined effects of genistein, quercetin, and resveratrol in human and 3T3-L1 adipocytes. J Med Food 2008;11:773-83.

53. Ronis MJ, Chen Y, Badeaux J, Badger TM. Dietary soy protein isolate attenuates metabolic syndrome in rats via effects on PPAR, LXR, and SREBP signaling. J Nutr 2009;139:1431-8.

54. Villa P, Costantini B, Suriano R, et al. The differential effect of the phytoestrogen genistein on cardiovascular risk factors in postmenopausal women: relationship with the metabolic status. J Clin Endocrinol Metab 2009;94:552-8.

55. Szkudelska K, Nogowski L. Genistein--a dietary compound inducing hormonal and metabolic changes. J Steroid Biochem M ol Biol 2007;105:37-45.

56. Lee YM, Choi JS, Kim M H, Jung M H, Lee YS, Song J. Effects of dietary genistein on hepatic lipid metabolism and mitochondrial function in mice fed high-fat diets. Nutrition 2006;22:956-64.

57. Rains TM, Agarwal S, Maki KC. Antiobesity effects of green tea catechins: a mechanistic review. J Nutr Biochem 2011;22:1-7.

58. Murase T, Haramizu S, Shimotoyodome A, Tokimitsu I, Hase T. Green tea extract improves running endurance in mice by stimulating lipid utilization during exercise. Am J Physiol Regul Integr Comp Physiol 2006;290:R1550-6.

59. Venables MC, Hulston CJ, Cox HR, Jeukendrup AE. Green tea extract ingestion, fat oxidation, and glucose tolerance in healthy humans. Am J Clin Nutr 2008;87:77884.

60. Ota N, S. S, Shimotoyodome A, et al. Effects of combination of regular exercise and tea catechins intake on energy expenditure in humans. J Health Sci 2005;51:233-6.

61. Smith AE, Lockwood CM, Moon JR, et al. Physiological effects of caffeine, epigallocatechin-3-gallate, and exercise in overweight and obese women. Appl Physiol Nutr M etab 2010;35:607-16. 
62. Dean S, Braakhuis A, Paton C. The effects of EGCG on fat oxidation and endurance performance in male cyclists. Int J Sport Nutr Exerc M etab 2009;19:624-44.

63. Wadden TA, Berkowitz RI, Womble LG, et al. Randomized trial of lifestyle modification and pharmacotherapy for obesity. N Engl J Med 2005;353:2111-20.

64. Garber A, Henry R, Ratner R, et al. Liraglutide versus glimepiride monotherapy for type 2 diabetes (LEAD-3 M ono): a randomised, 52-week, phase III, double-blind, parallel-treatment trial. Lancet 2009;373:473-81.

65. Vilsboll T, Zdravkovic M, Le-Thi T, et al. Liraglutide, a long-acting human glucagonlike peptide-1 analog, given as monotherapy significantly improves glycemic control and lowers body weight without risk of hypoglycemia in patients with type 2 diabetes. Diabetes Care 2007;30:1608-10.

66. Astrup A, Rossner S, Van Gaal L, et al. Effects of liraglutide in the treatment of obesity: a randomised, double-blind, placebo-controlled study. Lancet 2009;374:1606-16.

67. Zinman B, Gerich J, Buse JB, et al. Efficacy and safety of the human glucagon-like peptide-1 analog liraglutide in combination with metformin and thiazolidinedione in patients with type 2 diabetes (LEAD-4 M et+TZD). Diabetes Care 2009;32:122430.

68. Buse JB, Rosenstock J, Sesti G, et al. Liraglutide once a day versus exenatide twice a day for type 2 diabetes: a 26-week randomised, parallel-group, multinational, open-label trial (LEAD-6). Lancet 2009;374:39-47.

69. Hwa JJ, Ghibaudi L, Williams P, Witten MB, Tedesco R, Strader CD. Differential effects of intracerebroventricular glucagon-like peptide-1 on feeding and energy expenditure regulation. Peptides 1998;19:869-75.

70. Osaka T, Endo M, Yamakawa M, Inoue S. Energy expenditure by intravenous administration of glucagon-like peptide-1 mediated by the lower brainstem and sympathoadrenal system. Peptides 2005;26:1623-31.

71. Flint A, Raben A, Rehfeld JF, Holst JJ, Astrup A. The effect of glucagon-like peptide-1 on energy expenditure and substrate metabolism in humans. Int J Obes Relat M etab Disord 2000;24:288-98.

72. Flint A, Raben A, Ersboll AK, Holst J , Astrup A. The effect of physiological levels of glucagon-like peptide-1 on appetite, gastric emptying, energy and substrate metabolism in obesity. Int J Obes Relat M etab Disord 2001;25:781-92.

73. Sancho V, Trigo MV, Martin-Duce A, et al. Effect of GLP-1 on D-glucose transport, lipolysis and lipogenesis in adipocytes of obese subjects. Int J Mol Med 2006;17:1133-7.

74. Boschmann M, Engeli S, Dobberstein K, et al. Dipeptidyl-peptidase-IV inhibition augments postprandial lipid mobilization and oxidation in type 2 diabetic patients. J Clin Endocrinol Metab 2009;94:846-52.

75. Inoue K, M aeda N, Kashine S, et al. Short-term effects of liraglutide on visceral fat adiposity, appetite, and food preference: a pilot study of obese Japanese patients with type 2 diabetes. Cardiovasc Diabetol 2011;10:109.

76. Nauck MA, Hompesch M, Filipczak R, Le TD, Zdravkovic M, Gumprecht J. Five weeks of treatment with the GLP-1 analogue liraglutide improves glycaemic 
control and lowers body weight in subjects with type 2 diabetes. Exp Clin Endocrinol Diabetes 2006;114:417-23.

77. Flint A, Kapitza C, Hindsberger C, Zdravkovic M. The once-daily human glucagonlike peptide-1 (GLP-1) analog liraglutide improves postprandial glucose levels in type 2 diabetes patients. Adv Ther 2011;28:213-26.

78. Hare KJ, Knop FK, Asmar M, et al. Preserved inhibitory potency of GLP-1 on glucagon secretion in type 2 diabetes mellitus. J Clin Endocrinol Metab 2009;94:4679-87.

79. Lamers D, Famulla S, Wronkowitz N, et al. Dipeptidyl peptidase 4 is a novel adipokine potentially linking obesity to the metabolic syndrome. Diabetes 2011;60:1917-25. 
General discussion 
